Portland State University

PDXScholar

6-1-1977

\title{
Disengagement of Older People in an Urban Setting
}

Melvina Somers

Portland State University

Follow this and additional works at: https://pdxscholar.library.pdx.edu/open_access_etds

Part of the Public Affairs Commons, and the Sociology Commons Let us know how access to this document benefits you.

\section{Recommended Citation}

Somers, Melvina, "Disengagement of Older People in an Urban Setting" (1977). Dissertations and Theses. Paper 751.

https://doi.org/10.15760/etd.751

This Dissertation is brought to you for free and open access. It has been accepted for inclusion in Dissertations and Theses by an authorized administrator of PDXScholar. Please contact us if we can make this document more accessible: pdxscholar@pdx.edu. 


\section{DISENGAGEMENT OF OLDER PEOPLE IN AN URBAN SETTING}

by

MELVINA SOMERS

A dissertation submitted to the Faculty of Urban Affairs in partial fulfillment of the requirements for the degree of

DOCTOR OF PHILOSOPHY

Portland State University

1977

Copyright (C) 1977 by Melvina Somers 
TO THE OFFICE OF GRADUATE STUDIES AND RESEARCH:

The members of the Committee approve the dissertation of Melvina Somers presented June 1, 1977.

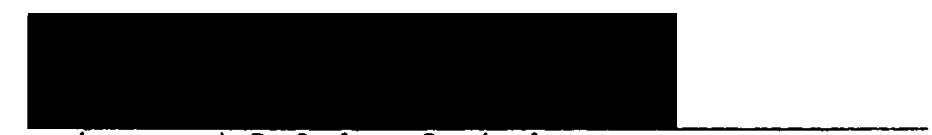

Leonard D Cain, Cochairman

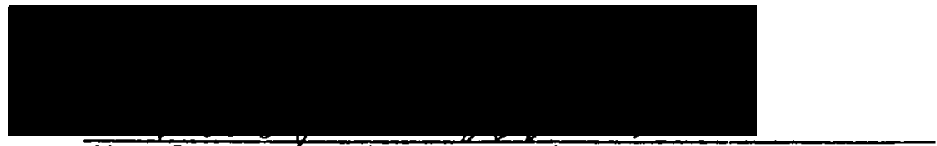

Charles D. Botton, Sochairman
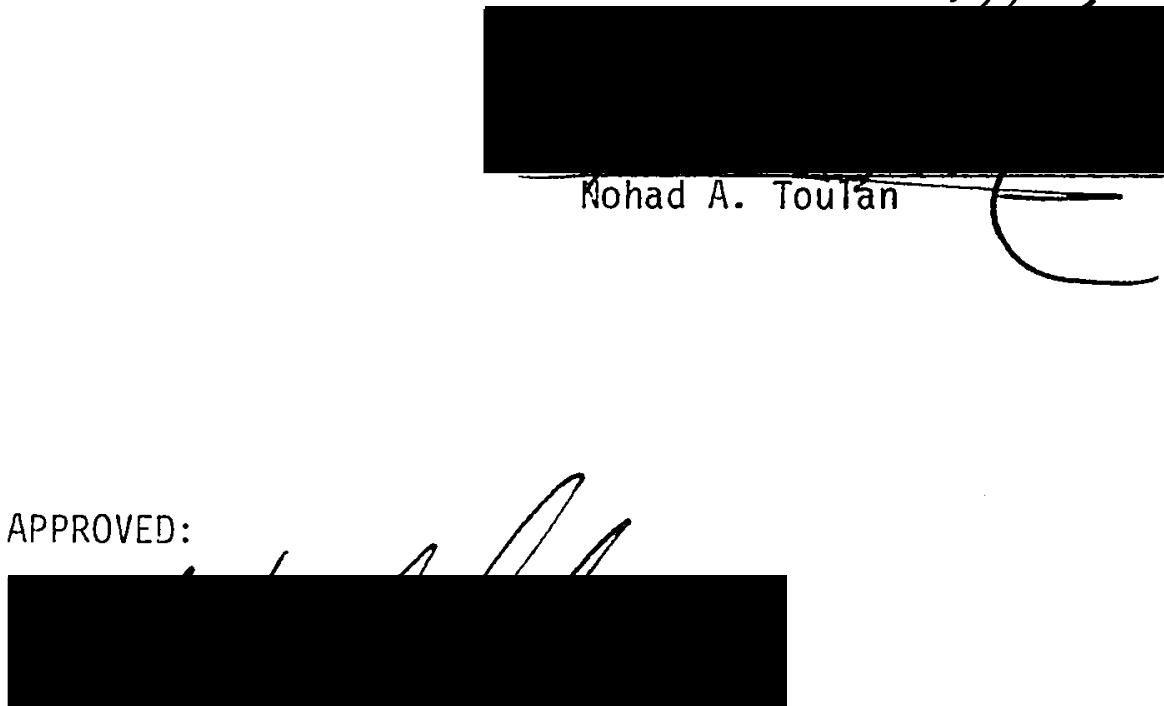

Nohad A. Toulan, Dean, School of Urban Affairs

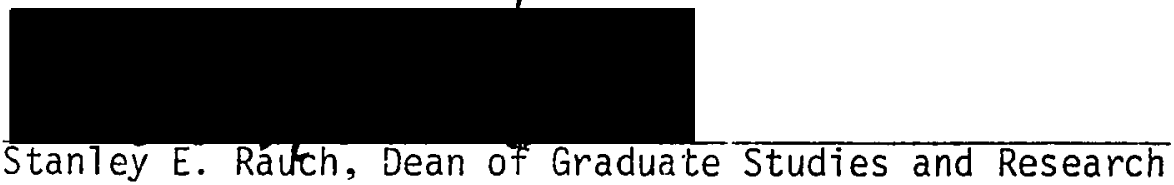


AN ABSTRACT OF THE DISSERTATIOiv OF Melvina Somers for the Doctor of Philosophy in Urban Affairs presented june 1, 1977.

Title: Disengagement of 01 der People in an Urban Setting. APPROVED BY MEMBERS OF THE DISSERTATION COMMITTEE:

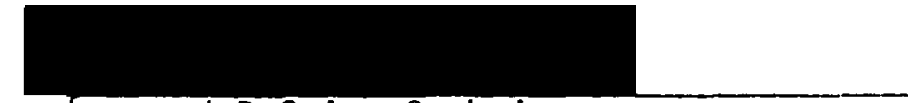

Leonard D Cain, Cochairman

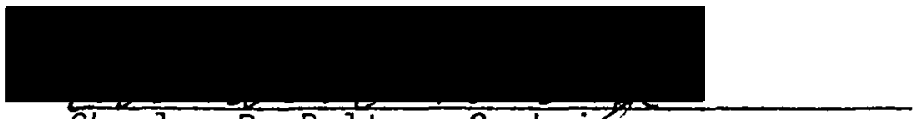

Charles D. Bolton, Cochajtman

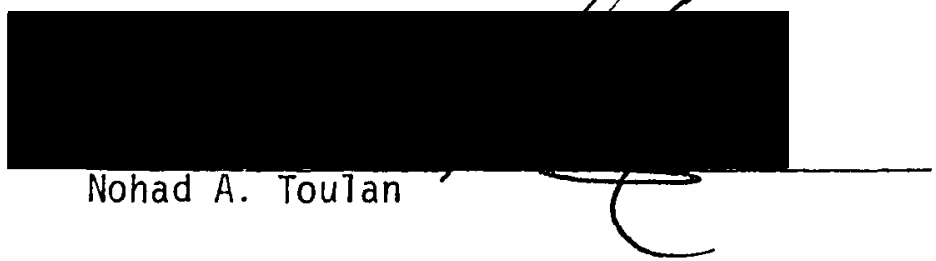

This dissertation reevaluates the controversial Disengagement Theory of aging introduced by Elaine Cumming and William E. Henry in their book, Growing 01d (1961), with particular emphasis on aging in the city.

Disengagement theory embodies the antithes is to the traditional activity theory of aging based on a work ethic. Disengagement theory holds that normal aging is an inevitable mutual withdrawal or disengagement between the aging person and others in the social system, that it is universal, and that, by implication, it is a mutually satisfying condition since it results in a new equilibrium between society and 
the aging individual. The theory proposes that withdrawal happens automatically in the aging person because of ego changes which are "programmed" into the human organism.

Activity theory, on the contrary, claims that maintaining physical, mental, or social activity is a prerequisite to successful aging. It implies that a meaningfu? social role is necessary to selfesteem, and that, allowing for biological impairments, the psychological needs of older people are not much different from those of middle-aged persons.

Since the United States population aged 65 and over has a net annual increase of over 300,000 people, the questions as to whether they tend to be engaged or disengaged, and whether they should be integrated in or separated from the rest of society, become very important. According to the 1970 Census, over sixty percent of persons sixty-five and over live in metropolitan areas. Therefore their housing, transportation, medical care, and other needs have to be considered in urban policies. In planning services for older people it is imperative to know what kind of services are needed, and hence engagement or disengagement becomes a crucial question. It is the assumption in this research that the city and its older population have an investment in one another, and that the city is interested in the welfare of its older citizens.

Theoretically, the study was guided by the principles of symbolic interactionism. Several methods were used in the approach to the research problem because it is believed that what is known as a "triangulated" perspective can come closest to revealing the various 
aspects of empirical reality. Specifically, the methods employed were the social survey, the depth interview, participant observation, unobtrusive observation, and the case study and life history technique. This research has used especially Weber's method of Verstehen or empathic understanding.

Three hypotheses guided the research:

Hypothesis One: Disengagement is not an intrinsic or inevitable phenomenon. If it occurs, it can be traced to various causes other than aging per se, such as $i 11$ health, personal misfortunes (such as widowhood), or social pressures (such as forced retirement). $\%$ :

Hypthesis Two: 0lder people do not enjoy a disengaged state. There is continuity in personality and life style, and if older people choose nonengagement, it is a continuation of former habits.

Hypothesis Three: A livable urban environment is a determinant in the life satisfaction of the aged.

These hypotheses were tested empirically, using both qualitative and quantitative data; and our hypotheses have been confirmed by prevalence and recurrence of expected patterns in the behavior of our samples. The use of the inductive method has given consistent results in that no instances of intrinsic disengagement were discovered. We have been able to show that other causal factors were responsible for relative nonengagement if it occurred. The dissertation also reports many suggestions which were received on how the urban environment could be improved and how the city could help older people lead better lives. 
This Work is Dedicated

to

Paul 


\section{ACKNOWLEDGMENTS}

I herewith express my deepest appreciation to the members of my committee for their invaluable help and guidance in the development and writing of this dissertation, and I pay tribute to their wisdom and to their outstanding scholarship.

I am profoundly grateful to Dr. Nohad A. Toulan, Dean of the School of Urban Affairs, for all the special help I received from his department. I thank Dr. Leonard D Cain, cochairman, for his enthusiasm and his stimulating ideas. It was his course, "The Aged in the City," that provided the inspiration for the undertaking of the present work. I express my gratitude to Dr. Charles D. Bolton, cochairman, for giving me assistance with his vast practical knowledge. He took over the direction of this project during the leave of absence of Dr. Cain, and made the completion of this dissertation possible. I am deeply indebted to all members of my committee for their helpful suggestions in all phases of my work.

I am a returning student. I had the privilege to return to my Alma Mater where I studied many years ago when this institution of learning was called the General Extension Division of the State of Oregon. I decided to come back to this University after my teaching at Clark College in Vancouver, Washington and to explore new ways of mental and spiritual enricimment. I was sure that the so-called "older person" should not be doomed to inactivity and stagnation. At 
Portland State University I found an understanding for the problems of older people and a spirit of encouragement to develop their potential. In the field of gerontology, which became my specialty, I found an opportunity to contribute to our knowledge of aging. My work at this University has turned into a fountain of youth.

In addition, I give special thanks to Dr. James E. Weiss, Director of the Center for Population Research and Census at Portland State University. He generously provided statistical assistance for the figuring of correlations and many valuable sources of information pertaining to the populations of Portland and Vancouver.

I deeply appreciate the kind and gracious help I received from administrators of various government agencies to whom I wrote or to whom I went with my requests for information on the aging generaliy, and on the aging in Vancouver, Washington specifically. I take pleasure in thanking Mr. Herman B. Brotman of the Administration of Aging in Washington, D.C., who personally answered my request for information; Mr. John R. Walker, Chief of the Population Studies Division in Olympia, Washington; and Mr. John D. Piacitelli, Chief of the Office on Aging in Olympia, Washington, who sent me valuable demographic data on the elderly, and Census figures on the aging, for Clark County.

I cordially thank Mrs. Betty Mage, Director of the Area Agency on Aging; Miss Kay Johnson, Coordinator of Projects on Aging; and Mr. Bob Tanner, Chairman of the Committee on Aging and Director of the Red Cross all of Vancouver. They were very helpful in making resources for my study available to me. 
I want to thank the Administrators of the Senior Nutrition and Activities Program (SNAP) at the First Christian Church in Vancouver, who permitted me to interview older people and to circulate questionnaires at the nutrition center. I particularly want to thank Mrs. Holly Kishpaugh and Mrs. Carol Lang for giving generous assistance.

Above al1, I humbly thank all those wonderful "older" people who participated in this undertaking by filling out questionnaires and granting me interviews. They are the ones that disproved disengagement theory to me by demonstrating that they still had enthusiasm and that tineir minds had not gone through the "ego change" claimed by disengagement theory, but that they still felt active and progressive. They represent an untapped reservoir of contributions to the betterment of mankind. ilany of them I cannot mention by name, but I do express my gratitude to them. I can mention Mr. Harold C. Hehlig, Mr. Douglas Russell, and Mr. Fred Breitmeier, and I take this occasion to express my gratitude to them. I pay tribute to the altruism and the inspiring philosophy of Mir. D'Brooks Hogan, who unselfishly is trying to help others although he himself has suffered more than his share of misfortunes. I herewiti gratefully acknowledge his generosity in making his Diary available to me for a study to help other older people.

I sincerely thank Mrs. Betty Tower of the Metropolitan Family Service for introducing me to Mr. Hogan, and for helping me with the access to Mr. Hogan's papers. I gratefully remember all the pleasant visits I ilad with Mrs. Tower. 
My heartfelt thanks go out to Kathy Grove for her phenomenal performance in typing the final copy of this dissertation. She did outstanding work under last-minute pressure to meet deadlines.

Last, but indeed not least, I express my gratitude to my husband, Paul, for his patience and his inestimable help. To him this work is dedicated.

M. S. 
TABLE OF CONTENTS

PAGE

ACKNOWLEDGMENTS ............................ iv

LIST OF TABLES .........................

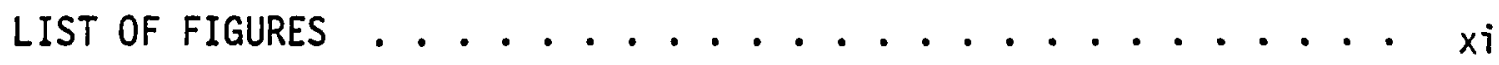

CHAPTER

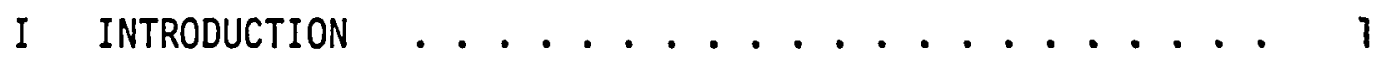

II REVIEW OF RELATED RESEARCH ............ 11

Activity Versus Disengagement ....... 23

Work and Retirement

Social Participation of the Aging

Adjus tment to Aging ........... 33

Heal th and Disease

Socioeconomic Factors

Personality and Life Style

The Environment

II I THEORETICAL ORIENTATION ................ 52

IV THE RESEARCH PROCESS: ATTITUDES AND ACTIVITIES $\ldots . .86$

Hypotheses 86

Definitions of Concepts 91

Real Definitions of Concepts

Aging

Disengagement

Engagement

Life Space 
Operational Definitions of Concepts

Characteristics of Engagement Characteristics of Disengagement Adjustment

Methodology .................

Self-Images

Independent Variables

Dependent Variables

The Population Studied ......... 106

The Survey .............. . . 107

The Sample

The Instruments

The Results of the Survey

Measurement of Attitudes--Form I

Measurement of Activities--Form II

Scoring of Questionnaires

$\checkmark$ THE RESEARCH PROCESS: THE OLDER PERSON IN THE CITY

The Personal Interviews . . . . . . . . . .

Type I. High Attitudes - High Activities

Type II. High Attitudes - Low Activities

Type III. Low Attitudes - High Activities

Type IV. Low Attitudes - Low Activities

The Life Histories . . . . . . . . . 200

The Life Story of D'Brooks Hogan

The Story of Fred Breitmeier

The Story of Mrs. S.

The Implications for the City ........ 215

VI SUMMARY AND CONCLUSIONS . . . . . . . . . 225

BIBLIOGRAPHY . . . . . . . . . . . . . . . . 234

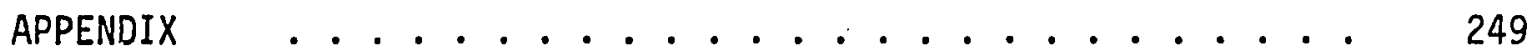




\section{LIST OF TABLES}

TABLE

PAGE

I Age of Respondents by Sex.............. 110

II Marital Status of Respondents by Sex . . . . . . . 111

III Living Arrangements by Sex . . . . . . . . . . 112

IV Length of Residence in Vancouver . . . . . . . . 174

y Self-Reported Health of Respondents . . . . . . . 116

VI Distribution of Responses to Attitude Questionnaire . . 122

VII Responses to Questions in Form II Personal Information . 128

VIII Reasons for Retirement . . . . . . . . . 129

IX Principal Activities of Respondents . . . . . . . 135

$X$ "How Often Do You See Members of Your Immediate Family or Other Relatives Not Living With You?" . . . . 139

XI "How Often Do You Visit With Friends or Neighbors . . . 140

XII "What Kinds of Current Events Interest You?" (a) . . . . 141

XIII "What Kinds of Current Events Interest You?" (b) . . . . 142

XIV Frequency Distribution of Attitude Scores . . . . . . 151

XV Frequency Distribution of Activity Scores . . . . . . 152

XVI Interrelationships of Attitude and Activity Scores

for Sixteen Respondents to Survey Questionnaire . . 160 


\section{LIST OF FIGURES}

FIGURE

PAGE

1 Frequency Distribution of Attitude Scores 153

2 Frequency Distribution of Activity Scores 154

3 Scatter Diagram of Relation Between Attitude

Scores and Activity Scores 


\section{CHAPTER I}

\section{INTRODUCTION}

This dissertation deals with a problem which concerns urban sociology. It investigates a much debated theoretical issue regarding our fastest growing minority, the population of the elderly. ${ }^{1}$ The controversy is about the respective merits of two prominent theories in social gerontology: disengagement theory and activity theory. Both sides claim to have the answer to successful aging. The present research has placed special emphasis on the analysis of disengagement-its effect upon the elderly, and its implications for the city.

Activity theory has been passed down to us as "the American formula for happiness in old age" (Havighurst and Albrecht, 1953). It, no doubt, goes back to our cultural values built around a strong work ethic which Weber compared to a religion (The Protestant Ethic and the Spirit of Capitalism, trans. Talcott Parsons, 1958). Work has a psychological as well as an economic significance. People work for remuneration, but also because they feel it is the moral thing to do.

This ideology, reinforced by industrialism, has been applied to the later years of life. Activity theory assumes that well-adjusted old

1

Herman B. Brotman, The Fastest Growing Minority: The Aging (Washington, D.C.: Administration on Aging, 1972). 
people have to be active or "engaged," because, allowing for biological impairments, the social and psychological requirements of older people living in our culture are not essentially different from the usual needs of middle-aged people. Constructive activity and social participation are necessary to self-esteem (Havighurst et al., 1963; Maddox, 1964, 1965; Palmore, 1969).

Disengagement theory, in contrast, postulates that "aging is an inevitable mutual withdrawal or disengagement, resulting in decreased interaction between the aging person and others in the social systems he belongs to"; that it is universal; and that, by implication, it is a successful and mutually satisfying condition since it results in a new equilibrium between society and the aging individual (Cumming and Henry, 1961, pp. 14-15).

Disengagement theory was formally introduced by M. Elaine Cumming and William E. Henry in their book, Growing 01d (1961), which had only one precursor (Cumming, Dean, and Newe11, 1960). Following is a summary of disengagement theory as restated by Cumming in 1964:

Disengagement theory was developed during a five-year study of a sample of aging people in an American city. These were 275 adults between the ages of 50 and 90 years; they were in good health and had the minimum of money for independence. Briefly, the theory proposes that under these conditions normal aging is a mutual withdrawal or "disengagement" between the aging person and others in the social system to which he belongs--a withdrawal initiated by the individual himself, or by others in the system. When disengagement is complete, the equilibrium that existed in middle life between the individual and society has given way to a new equilibrium characterized by greater distance and a changed basis for solidarity. ("New thoughts on the theory of disengagement," in Kastenbaum, 1964, p. 3.)

The vâlidity of disengagement theory has been questioned by various critics (e.g., Maddox, 1964, 1965; Pa7more, 1968; Rose, 1965; Tal1mer, 
1967; Ta11mer and Kutner, 1969, 1970; Zborowski, 1962; and Zborowski and Eyde, 1962). As Rose (1964) points out, the criticisms have been of three main kinds: (1) that disengagement is not inevitable, but that non-engagement in the later years may be a continuation of a life-long characteristic; (2) that empirical evidence shows the engaged elderly, rather than the disengaged, to be generally better adjusted; and that (3) disengagement theory, in the context of our social picture, is a poor interpretation of the facts.

This researcher has found ample evidence in support of all three lines of criticism, and believes that an especially strong case can be made for the third point: that the theory of Cumming and Henry does not agree with the facts in the real world.

The image of our older population which emerged during the course of this study was vastly different from stereotyped versions and from projections by disengagement theorists. Instead of being infirm and withdrawn, most of the subjects contacted were quite stable and eager to continue the business of Tife. There was a pronounced tendency to keep busy rather than to just sit and contemplate.

In reporting these findings, the writer has endeavored to assess their significance with regard to the theoretical and practical matters under consideration. Since the older population in the United States (aged 65 and over) has a net annual increase of over 300,000 people, ${ }^{2}$ the questions as to whether they tend to be engaged or disengaged, and

2 Herman B. Brotman, The 01der Population: Some Facts We Should Know (Washington, D.C.: Administration on Aging, April 1970. U. S. Department of Health, Education, and Welfare, Social and Rehabilitation Service), p. 1. 
whether they should be integrated in or separated from the rest of society, become very important. Thus far, the preponderance of evidence favors activity theory, but the debate has not yet been fully settled. In fact, as we examine the problem, we realize progressively how complex it is, and how far-reaching its ramifications may be. Erdman Palmore has offered some inspiring thoughts on a possible implementation of activity theory:

If the activity is generaliy valid, the practical implications are widespread and profound. If the maintenance of high levels of social interaction and other activities contributes to successful aging, then perhaps legislation should be enacted, agencies should be created, programs developed by government and private organizations, physicians and anyone interested in helping the aged adjust and have satisfying lives should encourage the maintenance of high levels of employment, membership in organizations, frequent contacts with friends and relatives, the development of skills, crafts and hobbies, and the general development of more useful and meaningful roles for the aged. ("Sociological Aspects of Aging," in Behavior and Adaptation in Late Life, ed. Busse and Pfeiffer, 1969, p. 60.)

Generally, information gathered from the aged themselves indicates a desire to remain active, while that obtained from employers and formal organizations discloses policies which enforce disengagement. Compulsory retirement at age sixty-five or earlier means that a large number of older Americans are automatically deprived of their identity in the work force regardless of their personal desires or their capabilities which are not governed by calendar age. Many workers could be fully productive well after sixty-five. Howard Whitman (1961) relates:

In a series of eight regional conferences on aging, the American Medical Association found that at least fifty percent of employees in large industries want to continue working after their sixty-fifth birthday. It is significant to note, too, that even in the opinions of the employers who mandatorily 
retire these workers, three-quarters of them are regarded as perfectly capable of continuing on in their jobs. (A Brighter Later Life, p. 232.)

In the monograph, Retirement: Background and Issues (1971 White House Conference on Aging), we read:

There is now little question that the establishment of age 65 as the minimum age for unreduced OASDI retirement benefits is today one of the most important factors influencing the age of retirement. Participation in the work force by men drops dramatically at age 65. For example, male labor force participation currently drops from about 90 percent for ages 55 to 59 , to about 80 percent for ages 60 to 64 , to about 35 percent for ages 65 to 69 .

In addition to making benefits available to workers who are considering retirement, OASDI "sets the pattern for private and for State and local government retirement plans and, more generally, . . conditions both employer and employee attitudes toward 'normal' retirement age" (Pechman, et al., 1968). 3

Since our society does not value the active participation of the elderly, it has virtually institutionalized disengagement. There are powerful pressures and social constraints to urge older people to relinquish their responsibilities. As Rose observes, "Forced disengagement in the occupational role has tended to cause disengagement in auxiliary roles--for example, in the occupational associations (trade union, businessmen's association, professional organization) and the 'service clubs' which have a membership based on economic activity" (1965, p. 363).

3

Prepared for the Conference by James H. Scinulz and the Technical Committee for Employment and Retirement (Washington, D.C.: White House Conference on Aging, February 1971), p. 24. 
The economy of the United States is geared to expediency and profit, and older workers are being "squeezed out of the labor force" (Brotman, 1972, p. 2). A changing technology and increasing automation have resulted in reduced manpower requirements and the obsolescence of formerly valued skills. But there are also some pernicious stereotypes at work which portray the elderly as being incompetent and apathetic, and as having no potential. Therefore, older people are vulnerable in their employment. They know, if they once lose their position, there are formidable obstacles to obtaining another one. They are made to feel that they have outlived their usefulness, and that it is their obligation to withdraw.

As a result of such imputations and suggestions, this very response may occur. It is the old story of the self-fulfilling prophecy, so eloquent1y expressed by W. I. Thomas: "If men define situations as real, they are real in their consequences" (The Child in America, 1928, p. 572).

By that token, older people may become discouraged and give up the fight against overwhelming odds. If they are met with frustration and rejection at every step, they feel insecure, and may even begin to doubt their own abilities. Paut H. Landis (1952) has well summarized the plight:

Senescence, in many cases, is no doubt in part a state of mind. Ill health, economic insecurity, loss of social prestige, the shock of dropping out of the work world, enforced idleness, and other factors, many of which are of external origin, may be so emotionally disturbing as to cause the individual to give up the struggle to advance or to be self-maintaining. (Social) Policies in the Making, p. 331.) 
Cumming and Henry do not take such possibilities into consideration in the construction of their theory. They start out with the assumption that a general decline of the older person is automatic and rationalize that social withdrawal is the "modal" way of aging (see pp. 101 and 190).

In contrast, this research indicates that disengagement is extrinsic rather than intrinsic, and that it is culturally and not biologically indured. While introspection and soul searching play an increasing part in later life, they can be combined with active roles. However, other factors drastically alter the life of older people and bring about a forced status for them. Consequently, the present problem has delineated itself in two parts: 1) to investigate the claims of Cumming and Henry that disengagement is "normal aging," or that it is "modal," and 2) to identify some of the real causes of disengagement.

Cumming and Henry have ignored the trend of the times. 01der people are not only increasing in sheer numbers; they are also in better physical and mental health as a result of medical, scientific and technological advances. One might say that some new stages have been inserted into the life cycle. Average life expectancy has grown from fifty to seventy-five years or more during the present century. ${ }^{4}$

The problem now facing the aged is how to fill the additional years with meaningful activities. Otherwise they are condemned to "the bleakness of empty time" (Koller, 1968) or to what Burgess called the "roleless role." Cumming and Henry (1961) have attempted to propagate

4

Clark Tibbitts, "Middle-Aged and 01 der People in American Society," in Readings in Gerontology (Eugene, Oregon: University of Oregon, School of Community Service and Public Affairs, Fal1, 1969), I-B, pp. 1-2. 
a myth that it is natural for older people to sever their relations with the mainstream of life. They, in effect, advocate "roleless roles" (Ernest W. Burgess, 1960, pp. 20-21) when they talk about "willingness to be disengaged" (p. 150), and "to play at work" (p. 152). But empirical evidence is at variance with such ideas. We must not overlook the many instances where people remain active past the critical age of sixty-five, or re-engage if their career is disrupted. Despite our established retirement system, many professionals, the self-employed, and public officials continue their occupations and often taken on new responsibilities. Nevertheless, the great majority of the American people are "disengaged" at a predetermined age. Herman B. Brotman has brought out the tragic paradox in "Success as a Problem":

It is a particularly frustrating irony that progress in man's search for a longer life should produce the "problems of aging." In fact, the very successes in economic, social, medical, and industrial "progress" that now permit such a large proportion of our population to reach old age, also have produced the changes that make the elderly a generally "dependent" group and have robbed them of their most important and traditional functions, roles, and statuses. 5

The problems of the aged are closely tied to community planning. More than sixty percent of persons in the United States aged sixty-five and over live in metropolitan areas (Brotman, The 01der Population: Some Facts We Should Know, 1970, p. 7). Therefore their housing, transportation, and other needs have to be considered in urban planning and policy making. As Birren says,

\section{5}

"The 01der Population: The Paradox-Success as a Problem," Facts and Figures on 01der Americans, An Overview (Wasinington, D.C.: Administration on Aging, 1971. U. S. Department of Health, Education and Welfare, Social and Rehabilitation Service), p. 1. 
The problems of the aged in the city have to be looked at in broad scope so key ideas can be evolved that will lead to improvement of the city, the common place of residence of the aged. The aged have not joined, or have not been able to join, the flight of the young family to the dubious "high water level" of suburbia to avoid the noise, the smog, the dirt, the social tensions, and the poorer housing of the "older city." The aged especially should be considered when we try to improve our present cities and plan cities of the future. Not only do millions of aged persons 1 ive in cities but they live in sections of cities with least adequate housing. 6

It is the assumption in this research that the city and its older population have an investment in one another, and that the city is interested in the welfare of its older citizens. In this connection, the writer would like to express the thought that industry and the professions may retire their older employees--but the city will still have them, and decisions will have to be made with regard to these people.

Several methods were used in the approach to the present research problem. It is believed that a "triangulated" perspective can come closest to revealing the various aspects of empirical reality. "When a hypothesis can survive the confrontation of a series of complementary methods of testing, it contains a degree of validity unattainable by one tested within the more constricted framework of a single method" (Webb, et a]., 1966, p. 174).

Theoreticaily, the study was guided by the principles of symbolic interac'cionism and its insights into sucial life. Older people were observed in their interaction with one another and with the rest of society. It is the essence of symbolic interactionism that each man

6 James E. Birren, "The Aged in Cities," The Gerontologist, 9, No. 3, Part 1 (Autumn 1969), p. 163. 
interprets his world and defines his situations as he goes along. Keeping in mind, then, that "acts are built up in transactions in episodes of interaction" (Bolton, 1970), ${ }^{7}$ an effort was made to probe beneath the surface. In line with George Herbert Mead's views of emergence in social relations, and Herbert Blumer's strong emphasis on empirical investigation, this research has regarded human behavior as an ongoing formative process. Blumer says in his "The Methodological Position of Symbolic Interactionism:" "People, individually and collectively, are prepared to act on the basis of the meanings of the objects that comprise their world. "8 The main effort of this researcher has been to see what factors might be related to the topic of disengagement, and social action was considered of prime importance. Blumer constantly admonishes us to have respect for the empirical world, which, in his words, is:

the world of everyday experience, the top layers of which we see in our lives and recognize in the lives of others. The life of a human society, or of any segment of it, or of any organization in it, or of its participants consists of the action and experience of people as they meet the situations that arise in their respective worlds. 9

With this preliminary view of disengagement theory and the problems that emerge, we shall now proceed to look at previous research in this area.

7

Charles D. Bolton, Outline of Symbolic Interactionist Frame of Reference (Portland State University: Mimeographed paper), p. 3.

8

In Herbert Blumer, Symbolic Interactionism: Perspective and Method (Englewood Cliffs, New Jersey: Prentice-Hal7, 1969), p. 50. p. 35 .

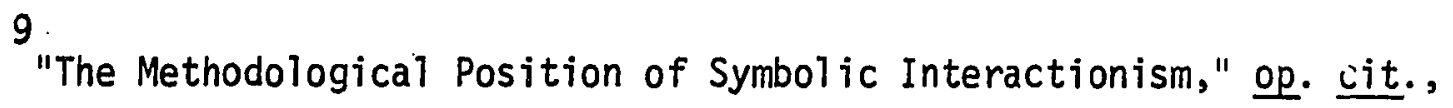




\section{CHAPTER I I}

\section{REVIEW OF RELATED RESEARCH}

Cumming and Henry view aging and withdrawal as correlated linear processes and aging as the determinant of disengagement. However, the present writer feels that such an explanation is oversimplified. Causes of non-engagement may be varied and multiple, and individuals are affected not only by the passage of time, but mainly by the happenings during that time (Cf. Tallmer, 1967).

Cumming and Heriry equate successful aging and good morale (1961, p. 131), with which decision one cannot quarrel. But they attribute good morale to their type of disengagement, which is the antithesis of the activity theory view. They advocate resignation to restrictions on the older person; they plead in favor of giving up instrumentality; and they condone the loss of autonomy ( $p .161$ ). Cumming and Henry recommend acceptance of retirement (pp. $162 \mathrm{ff}$. ), and generally laud a submissive attitude. They speak of "compensatory reidentification" (p. 169) and changed preference for "relational rewards" ( $p p .76 \mathrm{ff}$ ).

In contrast to activity theory, disengagement theory is entirely pessimistic. Indeed, it is devastating. It is linked to the expectation of death (Cumming and Henry, 1961, p. 211), and, according to the theory's proponents, the prospects for the older person are truly bleak: "The futly disengaged condition of the living car be considered to exist when 
only those bonds necessary to sustain life remain" (ibid.). That leaves no room for developmental tasks, 10 for continuing aspirations, or even for a feeling of belonging. "Wher most of the relationships connecting a person to his social system are severed, disengagement has occurred" (Cumming and Henry, 1961, p. 211). This statement conveys a sense of gloom: the aging are condemned to a state of progressive deterioration with virtually no interaction. There is no purposeful activity in disengagement theory, but rather a meaningless existence in a sort of limbo. The following is an example of what Cumming and Henry have in mind:

In our terms, Mrs. Clark is a successful ager because she has competently disengaged from the bonds of earlier relations and has done so in good spirits. She displays attributes which are an integral part of this process--reduced energy and cathexis to persons, shift from obligatory to gratifying interactions, and an overall reduced desire for interaction. At the same time, she is neither lonely nor disenchanted, pleasing herself by increased sma 11 indulgences and not doing "anything that I don't want to." (1961, p. 184.)

It is obvious that the road to disengagement leads one to become a nonperson. The activist position is more encouraging, and has been succinctly expressed in Sidney L. Pressey's words: "Not All Decline!"1l

Research on the adjustment to aging dates back to a long time before Cumming and Henry. Up to the late decades of the nineteenth century, the United States had been predominantly agricultural. It had rich natural resources and an expanding frontier, and it was the tradition

10

For a discussion of developmental tasks in the later years, see: Sidney L. Pressey and Raymond G. Kuhlen, Psychological Development Through the Life Span (New York: Harper, 1957), p. 201.

11 and 125.

"Viewpoint," The Gerontologist, 6, No. 2 (June 1966), pp. 66 
of the American people to be self-reliant. Through hard work and thrift, most people were expected to establish economic security and to provide for their old age, although many failed. They lived in a self-contained community with close family ties, and, in case of misfortune, the family or the group was generally able to take care of its elderly. Public relief was given in extreme cases, and the poorhouse was used as a last resort.

However, well before the turn of the century some major economic and social changes were under way. The impact of the Industriai Revolution was being increasingly felt, and the nation was moving out of the handicraft stage. Rapid mechanization and urbanization also brought about some changes in the structure of the family and affected the status of the aged. Under the factory system, in congested urban living, there was little room for older people. Furthermore, the companionship family was supplanting the former institutional pattern and the interests of husband and wife and their offspring were taking precedence over the needs of grandparents.

As the transition from an agricultural to an industrial state accelerated, it became more and more difficult to accumulate enough means for economic independence. The Great Depression of the 1930's underscored the fact that the American worker was at the mercy of elements beyond his control and that he could not save sufficient money for his later years. As expressed by Williams (1959), in a society increasingly characterized by large-scale associations, corporations, labor unions, and bureaucratic government, there often appeared little the 
individual could do on his own to maintain income, position, and status as he was overtaken by the frailties of aging. ${ }^{12}$

The changed position of the aged, the disproportionate share of poverty among them, together with their ever increasing numbers, led to their being defined as a social problem. As a result, pressures for social insurance were mounting, and the rudiments of $\mathrm{plans}$ for sustenance of the aged worker began to appear. The first three decades of the twentieth century were marked by experimentation with various kinds of private and public pension systems. The states also began to establish old age assistance programs during this time. The decade of the twenties also saw the rise of our large fraternal associations, businessmen's clubs and other philanthropic societies. It meant the establishment of homes for the aged by fraternal orders, labor unions and church groups. 13 The significance of these undertakings is that it was collective action to provide economic safeguards for the aged through their own organizations.

Although the Depression played havoc with most of these plans, a beginning had been made, and the Townsend Movement of the thirties

\section{2}

R. H. Williams, "The Changing Matrix of American Culture and Problems of Aging," in Aging and Social Health in the United States and Europe, ed. C. Tibbitts (Ann Arbor: University of Michigan, Division of Gerontology), pp. 156-66. Cited by Clark Tibbitts, "Origin, Scope, and Fields of Social Gerontology," in Handbook of Social Gerontology, ed. Clark Tibbitts (Chicago: The University of Chicago Press, 1960), p. 17.

\section{3}

Eugene A. Friedmann, "The Impact of Aging on the Social Structure," in Handbook of Social Gerontology, ed. Clark Tibbitts, p. 137. 
stirred new visions among the aged and called attention to their political potential. In the wake of the Depression came catastrophic unemployment which placed an unbearable burden on local relief agencies, and the states too were unable to cope with the great number of dependent aged. In addition, there was demand for separation of older workers from the labor force, so that younger persons could take their place. Consequentiy, the federal government was called upon to assume part of the responsibility for maintenance of the aged. Thus a number of factors combined to create an urgency, in answer to which the Social Security Act of 1935 was passed.

In ensuing decades, substantial gains were made toward the elimination of destitution among the aged. Retirement systems for most state and local government employees were established, and benefits for older people have been steadily expanded under federal legislation. Particularly, the 1950's and the 1960's saw some sweeping improvements in Social Security coverage. Starting with the 1940's, there has also been a continuous growth of private pension plans. ${ }^{14}$ Although many elderly people are still not adequately provided for because of inflation and rising prices, the trend is away from the dependent status of the aged. Nearly everyone can look forward to some kind of basic protection. Nevertheless, the older population is largely regarded as a social problem, as pointed out in The Aged and Society, published by the Industrial Relations Research Association (1950):

14

See Eugene A. Friedmann, "The Impact of Aging on the Social Structure," in Handbook of Social Gerontology, ed. Clark Tibbitts, pp. 120-144; and Margaret S. Gordon, "Aging and Income Security," in Tibbits, op. cit., pp. 208-260. 
For the first time in the history of the world, the aged and the aging constitute a basic social problem. The United States is experiencing the impact of greater 7 ife expectancies more than any other nation, for the typical life span of its population is the longest; but the problem is not confined within its borders. If greater length of $7 i f e$, so avidly desired by the individual, is not to become a curse to society, effective accommodations must be made to it. (Publication No. 5, Preface, p. v.)

It seems that disengagement proponents primarily look at the older person as a social problem, while the activists still see something of the rugged individualist in him.

It can be argued, and it is very strongly felt by this writer, that older people are a social problem because as yet there is no provision for them in the social system and no definite meaningful roles have been assigned to them (Cavan et al., 1949; Cavan, 1957; Ludwig and Eichhorn, 1967; Pollak, 1948; Rosow, 1967; Tibbitts, 1960). Rosow sees role ambiguity and a lack of role content for the aged:

The culture does not provide them with definitions and meaningfur norms as it does in all previous life stages. There are no clear expectations connected with the aged role, so this becomes subject to personal preferences and private definitions which are intrinsically unshared. Thus, with the loss of functions, the role of the older person becomes unstructured and there is little incentive to adopt with enthusiasm a basically empty role. Like other unstructured situations, role ambiguity in old age may be an independent source of anxiety. 15

Rising national concern with the problems of aging was reflected in a growing volume of research in this area. The first efforts concentrated on the biological aspects of aging and the material needs of older people. But it was gradually recognized that older people also needed emotional

\section{5}

Irving Rosow, Social Integration of the Aged (New York: The Free Press, 1967), p. 31. 
security, and an increasing number of researchers turned to challenging social-psychological questions. Notably, the topic of adjustment during old age moved into the limelight and received the attention of a great many writers (Birren, 1964; Cavan et al., 1949; Cavan, 1957; Goodstein, 1962; Havighurst and Albrecht, 1953; Kleemeier, 1951; Kuhlen, 1959; Lebo, 1953; Pollak, 1948; Pressey and Kuhlen, 1957; Pressey and Simcoe, 1950; Reichard, Livson and Petersen, 1962).

Cumming and Henry were the first sociologists to propose a theory of aging from the psychosocial viewpoint (Kastenbaum, 1969). When disengagement theory was launched (Growing 01d, 1961), its concepts "were hastily embraced by some, as hastily condemned by others" (Kastenbaum, 1969), and since theli "disengagement" has become a "household wor a": in gerontology (ibid.).

Talcott Parsons, in his Foreword to Growing 01d (1961), calls it an important book. He further says: "It may be safely predicted that this study will serve as the most important focus of discussion of the problems on this level for some time" (p. v).

Disengagement has indeed been widely discussed, and, in the judgment of the present writer, this is the real significance of the theory. Its principal value lies in the fact that it generated a great deal of research which has resulted in a clearer perception of the nature of aging.

Most of the critical literature relating to disengagement sinows findings contrary to it, but some authors agree with its tenets. Parsons (1963) accepted the theory of Cumming and Henry and added his version to it. He calls old age a "consummatory phase"--a period of "harvest" when the individual may gather in the fruits of his previous instrumental 
commitments (p. 53). Streib (1968) gives his support to the theory and feels that "there is abundant evidence to support the proposition that disengagement is universal," al though its incidence may vary according to personality and situational variables (p. 70). He further holds that the process is inevitable, and says in conclusion: "My task has been the more supportive one of indicating that a theory originating in common sense observations does have value in understanding aging and the aged in settings very different from that in which the theory was originally developed" (p. 76).

In a later study (Streib and Schneider, 1971), this view of disengagement was somewhat modified. Streib and his collaborator speak of "differential disengagement," and conclude that "disengagement in one sphere, such as retirement, does not signal withdrawal and retrenchment in all spheres" (p. 180). The authors state that, while deceleration or disengagement is inevitable in the human organism, it occurs at different rates. It may come quickly at the end of life, or slowly over one or two decades. The authors recognize that, for optimum morale, most people need some kind of activity; therefore, they say, the creation of new roles for older people becomes necessary (p. 181). Streib and Schneider point to flaws in both activity and disengagement theories and propose a third approach of "activity within disengagement" which would make available to the aged new roles in the areas of leisure and citizenship service (pp. 180-182).

Williams and Wirths (Lives Through the Years, 1965) also say that disengagement can come at various chronological ages. They have documented at least one case where it still had not occurred between the ages of 
eighty-two and eighty-six, and, the authors continue, a few cases of intrinsic disengagement can be found in the early fifties (pp. 195-196). Furthermore, the authors state, disengagement occurs in all styles of life (p. 196). Williams and Wirths used the same data source that Cumming and Henry did in their study, namely, the Kansas City Study of Adult Life. They generaliy accept the ideas of disengagement theory, but they have added some refinements:

We are convinced that disengagernent is a characteristic process faced by the majority of people within the predominant pattern of American, and probably western European, culture, and a problematical one for many . . . The relation of disengagement to successful aging, as we have defined it, is not that to age successfully the actor must disengage, but rather that he must cope with disengagement to the extent to which it does arise as an issue (p. 195).

Two key concepts emerged from the research done by williams and Wirths: "One is a ruw concept of successful aging, which is derived primarily from the theory of action as developed by Talcott Parsons. The other, which emerged empirically from the research data, is the concept of styles of life" (p. 2). Parsons, who wrote the Foreword to Lives Through the Years, as we11 as to Growing 01d, considers the study of Williams and Wirths to be a continuation of that done by Cumming and Henry (p. v).

Lowenthal and Boler (1965) give qualified support to disengagement theory, and emphasize the importance of viewing social withdrawal from a relative point of view. Criteria used to measure voluntary vs. involuntary withdrawal were retirement, widowhood and physical disability, and the data obtained suggest that "it is the deprivations themseives rather than consequent changes in social interaction that are decisive." 
This study lends indirect and qualified support to disengagement theory, but at the same time "it emphasizes the power of certain deprivations among the aged to obliterate the relationship between social interaction and morale" (p. 371).

The above criteria have been among the most crucial in much of the other research done on adjustment to aging, including the present study. They have been instrumental in clarifying the role of activity as related to morale in many cases. When some "insults of aging" (Kutner et al., 1956 , p. 23) were taken into account, the results did not bear out disengagement theory. In fact, several researchers used the same data that Cumming and Henry did, and/or employed the same measures that were used by them or by Cumming et al. (1960), and arrived at different results (Tal1mer, 1967; Tallmer and Kutner, 1969, 1970; Tobin and Neugarten, 1961). Havighurst, Neugarten and Tobin (1963) also used data from the Kansas City Study of Adult Life and found that affect and life satisfaction were positively related to activity or engagement. They say that most of their respondents regretted their loss of activity and that those with higher amounts of activity generally had greater psychological well-being than those with lower levels of activity (p. 422). These findings are obviously in support of the activity theory of optimal aging; however, the authors state that in some ways the data support the disengagement theory: "There are persons who are relatively high in role activity who would prefer to become more disengaged from their obligations; there are also persons who enjoy relatively inactive lives" (p. 424). The interrelations among engagement, affect and life satisfaction are far from 
simple, and the authors regard personality as the pivotal dimension in describing and predicting patterns of aging (p. 425).

There are many other writers who show strong support for activity theory but could be cited as partially agreeing with disengagement theory (Clark and Anderson, 1967; Havighurst and Albrecht, 1953; Havighurst, 1968;

Havighurst, Neugarten and Tobin, 1968; Kutner et al., 1956; Lehr and Rudinger, 1969; Maddox, 1964, 1965; Reichard, Livson and Petersen, 1962).

At times, researchers have found evidence of certain resignation or acceptance of restrictions on activity in their subjects, but this attitude is not explained according to the ideas of Cumming and Henry. For instance, Beckman (1969) made a participant observation study in a retirement village and found widespread acceptance of retired life. However, the residents had been "very quietly but powerfully influenced by a Christian attitude of pastoral service" which had "permeated the administration" (p. 285). Beckman notes there is general agreement to the effect "that older people should remain independent and active participants in normal community life as long as possible" (p. 282). Eventually, failing health, advancing years, or personal circumstances may make it necessary to seek some form of congregate living and to adjust to lower levels of activity. Beckman says that, in general, the people at the village refused to admit that "old age" had affected their decision to move there but rather recited the benefits afforded at the village. Beckman further states that "satisfaction with life at the village" was "strongly influenced by continued social interaction and the extent of friendships, in contrast to voluntary or enforced disengagement largely because of failing health" (p. 284). 
Aside from being expressed in writing, disengagement theory has been in actual operation for a long time. It manifests itself in the rejection and disparagement of the aged (Jacobs, 1969) and in the practices prevalent in our social system. Our who?e country is synchronized to an outdated number of "65." To illustrate: Social Security begins at age 65; the work life is typically terminated at age 65; Medicare eligibility begins at age 65 ; health and accident insurance of the conventional type are cancelled at age 65, and so on. Cumming and Henry have added to it that this is a two-way process, and that it is mutually satisfying.

The critics who have found disengagement theory inadequate have dealt with a great number of important topics. They may be arranged under several major categories. However, these categories overlap because the authors of the books and articles touch upon more than one aspect of aging. The subjects thus far investigated fall into the broad areas of 1) activity versus disengagement; 2) social participation; 3) work and retirement; 4) adjustment and morale; 5) health and disease; 6) the environment, including housing; 7) psychological factors, including religion; and 8) personality and life style, which are governed by the self-concept and roles of individuals. It is not possible to give an exhaustive enumeration of all the writings that might refer to disengagement, but following is a comprehensive survey of the most pertinent literature on the subject, presented under the eight listed categories. 


\section{ACTIVITY VERSUS DISENGAGEMENT}

The writers grouped in this section largely address themselves to the basic question, is activity or disengagement more conducive to psychological well-being and good adjustment of the aged? The findings show strong support of activity rather than disengagement (A1brecht, 1951; Be11, 1967; Carp, 1966; Clark and Anderson, 1967; Desroches and Kaiman, 1964; Filer and O'Conne11, 1962; Havighurst, 1968; Jeffers and Nichols, 1961 ; Kapnick, Goodman and Cornwe11, 1968; Kleemeier, 1951; Kutner et al., 1956; Paul H. Landis, 1942; Judson T. Landis, 1942; Lebo, 1953; Leveen and Priver, 1963; Lipman and Smith, 1968; Ludwig and Eichhorn, 1967; Palmore, 1968; Pressey and Simcoe, 1950; Reichard, Livson and Petersen, 1962; Tal1mer, 1967; Tobin and Neugarten, 1961; Videbeck and Knox; 1965; Youmans, 1967a; Zborowski, 1962; Zborowski and Eyde, 1962).

These writings contain a vast amount of evidence that older people tend to resist being "disengaged," and that they feel much better if they meet with even a moderate amount of success. A statement by Mark Zborowski (1962) can be taken as summarizing the conclusions of the other researchers in this category who have studied the activities and social roles of older people and have tried to relate them to the process of aging: "Contrary to the implications of the 'disengagement theory' our study shows little evidence supporting the concept of a voluntary withdrawal of the older person" (p. 309). This statement also expresses the preferred view held among practical workers in the field of gerontology who feel that older people should continue to act like middle-aged people as long as possible and find substitutes for those activities which they are 
forced to give up (Palmore, 1968, citing Havighurst, 1961). In line with this attitude, Bell (1967) reports from a research undertaken against the background of disengagement theory, that those individuals who were highly involved tended to conceive of thenselves as not old whereas those less socially involved were prone to classify themselves as old (p. 21). Desroches and Kaiman (1964) explored changes in activity participation as a function of time and change in environments among aged veterans. They found that activity participation does not change as a function of tïme (4-year interval), and that changing domiciliary environments results in only minimal decrements in activity participation (pp. 213-214). Kapnick, Goodman and Cornwell (1968) tested the political behavior in the aged at two state constitutional conventions (New York and Rhode Island). The prime purpose was to test propositions on the relationship between age and disengagement, activity, attitudes, and leadership. The findings were "that propositions suggesting that the aged would be underrepresented, less active, and more conservative were not supported" (p. 310). Very positive results in favor of activity theory were obtained by Pressey and Simcoe (1950) in a study designed to differentiate the characteristics of old persons who might be considered well or $i 11$ adjcisted. Fine subjects were vigorous old people of high socio-economic status, and it was found that there were many well adjusted individuals in this middleclass group. The authors say that the success of these older people was largely due to their many interests and activities and to their continued usefuiness to others ( $p .168$ ). The authors feel that, basically, that which most differentiates the successful was their active outgoing phitosophy of life (p. 175). 
Tobin and Neugarten (1961) developed some Life Satisfaction Ratings (LSR) which they used to measure psychological well-being. On the basis of these ratings and the measures employed by Cumming et al. (1960), Tobin and Neugarten arrive at the following conclusion: "It appears that, with advancing age, engagement, rather than disengagement, is more closely related to psychological well-being" (p. 346). Engagement means a person's involvement in various social roles. In the case of the older person, it may represent the measure to which he or she is able to withstand the erosion in these roles with the passage of time. The biggest changes usually occur at the time of retirement when the Protestant ethic suddenly becomes reversed and it is not dedication to work but disengagement that is expected of the individual. The significance of these changes for the activities and the life of the older person has been studied in writings on work and retirement and social participation of the aged.

Work and Retirement

Retirement is one form of disengagement or, as Streib and Schneider (1971) say, "retirement may be considered as one aspect of the disengagement process in later life and thus a 'narrowing' of the life processes" (p. 171). Retirement here particularly refers to retirement from the work force, although it may apply to various areas of a person's active life. Stephen J. Miller (1965) states that occupational retirement is "possibly the most crucial life change requiring a major adjustment on the part of the older person" (p. 78). Being forced into retirement can be a severe blow to a man's identity because, as Miller continues: "Work not only provides the individual with a meaningful group and a social 
situation in which to develop a culturally approved and personally acceptable self-concept, it also provides an identity with an accompanying rationale for his performance in other social situations as well" (ibid.). Therefore, the social and psychological consequences of retirement and its implications for disengagement theory have been the concern of many researchers (Arthur, 1969; Atchley, 1972; Cavan, 1957; Clark and Anderson, 1967; Cooley and Cooley, 1965; de Grazia, 1964; Field, 1972; Fields, 1966; Goodstein, 1962; Havighurst and Albrecht, 1953; Jacobs, 1969; Kleemeier, Judson T. Landis, 1942; Ludwig and Eichhorn, 1967; Miller, 1965; Pressey and Simcoe, 1950; Reichard, Livson and Petersen, 1962; Riesman, 1954; Streib, Thompson and Suchman, 1958; Streib and Schneider, 1971; Williams, 1960; Youmans, 1967a).

In 1974, pollster Louis Harris reported on a recently completed survey of aging to which he refers as "one of the most definitive attitudinal studies on old age ever conducted in America" and said that the study revealed a deepening resentment toward "forced retirement" among older Americans. A smashing majority of mature citizens (86\%) said that "nobody should be forced to retire because of age, if he wants to continue working and is still able to do a good job" (NRTA News Bulletin, November 1974, p. 8). "It is fair to conclude," Harris continues, "that senior citizens in the U.S. today feel that they are simply not used by society as they ought to be." The poll also showed that the vast majority of people aged sixty-five and over "want to mingle with, help in many different ways, and be active with people of all ages" (ibid.).

The findings of the Harris poll certainly contradict disengagement theory and its notion of mutually satisfactory withdrawal. There is not 
only interest and willingness, but also capacity to work and to become involved evidenced by the elderly. older people need something constructive to do, and most studies of work and retirement bear this out. Chris L. Fields (1966) has summarized this position from the standpoint of the elderly:

We are perhaps no different now than at periods in our youth in regard to strength of purpose and the ability to set goals, except that we have an advantage that we did not have in youth; we have the experience and observation of many things in life which are useful as guide lines upon which to base our opinions and to make decisions. We also have time now to experiment with some things we may want to do, that we did not have time for in days of our youth, or at least we did not think we had the time (p. 7).

There is substantial agreement among writers that for personal satisfaction, activities engaged in must be meaningful and usefur to one's self or of service to others (Arthur, 1969; Cavan, 1957; Clark and Anderson, 1967; Friedmann and Havighurst, 1954; Kleemeier, 1951; Kutner et al., 1956; Judson T. Landis, 1942; Pressey and Simcoe, 1950; Reichard, Livson and Petersen, 1962; Streib and Schneider, 1971). Crafts and productive hobbies can be helpful in maintaining good adjustment (Pressey and Simcoe, 1950; Reichard, Livson and Petersen, 1962), and travel may serve many interests of the aged if they can afford it and have good health.

Busyness by itself will not solve any problems in retirement (Cavan, 1957; Kutner et al., 1956) and the longer life span may become a "dubious blessing" (Havighurst and Albrecht, 1953, p. 3). It is highly doubtful that very many older people, raised in a work-centered society, could benefit from the kind of "play at work" that Cumming and Henry . (1961, p. 152) describe under the impressive heading of "Solutions to Retirement Problems" (p. 149). 
Ruth Shonle Cavan (1957) has approached the social-psychological problems of aging from the standpoint of symbolic interactionism and has analyzed them using interactionist concepts such as self-conception, roletaking, and role-playing developed by Mead, Cooley, and others. Cavan says that these concepts "have possibilities for a significant analysis of adjustment to old age" and she has applied them in her study to retirement from occupation and to the adjustments the retired man has to make. She has found that the two basic ingredients for retirement adjustment are a culturally approved concept of elderly self held in respect by groups that are meaningful to the old person, and provision to express overtly the implications of such a self-image. Cavan believes that these elements usualiy are not found in the present programs devised for the aged (pp. 526-530).

Goodstein (1962) also feels that many of the needs that work satisfies are not being met by retirement: "The needs for economic security, for status and prestige, for independence, for social contacts, and for spending time in satisfactory ways must be met in retirement as these needs have been met in work or some technics for otherwise resolving these needs must be developed." Goodstein stresses that "more understanding of the psychologic needs constitutes an area which requires thought and investigation" (p. 45). He points out that little is being done to help the worker make the changes required by a new way of life. He, therefore, recommends extensive, well-conceived retirement counseling programs.

How an intelligently administered work program can increase good adjustment in the aged is reported by Robert W. Kleemeier (1951) from 
research that was done in an institution operated by the Loyal Order of Moose (Moosehaven). Data were gathered in a survey of activities and attitudes of residents of this fraternal home for the aged, and the results show that participants in a regular work program of the institution exhibited better adjustment attitudes than did nonparticipants (p. 372). This study emphasizes the adjustment values of meaningful, voluntary work. Workers obtained higher adjustment attitude scores than nonworkers of comparable health status, and workers also had higher scores than nonworkers on subscales of the attitude inventory dealing with health, work, feelings of usefulness and happiness (pp. 378-379).

Streib has long been identified with the Cornell Study of Occupational Retirement. In 1958, Streib, Thompson and Suchman reported on their participation in a nation-wide study. In summarizing their findings, Streib and his associates say they found a picture of largely successful adjustment to retirement, even for those participants whose health and economic situation were poor. Overall, the researchers state, the data suggest that a high proportion of retirees possess "a degree of role flexibility which enables them readily to adapt to a greatly reduced income and to a new life situation" (p. 13). The book of Streib and Schneider (1971) is a more complete report on the Cornell Study of Occupational Retirement which is now greatly discussed in relation to disengagement theory. The authors refer to retirement as "a form of differential disengagement" (p. 171) and say that it is "only part of the deceleration which accompanies aging and that retrenchment in one sphere does not imply retrenchment in a11 areas" (p. 191). The authors speak of new roles for the aged, and it is significant that their 
proposal calls for the creation of roles for older people involving activities which should not be mere "busy work" but should be satisfying in social-psychological terms and recognized as valid, prestigeful pursuits that are socially useful (p. 181).

There are few such roles available as yet. Sometimes the individual strives to create them for himself; but it takes an unusually strong character to hold out against the onslaughts of aging when, as Riesman (1954) says, "the culture does not carry the individual onward but drops him" (p. 383). Kutner et al. (1956) have found that "within each activity level group, the employed have higher morale than the other employment status groups," and that "those who are gainfully employed but otherwise inactive have a higher level of adjustment than do the unemployed or retired who engage in nongainful activities" (p. 121). In view of current employment practices, it is something of an achievement to be employed in the later years (p. 69). In case of retirement, "the feeling of being useful and wanted is paramount" (p. 89). How to fulfill this need is still an unresolved question. In the meantime, a process, aptly described by Fields (1966), continues:

Retirement is an anomaly, yet it is American domestic efficiency in operation. It is operated from the sidelines by people who subscribe to it, then become a part of it. Upon becoming a participant, their operating obligation ends; it is then that adjustment to the new role must stand the test (p. 15).

\section{Social Participation of the Aging}

The authors in this group have studied the social activities of the aged in relation to adjustment and life satisfaction (Beckman, 1969; Bell, 1967; Burgess, 1954; Carp, 1966; Clark and Anderson, 1967; Desroches 
and Kaiman, 1964; Havighurst and Albrecht, 1953; Jacobs, 1969; Kutner et al., 1956; Judson T. Landis; Leveen and Priver, 1963; Palmore, 1968; Reichard, Livson and Petersen, 1962; Tallmer and Kutner, 1969; Tobin and Neugarten, 1961; Videbeck and Knox, 1965; Zborowski, 1962; Zborowski and Eyde, 1962). Generally, these researchers found that activity and morale are related, and that frequent social interaction is associated with good adjustment. The results as a whole are contrary to the first major proposition of disengagement theory, namely, that, with age, social relationships are inevitably severed or altered (Cumming and Henry, 1961, p. 211). Following are some notable examples.

Burgess (1954), in another study of the fraternal community at Moosehaven, found that men with the highest happiness scores participated nine times as much in group recreational activities as those with the lowest happiness scores (p. 360). Havighurst and Albrecht (1953) say, "It is clear that those people who continue to be active in associations are happier and better adjusted than those who do not" (p. 340). Judson T. Landis (1942) states, "The aged who visit frequently are better adjusted than those who visit less frequently. Those who express a desire to visit more are not as well adjusted as those who do not care to visit more" (p. 469). Palmore (1968) conducted a ten-year study of aging to assess the changes in activities and attitudes among 127 panelists and found no significant overall decrease in activities or attitudes. He says, "Changes in activities were positively correlated with changes in attitudes so that reductions in activity were associated with decreases in satisfaction. This was interpreted as contrary to disengagement theory but supportive of activity theory" (p. 263). 
Reichard, Livson and Petersen (1962) also determined that men who adjusted successfully to aging were more active socially than those who were unsuccessful (p. 98). Zborowski (1962) studied the effects of aging upon the recreational life of a group of (204) men and women at the Age Center of New England, a non-profit organization devoted to research in aging. The major conclusion derived from his analysis was that "aging has a rather insignificant influence upon people's recreational patterns and preferences" (p. 308). Another study at the same locale was done by Zborowski and Eyde (1962) to test the stereotype that people, as they grow older, tend to limit their social participation. The interview data did not suggest many changes in the area of social participation as people grew older. In summing up this survey, the authors state:

It is fair to say that, although on the whole there were not many indications of changes over the years in the patterns of social participation of our subjects, the changes which occurred cannot be attributed to increase in age alone but to an interdependent constellation of several variables of which age is only one and hardly the most significant one (p. 430).

The variables that these researchers examined besides chronological age were sex, marital and socio-economic status, and occupational situation. It is noteworthy that this investigation was conducted from the standpoint that "a true indication of a tendency to withdraw from social participation is not so much the quantitative decrease in the number of social contacts with relatives and friends, which can be due to losses through death or reduction of social opportunities through retirement, but in the presence or absence of a feeling of satisfaction with the decrease and in the expressed desire to increase the amount of social participation" (p. 424). 
Satisfaction with one's life situation is the true indicator of successful aging because, as is often pointed out, the aged are not a homogeneous group (Kutner et al., 1956, p. 122). Some individuals prefer relative social isolation for various reasons. There are many solitary activities that can be recreational or creative and are highly satisfying, such as reading, writing or painting. In some cases, watching or listening to mass media may very well substitute for interpersonal rełationships. Therefore, in appraising a person's activity or withdrawal, that person's personality and life style have to be taken into consideration. Age per se does not account for social non-engagement (Clark and Anderson, 1967; Tal1mer, 1967). The complex nature of adjustment in old age, and some vital factors of it, are revealed in the literature on the subject.

\section{ADJUSTMENT TO AGING}

Kutner et al. (1956) consider adjustment and morale part of the same phenomenon: "Morale refers to a mental state or a set of dispositions, while adjustment refers to behaviors that stem from these dispositions" ( $p .48$ ). It seems that the terms adjustment, morale, happiness, and life satisfaction have all been used to describe successful -..aging. Fundamentaliy, adjustment to aging may be viewed from two standpoints: social and personal. But, as Kuhlen (1959) says, it is often difficult to make a distinction between the two. "Social values and norms tend to become 'interiorized' and personal during the course of personality development, and social evaluation of adjustment, as reflected, for example, in biases toward older age groups, may constitute important 
personal threats affecting personal adjustment" (p. 853). In this respect, it is useful to consider Pollak's (1948) explanation of the term "social adjustment":

Patterns of adjustment in their broadest range can be conveniently covered by the term social adjustment which in its common-sense meaning refers to all efforts of human beings to find more satisfactory ways of getting along with one another. In this sense it includes the efforts of an individual to satisfy his personal needs as well as to live up to the expectations of others, on the one hand, and the efforts of groups to provide better opportunities for need satisfaction on a mass basis, on the other ( $p .8)$.

Cumming and Henry (1961) call their theory social-psychological (p. 10). Hence the writings on adjustment to aging have also been examined from a psychological point of view. No support was found for the central hypothesis of disengagement theory, namely, that morale and disengagement as such as positvely related (Albrecht, 1951; Beckman, 1969; Birren, 1964; Burgess, 1950, 1954, 1960; Cameron, 1967; Carp, 1966; Cavan, 1957; Cavan et al., 1949; Filer and O'Conne11, 1962; Goodstein, 1962; Havighurst and A1brecht, 1953; Jacobs, 1969; Jeffers and Nichols, 1961; Kleemeier, 1951; Kuhlen, 1959; Kutner et al., 1956; Paul H. Landis, 1942, Judson T. Landis, 1942; Lebo, 1953; Leveen and Priver, 1963; Lowenthal and Boler, 1965; Palmore, 1968; Pollak, 1948; Pressey and Kuhlen, 1957; Pressey and Simcoe, 1950; Reichard, Livson and Petersen, 1962; Riesman, 1954; Streib, Thompson and Suchman, 1958; Tallmer, 1967; Tallmer and Kutner, 1969, 1970; Taves and Hansen, 1962; Tobin and Neugarten, 1967; Youmans, 1967a; Zborowski and Eyde, 1962). The degree of adjustment in the later years is determined by many personal and environmental factors, and attempts to appraise or measure it often pose problems. However, Kuhlen (1959) has given a workable definition of personal adjustment which is applicable to older adults: 
"The major symptoms of adjustment include (a) feelings of happiness and contentment, and positive self-regarding attitudes; (b) freedom from handicapping anxiety; and (c) evidences of frustration tolerance and ability to deal effectively with stressful, threatening situations" (p. 892). The last point may be the crucial one for studies of aging. Kuhlen states the question is often "not how happy and free of anxiety is the person now but how well he can maintain this state of affairs as he meets the inevitable crises of aging" (p. 853).

Chronological age, Kuhlen feels, is a convenient means of ordering developmental data, but its influence on adjustment consists mainly in agerelated variables that have greater psychological significance. Adjustment depends upon the meaning of life and aging to the individual, his role at a given age, his style of life and his personality makeup (p. 892). These and other personal and situational factors influencing adjustment to aging appear in the analyses shown below.

Health and Disease

Health status obviously has an impact upon social participation, and may have a direct relation to the older person's activities and attitudes. Still there are many older people with various heal th handicaps or chronic diseases who achieve relatively good adjustment and maintain some social relationships in spite of their ailments. Health problems in the elderly and their effect on life adjustment have been investigated or discussed in many studies (Beckman, 1969; Brehm, 1969; Cavan et al., 1949; Filer and 0'Conne11, 1962; Havighurst and Albrecht, 1953; Jeffers and Nichols, 1961; Kleemeier, 1951; Kutner et al., 1956; Judson T. Landis, 1942; Lebo, 1953; Leveen and Priven, 1963; Ludwig and Eichhorn. 
1967; Menotti, 1967; Palmore, 1968; Streib, Thompson and Suchman, 1958; Tal1mer, 1967; Taves and Hansen, 1962; Veney, 1966; Videbeck and Knox, 1965). In general, there is agreement that poor health can seriously impair adjustment, and that those older people who regard their health as good or excellent rate higher on adjustment scales than respondents who report various degrees of disabilities (Havighurst and Albrecht, 1953; Jeffers and Nichols, 1961; Kutner et al., 1956; Taves and Hansen, 1962). Havighurst and Albrecht (1953) devised a "heal th handicap score" for their study sample of older people in a small midwestern city which they call Prairie City, and evaluated the relation of this score to adjustment ratings. They decided that "health is more definitely related to happiness and adjustment than either age or socioeconomic status." "Neverthelesș," they say, "there are many exceptions to the rule that good health and adjustment go together" (p. 54). Consequently, poor personal adjustment or low role activity may be due to causes other than health handicaps. of course, there is a greater incidence of illness and more disability among older people than in other age groups, but most researchers found that, as a whole, older people have fairly good health and that, as Havighurst and Albrecht report, "the number of invalids is relatively small" (p. 63). This finding agrees with a report by Brotman (1970), who states that, in 1968, of every 100 older persons, 96 lived in the community and only 4 were in institutions. ${ }^{16}$

16

Herman B. Brotman, The 01der Population: Some Facts We Should know (Washington, D.C.: Administration on Aging, April 1970. U. S Department of Health, Education, and Welfare), p. 6. 
Many older people exhibit remarkable determination to continue being active despite failing health. They are able to compensate for their deficiencies. If physical disability disqualifies them for certain tasks, they take on others that are less strenuous or increase their participation in different areas (Jeffers and Nichols, 1961: Leveen and Priver, 1963; Palmore, 1968). Leveen and Priver emphasize the supporting nature of roles to help people live out to the end constructive and meaningful lives: "Through playing certain roles, individuals with underlying pathologies have maintained an intact personality and have been able to function in society with a degree of comfort" (p. 57). Palmore (1968) found almost no association between changes in health and changes in attitudes during the ten years of his longitudinal study on aging (p. 262). Similarly, Videbeck and Knox (1965) say that decline of health and physical strength can hardly account for observed patterns of differences in participation, and that "it is more plausible to view the participatory contractions as directly related to the stability of life circumstances" (p. 46).

Veney (1966) reexamines disengagement theory by applying it to an aging population of farmers with heart disease. He points out that Cumming and Henry excluded diseased people from their study and that this fact greatly limits the applicability of the theory even to older people. Veney also seeks to determine whether chronic disease as a reminder of impending death promotes disengagement. He found that health state has little influence on disengagement from social contacts, but that it is a primary factor in influencing disengagement from work. At the same time, poor health leads to increased use of health facilities. Thus it aids disengagement in one area but hinders it in another. 
The disposition in the elderly to use community health services has received special attention by Kutner et al. (1956) in their study of five hundred older people living in New York. They confirm that health status does play an important part in disposition to use health resources. "The poorer the health, the greater is the positive attitude within each economic class group" (p. 189). However, Kutner et al. also bring out the interesting fact that self-perception with regard to aging is linked to use of health facilities. The researchers employ the terms "age conservatism," which represents conventional thinking about the behavior of older people, and "youth orientation," which is linked to actions to preserve youthfurness. They find "a youth orientation toward the aging process ieads (for nearly a third of those who are low in conservatism) to a decreased tendency to seek medical care despite the fact that they are in poor health. For these people, the preservation of youthfulness obscures the need for medical care to a significant extent. At the same time, poor heal th is at least one factor that "causes" some older people to feel their aging" (pp. 195-196).

Ludwig and Eichhorn (1967) have tested the theory that there is a modification and reorganization of values accompanying the disengagement of the elderly, that is, their removal from the mainstream of life. The question is whether the aged adapt their outlook upon life to rationalize the new "minority status" they are forced to assume. The authors stress that society has not supplied aging Americans with a set of values for coping with traumatic personal experiences such as illness, disability and death. These experiences together with the loss of roles contradict the values of a youth-oriented culture which the person has internalized 
and which stress activity, mastery, and faith in the future. The result for the aging is disillusionment or accommodation to reality. However, the authors found that "concurrently, belief in hard work and physical activity as a means for solving life's problems can be heightened at a time when society expects the older person to retire" (p. 59). Furthermore, "with respect to the work-activity orientation, poor health appeared to increase the value placed on work, and age, if not clearly increasing work orientation, did not diminish it" (p. 64).

\section{Socioeconomic Factors}

According to Taves and Hansen (1962), "personal adjustment studies have quite uniformly revealed that high socioeconomic status and activity in significant social roles are positive correlates of good adjustment" (p. 315). High income, good education, and home ownership are also associated with better adjustment in old age. But a sense of adequacy, regardless of income or other assets, is often most imporiant. Regarding oneself as middle-aged is another aid to adjustment (ibid.). Furthermore, Taves and Hansen found that "higher proportions of married persons than those single, divorced, or separated were well adjusted" (p. 372).

With regard to the economic situation of older people, the ones with a high income constitute a sort of elite. Unfortunateiy, the vast majority of retirees experience a sharp and abrupt reduction of income. This is apparent when we look at the median incomes for all people aged sixty-five and over.

In 1970, half of the 7.2 million families with $65+$ heads had money incomes of less than $\$ 5,053$; this was only $48 \%$ of the median income $(\$ 10,541)$ of younger families. Almost a quarter of the older families had 1970 incomes of less than $\$ 3,000$ while another quarter had $\$ 9,000$ or more. 
of the 5.8 million older persons living alone or with nonrelatives, half had 1970 incomes of less than $\$ 1,951$, an amount only $42 \%$ of the median income $(\$ 4,616)$ of under65 individuals. Almost a third of the older unrelated individuals had incomes of less than $\$ 1,500.17$

Accordingly, in 1970, "about 4.7 million older persons or almost a quarter lived in households where the total income fell below the poverty threshold for that specific household type. "18 These figures mean that, al though we have made a great deal of progress toward e? iminating indigence among the aged, there are still many elderly whose incomes are not adequate.

01 der peopie of necessity adapt to deprivations and go without the things they cannot afford--in some cases the proper food and medical care. One might call that economic disengagement. Or, they withdraw from interaction because they feel they are not wanted and they want to preserve their self-respect. That could be named social disengagement. But neither withdrawal brings about the psychological satisfaction that Cumming and Henry claim takes place with advancing age. Clark and Anderson (1967), who studied a group of older people in San Francisco, say the happy people in their sample were not withdrawn from social 1ife. It was different with those who resorted to defensive means:

Those in our sample who do hide themselves away from the young, those who pay ritual service to modern society's decree that the elderly should be neither seen nor neard, those who gather themselves up into a fragile shell of

\section{7}

Herman B. Brotman, Facts \& Figures on 01der Americans: An Overview (Washington, D.C.: Administration on Aging, 1971. U. S. Department of Health, Education, and Welfare), p. 8.

18 Ibid. 
righteous self-reliance--these are not the happy and

fulfilled elderly men and women we have met in

San Francisco. They are those who, when sickness, poverty, and need at last threaten their defended

little worlds, often succumb to madness ( $p .389$ ).

Marital status and family contacts in relation to successful aging have been dealt with in a good many studies (Cavan et al., 1949; Clark and Anderson, 1967; Havighurst and Albrecht, 1953; Jeffers and Nichols, 1961 ; Kutner et al., 1956; Snyder, 1971; Taves and Hansen, 1962;

Youmans, 1967a, 1967b). It is generally recognized that being married and living with one's spouse is a boon to adjustment in old age. Snyder (1971) studied the effect of new marriages among the aged upon the disengagement process. His sample population was composed of persons sixty years of age or over whose marriages were of less than five years' duration, and the central hypothesis argued that marriages contracted late in life serve to retard the disengagement process. The data obtained gave some support to hypotheses dealing with the influence of being newlywed, being married, having more children, having more siblings, and having a young spouse. Happy marriages are especially favorable to good adjustment. Clark and Anderson (1967) were told by some of their happily married subjects that, over the years, husband and wife become closer together, and these researchers feel that "in some cases, this enhancement of the marital relationship is a godsend" (p. 238). Havighurst and Albrecht (1953) state that "the men and women who are married and whose spouses are living have strikingly superior adjustment scores over those who are widowed or single" (p. 153), and Kutner et al. (1956) also find that married older people tend to be better adjusted than single or widowed older people (p. 67). At the same time, most researchers 
point out that family relationships in the later period of life may be attended with some problems and that often the older couple needs to make adaptations in their conjugal existence. Some observations on family contacts of the elderly follow.

As a rule, older people more active in family relations are happier than the average (Havighurst and Albrecht, 1953). Yet is it not always the case according to the findings of Kutner et al. (1956). These researchers say that, among their low status group, frequency of visiting with family and associates had no relationship to morale. Among the high status group, "increased proportions of persons having low morale was found to accompany frequent visiting with children and relations. This was not true of frequent contacts with friends." Kutner et al. suggest that some friction between generations may have been involved, or that the contrast between the generations may "emphasize for the older person that which he would deny--his own aging" (p. 122).

Concerning the theoretical question of withdrawal from family life by the aged, there are two studies by E. Grant Youmans, who explored disengagement in several areas among older rural and urban men (1967a) and specifically family disengagement among older urban and rural women (1967b). Youmans found that, in both residential areas, the older men showed only slightly more disengagement in fanily life than did the younger men. As for the women, there was only slight evidence of disengagement from family life, and this evidence was found only in the rural area. In the metropolitan center, no statistically significant differences were found between older and younger women in the frequency 
of visits by family members or the amount of help and advice given to children and relatives (p. 211).

Youmans admits that the matter of transportation might have played a part in some of the differences that he did find, or that generational phenomena rather than age changes might have accounted for differences in behavior and attitudes. In both studies, Youmans used two age groups: people aged 60 to 64 and people aged 75 and over. Differences between these two age groups, it was theorized, reflected aspects of the disengagement process. However, the author is inclined to view findings from two age groups with caution. Nevertheless, it is significant for the theory of disengagement to note that his research "supports the contention of Kutner ("The Social Nature of Aging," The Gerontologist, 2, 1962, 5-8) that changes with advances in age are not necessarily degenerative or linear," and that "it adds support to the findings of Williams and Wirths (1965) that disengagement can occur in different aspects of a person's behavior and at different rates in these various aspects" (p. 115).

\section{Personality and Life Style}

Since disengagement theory has evidently raised more questions than it has answered regarding the complex relationship between aging and adjustment, researchers have look chronological age to explain variations in the attitudes and behavior of older people. Personality and life style are prominent among the variables which have been examined for clues. The value of these symptoms for research has long been recognized (Butler, 1963; Ca:an et al., 1949; Clark and Anderson, 1967; Desroches and Kaiman, 1964; Havighurst, 1968; Havighurst, Neugarten and Tobin, 1963, 1968; Kuhlen, 1959, 1964; Kutner 
et al., 1956; Lehr and Rudinger, 1969; Leveen and Priver, 1963; Maddox, 1964, 1965, 1966a, 1966b; Maddox and Eisdorfer, 1962; Neugarten, 1963, 1964, 1968; Neugarten and Associates, 1964; Neugarten, Havighurst and Tobin, 1968; Palmore, 1968; Pollak, 1948; Pressey and Simcoe, 1950; Reichard, Livson and Petersen, 1962; Riesman, 1954; Tallmer, 1967; Videbeck and Knox, 1965; Williams, 1960, 1963; Williams and Wirths, 1965; Zborowski, 1962; Zborowski and Eyde, 1962).

If we were to look for a common theme among this wealth of research dealing with the adult personality, we would find that there is no sharp discontinuity with age but that the individual tends to persist in his ways of life. Cavan et al. (1949) says: "The personality of the old person rests upon and grows out of his earlier personality. There is a continuity of personality from birth to death" (p. 75). The evidence that emerges from studies of the aging process indicates there is a great deal of stability in the characteristics of people; at the same time, some changes have been known to occur (Neugarten 1963, 1968). The moot question has become to what to attribute observed changes. Disengagement theory has it that, as people grow old, they "naturally" lose most of their social contacts and their psychologic ties to the environment, and, furthermore, that this kind of withdrawal results in increased life satisfaction or morale. In analyzing the personality of their respondents, Cumming and Henry (1961) concentrated on those variables that could be related to disengagement theory. They used TAT stories for their data and their interpretations of them seemed to "anticipate the concept of readiness for disengagement" (pp. 107-110). In other words, Cumming and Henry assume there are personality changes with age which are consistent 
with their general theory of a movement away from an active outer world orientation to an adaptive and abstract inner world orientation (Henry and Cumming, 1959, pp. 387-388). This hypothesis, of course, contradicts the view of activity theory that older people are best adjusted when they maintain their personalities and life styles of middle age.

Critics of disengagement theory remonstrate that Cumming and Henry assume too much homogeneity among older people when they postulate an internal law that would apply to all (Maddox, 1962a). Tallmer and Kutner (1970) show that, in their study which duplicated a number of research instruments employed by Cumming and Henry, aging and morale were not systematically related but "depend on other factors (i.e., income, retirement status, sex, age of widowhood, and health) as intervening variables" (p. 318). These changes in life circumstances may affect the older personality rather than age itself. Neugarten (1968b) points out that "personality changes occur in the last half as well as in the first half of the life cycle," and that there are many differences among older people (p. 45). Therefore, in analyzing behavioral or attitudinal phenomena among the elderly, it would no doubt be most useful to distinguish the "changers" from the "nonchangers" and to establish "baselines against which individual change may be measured in a meaningful way" (Maddox, 1966a p. 329). Persistence of life style often explains what may appear to be patterns of disengagement, and has been recognized as an important factor in achieving adjustment to aging. For instance, Reichard, Livson and Petersen (1962), in their study of the aging personality, found that people who adjusted well to retirement "were able to develop a life style that provided continuity with the past and 
met long-term needs" (p. 170). In relating patterns of aging to disengagement, Havighurst, Neugarten and Tobin (1968) say:

The aging individual may or may not disengage from the pattern of role activities that characterized him in middle age. It is highly doubtful, however, that he ever diser:gages from the values of the society which he has so long internalized. It is even more doubtful that the aging individual ever disengages from the personality pattern that has so long been the self ( $p .172)$.

Just how a person adjusts to the stresses of aging also largely depends upon his or her personality make-up. As Leveen and Priver (1963) say, some people become depressed and withdraw, while others "are able to utilize and transfer their time and energy to new tasks and roles, thus living out to the end a more constructive and meaningful life" (p. 57). Whether or not the adjustment will be successful will be determined by the individual's ability to cope with outer or social and inner or personal frustrations. It will further be dependent upon the subjective needs and the world view of the individual. A pattern of aging that suits one person may not be the choice of another. As a whole, the foregcing group of findings indicates a major trend toward the maintenance of habitual modes of life regardless of increase in age.

In the progression of this review it has been brought out how very important for the older individual's adjustment his self-image is. Those people who perceive of themselves as "young" or "middle-aged," or regard themselves in good health, are usually among the better adjusted groups. Kutner et al. (1956) find self-image and morale fairly closely associated (p. 100). They say that those among their low status groups who felt deprived compared to their peers showed a very. low level of morale. The authors consider this as testimony of the interrelationship between 
self-concept and adjustment. At the same time, they point out, "it should be borne in mind that the relationship between self-image and morale may be mutually reinforcing" (p. 96). Kuhlen (1964) has perfectly summarized this association: "It is apparent that the well-adjusted individual will have positive self-regarding attitudes, whereas the individual who is maladjusted and insecure--and hence more susceptible to anxiety and threat--will tend to have a low regard of himself and be lacking in self-confidence" (p. 226). It remains to be stressed how very difficult it is for the older person to establish a socially respected and personally acceptable self-concept in a culture that is given to a negative appraisal of the elderly (Miller, 1965; Tuckman, Lorge, and Zeman, 1961) and to their exclusion from the ongoing life in the community (Jacobs, 1969).

The Environment

The environmental needs of the aged have been dealt with primarily from the standpoint of physical settings, and a vast literature exists in this area (e.g., Abrams, 1965; Donahue, 1954; Doyle, 1954; Hoben, 1954; K.7eemeier, 1963; Lowenberg, 1954; Niebanck, 1965; Niebanck and Pope, 1965; Strunk, 1954; Vivrett, 1960; Wilner and Walk1ey, 1966; Wilson, 1960). However, some writers recognize the vital importance of social and psycinological elements in the surroundings of older people. Wilson (1960), for instance, says there should be included in city plans opportunities for older people to be near special work and hobby centers and to find "emotionally significant social contacts" (p. 28). Birren (1969) suggests that "the urban environment of the near future should recognize the wide 
range of individual differences in interests, education, energy level, health, religion, and customs." Consequently, he feels, there is need of a pluralistic approach to the living arrangements of the aged (p. 164).

The stimulating effect of the proper environment has been demonstrated in two especially important studies in which it was possible to manipulate the environment so as to test certain propositions with regard to morale, adjustment and disengagement. Filer and $0^{\prime}$ Connell (1962) were able to establish a "useful contribution climate for the aging" by modifying part of the setting in a pilot program at Veterans Administration Center, Wood, Wisconsin, in 1956. This was an activity program to place the residents of the Center into constructive work assignments in keeping with their abilities and interests. However, 20 percent of this population were rated as "non-duty," that is, they were judged as being too disabled to perform any regular work assignments. Filer and $0^{\prime}$ Connell state that these men were neither acutely $i 11$ nor so disabled that they required hospitalization. This became the experimental group. Filer and $0^{\prime}$ Connell explored the hypothesis that "these most disabled and aged residents if involved in a rehabilitative climate which both enables and expects them to 'se useful, productive, and contributing group members will more effectively attain or maintain acceptable standards of Personal Appearance and Hygiene, Friendship and Social Adjustment and Recreation and Leisure Time Adjustment." In structuring the workshop for the experimental group (70 men), care was taken to exclude tasks which could be construed as only "busy work." "Each task had a specific functional use, either directly related to the operations of the Center or as a contribution to the community-at-large outside the 
Center" (p. 53). The results of the program gave an affirmative answer to the question of whether a climate of productive work activities could be devised to gain the participation of aging and chronically ill domiciliary members. The ratings showed that 71 percent of the experimental group among the participants had a satisfactory level of work performance. There was also a significant relationship between involvement in the "useful contribution" climate and greater attainment of personal and social adjustment (p. 55).

Filer and $0^{\prime}$ Connell have in effect reversed the disengagement process for most of their subjects, thus disproving the contention that it is universal or inevitable. If some members of the experimental group did not respond with higher adjustment ratings, the authors fee] that it is a matter of personality and that for some people disengagement is the preferred type of adjustment. But, in general, if there is reinforcement, even an aging and disabled organism will respond to constructive suggestions.

The other noteworthy instance in which disengagement was reversed is the research of Frances Carp (1966) concerning the public housing project, Victoria Plaza, in San Antonio, Texas, to which the author proudly refers to as "A Future for the Aged." As in the previous example, it was possible to test for the effect of the environment on an aged population. The subjects were obtained from the list of applicants for public housing who wanted to live in Victoria Plaza. It was made clear to them that participation in the study was voluntary and that it had no bearing on admission to Victoria Plaza or other public housing facilities (p. 15). Applicants who were willing to participate were interviewed and 
tested, and if they were admitted to the Plaza, they were again interviewed after they had moved. It is important for us to note that, together with other measures, a Disengagement Index was devised for the Carp study and was used to estimate certain changes in the subjects (Appendix A, p. 242). According to the scores, the nonresident group showed a tendency toward disengagement during the period between the first and second contacts, and the resident group exhibited a contrary tendency. This is the way Carp describes the transformation:

This reversal of disengagement was associated with more favorable self-concepts, improved interpersonal relationships, and increased happiness and satisfaction with past and present life, factors which suggest that this group of older people had been disengaging not from developmental readiness but from press of life circumstances. Given a comfortable and attractive physical environment and one rich in social possibilities as wel1, they seemed to re-engage and to enjoy it ( $p .143)$.

It is apparent from the foregoing review that there exists a widespread skepticism about the adequacy of disengagement theory for determining optimum aging. Most researchers feel that additional studies are needed in order to come closer to the truth. With regard to the immediate controversy, a number of writers believe that neither disengagement nor activity theory is in itself sufficient to explain successful aging (Havighurst, Neugarten and Tobin, 1963, 1968; Havighurst, 1968; Henry, 1963; Hochschi1d, 1975; Lehr and Rudinger, 1969; Neugarten, Havighurst and Tobin, 1968; Snyder, 1971; Streib and Schneider, 1971; Tal1mer, 1967). Obviously, much remains to be done before we can fill in some of the gaps in our knowledge about the processes of aging. 
In this chapter we have examined the literature pertaining to disengagement. We have also laid the groundwork for the following chapters which pursue the argument of optimum aging. The next chapter will deal with the theoretical approach to activity and disengagement, and it will outline how the present dissertation endeavors to make a contribution beyond existing research. 


\section{CHAPTER III}

\section{THEORETICAL ORIENTATION}

Tal1mer and Kutner (1969) write: "Disengagement theory by all odds is widely acknowledged to be one of the most inventive of conceptions about the nature of the human aging process" ( $p .70)$. It is not only that; it could be dangerous. If taken literally, most older people would be condemned to either stagnation or madness because there is no redeeming feature about disengagement theory. It completely wipes out any productive years that the older person might have left and leads into senility and nothingness. Cumming and Henry nownere demonstrate that disengagement produces morale. Tallmer and Kutner (1970) replicated a number of research instruments used by Cumming and Henry, including their "morale index." This measure assumed a special importance for Tallmer and Kutner since they were interested in testing the central issue of optimum aging, namely, the maintenance of morale when associated with disengagement. They feer that Cumming and Henry do not confront this issue directiy although such a procedure would be necessary for the support of the hypothesis in question. This writer tends to agree that the theoretical formulation of disengagement (Cumming and Henry, 1961) is not adequate to identify a condition of optimal mutual satisfaction allegedly brought about by withdrawal of aging individuals and society from one another. Maddox (1965) has pointed out that in the initial reports of Cumming and Henry, "The morale scale scores, which 
include items on satisfaction with activity, are not analyzed in relationship to the amount of activity reported. Hence, it was quite possible that those who were most satisfied were also most active" (p. 326). Tallmer and Kutner report serious difficulties with the morale measure used by Cumming and Henry (1961). It is not clear whether this so-called morale scale measured apathy or life satisfaction (p. 319). Tallmer and Kutner found in their own study, "morale appears to be related to life style and circumstances often beyond control: health, income, widowhood, and retirement" (p. 317). They also believe that a crucial theoretical issue centers on the question of volition in the process of disengagement. However, from the Cumming and Henry research, they could not determine to what extent disengagement was voluntary (p. 320). They summarize their findings by saying:

The prediction of Cumming and Henry that disengagement must take place with aging to maintain morale is not substantiated in our study, and we must dispute the alleged improvement in morale in individuals who are disengaging (p. 319).

Cumming and Henry have indeed encountered difficulty in convincing most critics that disengagement is beneficial to older people. For instance, Sidney Levin (1964) associates disengagement with depression. In commenting upon disengagement theory and those old people designated by Cumming and Henry as successfully disengaged, that is, leading static, tranquil, self-centered lives, Levin asks: "Is it true that such individuals are usually as happy as they appear?" He does not believe so. He suggests that "the self-centeredness to which these authors refer is frequently a manifestation of narcissistic regression occurring in an apathetic type of depression." Levin also believes that such depressions are often reversible (pp. 180-181). Maddox (1964) has 
expressed similar thoughts, and he feels that the possibilities of such reversal should be investigated:

Additional research is clearly indicated to explore the conditions under which subjects classified as disengaged by the Kansas City procedures can be ego-involved and can experience stress as a result of that involvement. It is possible that psychological disengagement is most probable in those situations which minimize the chance of exposing the individual to ego-involving tasks. Another way to say this would be that psychological disengagement is conditioned in important ways by social disengagement. 19

It is not possible to reconcile the claims of Cumming and Henry with their data. The present researcher must come to the same conclusion that Tallmer (1967) did: "The Cumming and Henry approach to theoretical construction strays more and more from their data and terminates in unsupported speculation" (p. 160).

Cumming and Henry have chosen their sample to fit their theory (Growing 01d, p. 210). In the selection of their study group, a sample was chosen from a population of physically healthy adults who had no major economic worries. The most important criterion for selection of the panel members was age (ibid., p. 27). The panel chosen was aged forty-eight to sixty-eight. After the chronically $i 11$ and Negroes had been eliminated, it was decided also to eliminate the lowest and the highest layers of the class structure (pp. 232-233). Cumming and Henry admit that their sample is biased: "As a result of our method of selection, we have a strong middle-class bias. Our panel is better

\section{9}

George L. Maddox, "Disengagement Theory: A Critical Evaluation," The Gerontologist, 4 (June 1964), pp. 80-82, rpt. in Readings in Gerontology (Eugene, Oregon: University of Oregon, School of Community Service and Public Affairs, Fall, 1969), II-C, p. 3. 
educated, wealthier, and of higher occupational and residential prestige than the universe" (p. 233). Subsequently Cumming and Henry felt they needed to extend the age range. Therefore, a separate quasi-sample was constituted, which was chosen by the so-called "bush-fire" method, described by the authors as follows:

Three interviewers were chosen who came from markedly different socioeconomic classes. They were asked to collect a group of people over seventy years of age who met, as nearly as they could discover, the criteria of health we had imposed on the panel. The respondents were located by inquiry in the neighborhoods where the interviewers themselves lived (pp. 27-28).

The age of this group of respondents was between seventy and ninety. They were ambulatory and not obviously ill. Although the chronically impaired had been excluded from the regular panel, 19 members of the quasi-panel were included even though they were seriously impaired (p. 239). It is of significance for the theory to note that this quasi-sample is also admittedly unrepresentative: "Our oldest respondents are probably unrepresentative of the universe of eighty- and ninety-year-olds for another reason. Owing to the 'bush-fire' technique of choosing them, we found ourselves with a markedly religious group because two retired clergymen had led us to their friends" (p. 204). This fact may have had something to do with the attitude of resignation that the authors say they observed in these old people: "The factor with the greatest bearing on morale seems to be the ability to disengage" (p. 209).

This statement directly opposes the view supported by most of the foregoing research, namely, that "among the elderly, maintenance of contact with the social environment is a condition of maintaining a sense of life satisfaction" (Maddox, 1966a, p. 329). It is a matter of 
logic that it would be among the very old that a state of relative disengagement would be most likely to be observed. They are probably less mobile than younger people, and their health may be failing. But Cumming and Henry present no evidence that, if the morale of these old people is high, it is because of their withdrawal rather than in spite of it. The data of Cumming and Henry have also been interpreted to suit their theory, and it would be wise to keep in mind, from the beginning, what Maddox (1965) has to say about disengagement theory as a vehicle for research:

It is argued that in most published research purporting to evaluate hypotheses derived from disengagement theory it is difficult, if not impossible, to distinguish the artifacts produced by sampling bias and styles of data analysis from the facts about social and psychological aspects of aging processes, on the one hand, and about the process of successfut aging, on the other ( $p .328$ ).

In illustrating their theory as applied to older people Cumming and Henry make unsubstantiated statements such as "readiness to disengage," or "reluctance to prepare for disengagement" (Growing 01d, p. 86); "jumping-off point for the disengaging process" ( $p .104$ ); and the "threshold of disengagement" ( $p .171)$. "Modal" cases of disengagement are evidently those that conform to the theory of Cumming and Henry and thereby win their approval, as does, for instance, Mr. Allen, a man sixty-eight years 01d: "He appears to be gradually working free of the demands of instrumentality. He is doing this with considerable success, and is only moderately distressed by the loss of autonomy which disengagement" carries with it" (p. 161). . . "One important characteristic of Mr. Allen since we have known him has been his readiness to give up his strong bonds to work" (p. 164). People who postpone disengagement or are unwilling to consider themselves retired are "aging unsuccessfully" 
(p. 196), and, if they continue to be engaged, they are termed "atypical" or outright "failures" (p. 180). It must be said that such phenomena are at variance with what this researcher encountered in the real world. Cumming and Henry make caricatures of older people. They talk about them as though they were different creatures, and not just "ourselves in the not very distant future" (Jul ietta K. Arthur, 1954, p. 51).

It must be realized that, to Cumming and Henry, aging is withdrawal or disengagement: "In our theory, aging is an inevitable mutual withdrawal or disengagement, resulting in decreased interaction between the aging person and others in the social systems he belongs to" (Growing 01d, p. 14). Curming and Henry (1961) say that this separation is built into the social structure and also into the system of the human being: "The individual shifts his orientation and modifies his attitudes so as to 'ready' himself for the disengagement process" ( $p .75)$. They have had considerable difficulty in convincing the critics of this neat arrangement. Atchley (1972), for instance, declares it "inoperative":

A serious difficulty arises when we examine the political institution in the United States. If societal disengagement were a functional necessity, then we would expect it to apply. to the political institution perhaps more than to any other. Yet when we examine the key positions in American politics we are forced to conclude that the norms of societal disengagement are clearly inoperative. The average age of Senators, for example is around fifty-eight, and many are over seventy (p. 32).

Whitman (1961) has stated this argument even more specifically. He says that, if we were to rigidly enforce the age sixty-five retirement requirements in all cases, it would mean that we would have to dismiss about twenty-eight percent of America's top executives, forty percent of our Senators and twenty-one percent of our Representatives as of the time 
he was writing. Dwight Eisenhower could not have served his second term as President, Winston Churchill would have been deprived of his leadership in the Second World War, and many. religious leaders, such as Popes, would have been eliminated from service. By way of analogy to our practices, Whitman quotes from Maurice DuPont Lee: "We are building in the United States the biggest graveyard of rusting brains ever assembled in one spot" (p. 233).

Four decades ago, Elise Whitten wrote: "If you think that life is over at forty, fifty, or even sixty, you are mistaken." She compiled the following array of prominent persons who continued to make great contributions regardless of age and refused to be "disengaged":

Madame Schumann-Heink made her debut on the screen at 74; May Robson is past 70; Laura Howe Richards is past 84 and writing children's literature; Selma Lagerlof wrote her best after 77; Dr. Charles F. Thwing, president-emeritus of Western Reserve University, of Cleveland, has completed two books the past year and just had his 83rd birthday; Coin Harvey, noted writer and lecturer of Monte Ne, Arkansas, was candidate for president on the Liberal ticket when 80 . Still kept writing unti] his death a few months ago.

Luther Burbank could run a race, kick above his head and vault a high gate when 77 . Asked why he was so nimble he said, "My body is no older than my mind, which is still adolescent. I am as inquisitive as a child. The mind makes the man."

Consider the late Justice 0liver Wendell Holmes, active till 90. His father wrote, "Over the Teacups" when 79. Tennyson wrote "Crossing the Bar" when 83; Cato the Censor learned Greek after 80 and lived to make good use of it; Verdi produced "Ave Maria" at 85; Titian was 98 when he painted the "Battle of Lepanto" (The Digest, August 21, 1937, pp. 20-21).

We could add many more names, both historical and contemporary, of . eminent personalities who have made outstanding contributions at an advanced age. Among the more recent would be Charles De Gaulle of France, President while in his seventies; Chancellor Konrad Adenauer, architect 
of postwar recovery of West Germany, also in his seventies; and Pope John XXIII, in his eighties. Examples of the great number of remarkable older people in America are two elder statesmen "with young ideas": Former Democratic national chairman, James A. Farley, who started his political career as town clerk in 1911, and reached his peak in his alliance with President Roosevelt in the 1930's; and Governor Alfred M. Landon of Kansas, Republican, who ran in the Presidential campaign against Franklin Delano Roosevelt in 1936. Managing Roosevelt's strategy that year was Postmaster General Farley. L. H. Whittemore wrote of these two men in The Oregonian (November 23, 1975): "In the American history books, Alf M. Landon and James A. Farley are already indelible fixtures as characters in the political drama of this century. But Alf Landon and Jim Farley, 88 and 87, are also involved in today's world. They are as active, keen and cheerful as ever" (Parade section, p. 10).

In the field of labor, there is AFL-CIO President George Meany, who is 81 in 1976, and seems to be in good health and good spirits, and is still performing an excellent job. We can also point to a distinguished Oregon businessman, Fred G. Meyer, who has been a Portiand resident for 68 years, and, at 90, continues to be active chairman of the Fred Meyer Inc. merchandising chain which comprises more than 50 stores. After all these years at the helm, Fred Meyer still runs a taut ship, writes William Wong about him in The Wall Street Journal (June 11, 1975). He quotes Fred Meyer as saying: "You rot if you retire" (p. 1). In 1976, Fred Meyer was honored as Portland's "Citizen of the Year," and was proclaimed as Distinguished Oregon Citizen by Governor Bob Straub (The Oregonian, January 18. 1976, p. E-1). 
This writer was particularly impressed by an article in The Plain Truth, a nonprofit magazine, published by Ambassador College, Pasadena, California (Vol. XLI, No. 11, December 1976). The author is the magazine's Editor-in-Chief, who is also its founder, President and publisher, Herbert $W$. Armstrong, and the title of the article is, "The Western World's Growing Tragedy--Growing 01d Before Our Time." Mr. Armstrong says that one of modern civilization's greatest tragedies is the myth about old age:

Somehow, I never could quite understand that type of outlook on life. I have never reached "middle age," at least not consciously--not in my mind and manner of thinking and acting. After age 83, I have enjoyed joking about being "37, going on 36." I have simply been TOO BUSY to think of "growing old" or ever "retiring" (p. 1).

Finally, the present writer also wants to share a note on a Christmas card just received from a friend: "I am always very pleased to hear from you, and am glad you are well and happy! I am still all right considering my 93 (soon 94) years, and am very happy that I fee1 good and am able to do all my work yet. Many hearty greetings."

These examples from real life should suffice to show that the Cumming and Henry theory of mutual satisfaction does not apply universally-not even in cases of the "very old" who are cited by the authors as having particularly high morale because of their disengaged state (p. 209).

Cumming and Henry say that the disengagement theory of aging which they are developing is a "common-sense theory" (p. 13). It would seem that common sense would dictate to take an objective view of all available evidence regarding the behavior of older people. But Cumming and Henry evaluate it as to whether or not it conforms to their preconceived theory. They say: "In analyzing the personality of our respondents, our central 
concern has been to consider variables that could be related to disengagement theory" (pp. 107-108). Some of the data that Cumming and Henry refer to could just as wel1 be interpreted as contrary to disengagement theory, and, as already mentioned, they have been. But these authors have a peculiar way of distorting or disregarding evidence that does not suit their purpose. For instance, if some respondents say they "don' $t$ feel any particular age," or that they "feel as young as ever," Cumming and Henry call these answers "evasions" (p. 73). They mention older people who have not disengaged. For example, they refer to Bertrand Russe11 (pp. 201, 215), and to Toscanini, Bernard Baruch and Bernard Shaw (p. 201). But they simply dismiss such information, and do not seem to attach any particular importance to the fact that these people have made great contributions at an advanced age. Cumming and Henry recount the areas in which Bertrand Russell has consecutively re-engaged himself, namely, as mathematician, logician, educator, social philosopher, historian of philosophy, moral and political philosopher, and, finally, as a writer of fiction (p. 215), but that does not appear to bother their theory. However, it should be clear that, if some people can re-engage, or do not disengage in the first place, disengagement cannot be "inevitable mutual withdrawal."

Among the respondents of Cumming and Henry is an eighty-year-old woman whom they describe as fully engaged. "Her daily round would exhaust many women half her age" (p. 196). The authors say of her: "She appears to be one of those few people who have stayed engaged because they have such a high level of vitality, place a high value on activity, and tolerate obligatory contact excellently even when very old. When they are forced to disengage, however, through physical impairment, their inner 
resources and outer supports sustain them" (p. 198). Here Cumming and Henry seem to be arguing against their own theory, but they only comment regarding this remarkable woman (Mrs. Elton): "Her kind is extremely rare among old people" (ibid.). Nevertheless, in the opinion of this writer, such cases disprove the theory.

Regardless of obvious contradictions, the authors of Growing 01d (1961) have their own way of rationalizing optimum aging. They have their sights fixed on disengagement theory and are oblivious of the things that do not support it. Rose (1965) believes that it is no accident that the disengagement theorists "are ethnocentric and ignore major social trends" (p. 365). He believes that this attitude is due to "the general functionalist theory which underlies Cumming's work" (ibid.).

Growing 01d (pp. 11, 77) has admittedly been influenced by Talcott Parsons, the leading American theorist of functionalism, and the work of Cumming and Henry is built on the functionalist doctrine of balance and automatic strain toward equilibrium in the social system. Among the basic principles of this approach seems to be a general inflexibility. It is not unusual for functionalists to posit certain assumptions about social life, and then to attempt to demonstrate that the situation unalterably must be so. Rose (1965) further comments on this: "The functionalists' assumption that 'whatever is, must be' merely ruins an initially valid observation by exaggerating it and denying any possibility of countertrends by declaring its inevitability" (p. 365). 
But, in order to get to the core of the conception of aging which has been named "disengagement theory," the implications of Cumming and Henry have to be fully understood. Rose (1965) says there has been a widespread misinterpretation of the theory of disengagement expressed by Cumming and Henry, and that one must state what it is before it can be evaluated. Rose explains that this theory is not merely a hypothesis which states that, as people get older, they are separated from their social functions; neither is it a matter of poor health nor reduced income which might force them to abandon their associations. What the insight of Rose reveals is the following:

The Cumming and Henry theory of disengagement is that the society and the individual prepare in advance for the ultimate "disengagement" of incurable, incapacitating disease and death by an inevitable, gradual, and mutually satisfying process of disengagement. Each of these terms must be understood before the theory can be understood. Disengagement is inevitable, because death is inevitable; and, according to a basic principle of functionalism, society and the individual always accommodate themselves to the solid facts of existence. Society and the individual always seek to maintain themselves in equilibrium and avoid disruptions, according to the functionalist (pp. 360-361).

Here is the crux of disengagement theory. In the Cumming and Henry book, there is a constant implication that older people have an obligation to withdraw from their accustomed interaction. If they do not comply with this expectation, the theorists seem to regard such behavior as abnormal. A case in point is their example of Mr. Everett, who, Cumming and Henry say, "is having difficulty making the transition" (p. 190). They refer to him as a "late bloomer" (p. 196), who, in their view "is aging unsuccessfully" (ibid.). 
Evidently Cumming and Henry are trying to substantiate a theory of transition based on some kind of compulsion or unwritten law which says that the older individual must change purely because of age instead of living fully within the limits of unavoidable disadvantages or misfortunes. As can readily be seen from various foregoing quotations, the attitude of Cumming and Henry toward the older person is rather disparaging. The book shows a reflection of what Rosow (1967) has called "a general devaluation of the aged" (p. 31). Cumming and Henry justify their detraction from the image of the elderly by claiming that the meaningless existence they describe is pleasant (pp. 166-167). They base their case primarity on their representation of the very old, among whom they say there is a "chirpiness" (p. 202). Cumming and Henry suggest that "given an adequate income, the very old enjoy their disengaged existence" (p. 209).

In order to show that psychological and social withdrawal are conducive to successful aging, Cumming and Henry would have had to establish a positive correlation between disengagement and morale, but this they omitted to do. Their statement on the interrelationships of the main variables used in the study (1961, pp. 267-270) does not warrant such a conclusion. They do not measure disengagement proper: "Although an attempt to measure disengagement is premature, we have indices that give us the respondent's level of engagement, in the interactional sense. These are Role Count, Interaction Index, and Lifespace. We also have some social-psychological indices of engagement" (p. 267). These latter variables are Perceived Lifespace, Alienation, F-score, and Ego Energy (p. 269, Tables 4-1, 4-2, and 4-3). The vagueness of the Cumming and Henry approach is apparent from some of 
their comments concerning their research. For instance, with regard to the seven "main variables" just mentioned, they say: "In summary, none of the relationships among the variables are dissonant with disengagement theory; most of them are harmonious with it, and a few are explainable only on a post hoc basis. However, it should be kept in mind that except for Alienation, F-score, and Ego Energy, the scores are not totally independent, being developed from overlapping data, and therefore their relationship is inflated to an unknown degree" (p. 270).

Although Cumming and Henry did not actually measure disengagement, they did sort their respondents into four groups or "stages of disengagement" for the purpose of associating them with relative levels of morale. These four stages are broadly defined according to age, occupation with a characteristic central task (marriage for women, work for men), and reduction in ego investment or object cathexis as indicated by the Perceived Lifespace Measure (p. 133). No score for disengagement is shown, but following is a description by Cumming and Henry of the four stages:

Between the beginning and end points, there are two intermediate states of disengagement, based on the respondents' characteristics of disengagement. These four states, the beginning, end, and two intermediate points, are thought of as four stages or steps in the process of disengagement. Those at the beginning or first stage have none of the three characteristics of disengagement; namely, over sixty-five years of age, withdrawn object cathexis, or lack of a central task. The respondents in this category are considered fully engaged. Those at the second and third stages are considered partially disengaged and have one and two characteristics, respectively. Those at the fourth level have all three characteristics and are considered fully disengaged (p. 134).

Cumming and Henry have made an attempt to measure morale and arrived at some scores, but they say about these: "Our primary concern is not 
with individual scores per se but with relative levels of morale that may be associated with the disengagement process" (p. 133). They then exhibit (p. 135) an arrangement of average morale scores according to stage of disengagement in association with type of kin, that is, siblings and children, living in the same geographic area. This combination is explained as follows: "Because of the importance of kinship relationships in the disengagement process, and since satisfaction with the frequency of social contacts is a component of the morale index, the data are presented according to types of close kin living in the same geographic area" (p. 136).

The statement of "importance of kinship relationships in the disengagement process" is a surprise element, since it is not contained in the formulations of disengagement theory (Chapters II and XII), and conflicts with the theorists' claim of an intrinsic compulsion toward mutual withdrawal or disengagement because of aging (p. 14). Cumming and Henry conclude their discussion of the measurement of morale by saying: "Summing up, we have found that it is not uncommon to find general improvement in total morale and increasing satifaction in most of the areas of the morale index in the later stages of the disengagement process among this group of healthy, economicaliy independent men and women" (pp. 139-140).

As noted, Tallmer and Kutner (1970) have taken issue with the morale measure of Cumming and Henry. With regard to the adequacy of the procedures adopted by the disengagement theorists, Tallmer and Kutner observe: 
Measures of happiness or unhappiness fail to yield much information regarding the aging process itself. We know little about the nature of disengagement. It is necessary to study the process of withdrawal and then measure the degree of satisfaction expressed by the individual. These attitudes would then become a separate question, namely the psychological end effect of a process of detachment (p. 319).

To say the least, the conclusions of Cumming and Henry appear unfounded and not backed up by tangible evidence. It is futile to try to unravel the many discrepancies that their statements present. Tallmer (1967) has rightiy noted: "The basic difficulty with accepting the Cumming and Henry position is the ease with which they move away from the information they have collected into 'explanations' that go far beyond their data and become philosophical tracts cloaked as theories" (p. 161$)$.

One answer to some inconsistencies in the book may be the fact that it has too many authors. Besides Cumming and Henry, the two senior authors, Growing $01 d$ numbers among its creators six other writers ${ }^{20}$ who have written or collaborated in different chapters, among them the most important one, "A Formal Statement of Disengagement Theory" (Chapter XII), "with" Ernest Damianopoulos. Their joint product calls for serious examination, because what they are proposing is a theory of major proportions that, if accepted, would affect all older people. This is no modest proposal.

20

Dávid S. Newe 11, Chapter IV; Lois R. Dean and David S. Newel1, Chapter V; Lois R. Dean, Isabel McCaffrey and Rhonda Cassetta, Chapter VII; with Mary Lou Parlagrego, Chapter XI; with Ernest Damianopoulos, Chapter XII. 
To recapitulate, the theory which is referred to under the names of Cumming and Henry, as originally proposed, states that disengagement is an inevitable, universal, and self-perpetuating process. It is mutually satisfying to society and to the individuais concerned, and it is a gradual preparation for death--in advance. It is marked by a lessening of ego energy, reduced social interaction, and increased selfabsorption. Those ties to the social system which remain are said to show a changed quality (Cumming and Henry, 1961, Chapters II and XII). There is a suggestion that this change may stem from "an altered basis in the person for the reception and initiation of social events" (Henry, 1963, p. 416).

The theory of disengagement is evidently primarily the conception of Elaine Cumming (William E. Henry and Elaine Cumming, 1959). Subsequent to the publication of Growing 01d (1961), in her article of 1964, Cumming made a few modifications in the initial proposal by recognizing some complexities in the manner of aging and making allowances for "nonmodal" cases of widowhood or retirement. She also suggested "some characteristics of aging people that might make an important difference to their patterns of disengagement" and maintained that we must have some "typologies of withdrawal and retreat." She proposed a temperamental variable, basically biological, in the style of adaptation to the environment, and then introduced the types of the "impinger" and the "selector," which might be compared to Riesman's well-known ideal types of otherdirected man and inner-directed man, respectively (Cumming, 1964, pp. 4-5). Basically, however, Cumming did not change her position in 1964 , as can be seen by her restatement of the theory which is quoted at the 
beginning of the present work (p. 2). As kose notes, "Cumming essentially has adhered quite closely to the basic outlines of the functionalist theory of disengagement" (1965, p. 362).

William Henry (1963), on the other hand, receded considerably from the original propositions of the theory. He admits the importance of personality factors in the manner of aging and in determining both engagement and disengagement, and points out that the question of intentional outside activation has not been dealt with. He goes so far as to say that neither the activity theory nor the disengagement theory is sufficient to account for the facts we know (p. 418). Most importantly, he suggests, "The degree to which disengagement is an intrinsic process seems still an open question" (p. 417).

The present research has taken up this question. Biological variables have played a great part in the framing of disengagement theory. In its original form the theory suggests "an uitimate biological basis for a reduction of interest or involvement in the environment" (Cumming, 1964, p. 5). Disengagement was introduced as a social-psychological theory (Henry and Cumming, 1959, p. 386; Cumming et a1., 1960, p. 25; Cumming and Henry, 1961, pp. 10, 106). However, according to the hypothes is of Cumming and Henry, there are some inherent biological factors which may cause psychological transformations:

We suggest that there may be some intrinsic change with age-the analogue of maturation in children--which results in a removal of psychological involvement from the environment and which leads the individual to initiate the disengagement process. This process may be hastened by a withdrawal of the environment but . . We believe certain important inner changes may be autonomous $(1961$, p. 104). 
Thus, the theory proposes intrinsic disengagement which is biologically activated to bring about personality changes in old age. "The basic nature of this principle of change appears to be a movement from an active, combative, outer world orientation to an adaptive, conforming and abstract inner world orientation" (Henry and Cumming, 1959, pp. 387-388). Supposedly, there are also ego changes: "It is also possible that there are some inevitable ego changes 'programmed' into the development of the organism, which occur regardless of any but the most extreme experiences" (Cumming and Henry, 1961, p. 213).

The peculiarity of disengagement theory is that it postulates an internal "mechanism for integrating one's life as it has been lived and the final acceptance of the reality of death" (Henry and Cumming, 1959, p. 390). This is no doubt the "preparation in advance" that Rose (1965) had in mind. It allegedly is brought into operation by some kind of an automatic switch "at the point where the psychic investment turns from outside to inside" (Henry and Cumming, 1959, p. 385). But the most novel proposition of the theory is the postulated relationship between disengagement and we11-being: "Contrary to general expectation, we think the older person experiences some rewards, rather than loneliness or despair, in this inward turning" (Henry and Cumming, 1959, 385). This question of psychological well-being in the face of disengagement has been the most disputed aspect of the theory, as brougint out in the foregoing analysis of critical literature. The idea that disengagement is a kind of built-in regulator for behavior in the later years is even more revolutionary, but, to the extent that this writer could determine, it has not been specifically dealt with in other pertinent 
research. However, the notion of intrinsic disengagement is at the center of the Cumming and Henry theory. Therefore the present writer, as indicated, has chosen to devote special attention to the possibility of its existence. It must be stressed that the data of Cumming and Henry do not warrant an affirmative conclusion.

The present writer is especially skeptical of a "programmed" disengagement in view of another suggestion by Cumming and Henry (1961). They make the statement that, analogously, "marriage can be thought of as programmed" into the biological organism "until the central task of child-raising is over" (p. 155). This seems to be going from the merely unfounded to the preposterous, when it is common knowledge that some people marry several times, are divorced, or do not marry at all. One wonders whether these theorists are offering a serious piece of research or whether they are trying to entertain the reader with facetious remarks. At any rate, as far as intrinsic disengagement is concerned, the evidence from the present research points to its nonexistence.

However, before leaving the subject, an all-important connection with the genesis of disengagement theory has to be brought out. What evidently has been overlooked by the critics is that the theorists virtually tell us where the idea for disengagement theory came from:

Some studies of very old people have adumbrated our own research. Cosin expresses the opinion that "deterioration of 'communications' through declining mental and physical abilities is not the main source of senile failure, but that more basic personality functions described in terms like 'drive' or 'self-motivation' have become defective" (Cumming and Henry, 1961, pp. 104-105).21

${ }^{21}$ Quoted from L. Z. Cosin, Margaret Mort, Fel ix Post, Celia Westropp, and Moyra Williams, "Experimental Treatment of Persistent Senile Confusion," The International Journal of Social Psychiatry, IV, No. 1 (Summer 1958), p. 47. 
By means of this quote, Cumming and Henry and their associates (Dean and Newe17, in Chapter V) are apparently endeavoring to show a connection between their own claim of an automatic inner change in older people and the work of Cosin et al. But one must consider the circumistances of the latter research. Cosin et al. (1958) dealt with chronically confused old people and patients with established dementia. They were testing the effectiveness of different methods of treating deteriorated old people in an institutional setting (pp. 24-25). Furthermore, the study group of Cosin et al. Was composed only of women because "severe senile deterioration becomes a numerically important problem mainly in women" (1958, p. 25). Moreover, Cosin et al. were working with a very small number of patients, altogether not many more than eighteen. They say:

Our subjects were female in-patients of the Geriatric Unit and of its half-way house; one group consisted of nine Confused patients ("Homogeneous Group"), and the other one contained three Confused patients alongside with six women without mental confusion ("Mixed Group"). But as from time to time one or another patient had to drop out and was replaced, the total number of subjects involved was higher than eighteen" ( $p .27)$.

The studies of Cumming and Henry (1961) and Cosin et a]. (1958) are really not comparable because, as will be recalled, Cumming and Henry excluded chronically ill people from their panel and kept only nineteen "impaired" members in their quasi-panel which is the group of the oldest subjects (1961, p. 239). Cumming and Henry do not say in what way these people were impaired, but they would be the only ones who could possibly be compared to the Cous in study. What might remotely resemble the "inevitable" process that Cumming and Henry postulate are 
some descriptions by cosin et al. of their results which are "in keeping with a widely held assumption that treatment of permanently confused old people is unlikely to reverse the process of intellectual deterioration, but that it might be successfur, up to a point, in allowing these patients to function at a better level" (p. 41). Cosin et al. state that again and again they met the recurring pattern of treatment having a boosting effect, which is not sustained. As far as the funtions of "drive" and "self-motivation" are concerned, these investigators add that, as long as these are supplied from the outside by a therapist, the patients "showed themselves capable of functioning at a level limited only by physical and intellectual handicaps, but treatment even when continued for more than six months failed to rekindle the forces of self-motivation" (pp. 41-42). If this study "adumbrated" the theory of disengagement, then Cumming and Henry associated the disengaged state with the deterioration of self-motivation. But Cosin et al. do not say that such a condition is pleasant or satisfying. They do suggest, however, that there might be a possibility of prevention: "More ambitious efforts aimed at preventing or retarding senile deterioration will have to be applied to people who have not yet lost drive and the powers of self-motivation" (p. 42).

If it is indeed the cosin et al. study that gave rise to the idea of intrinsic disengagement, then this fact tells us a great deal about the theory and its proponents: 1) Disengagement theory is a theory of decay; 2) homogeneity among the elderly is assumed in that Cumming and Henry associate all older people with an irreversible defect observed in a limited group of subjects; 3 ) it is here that the answer may lie 
to some of the artificial characteristics of the data of Cumming and Heriry. They may have conceived the idea of extending the findings of the Cosin study to their own sample and then contrived to reach the desired results. It would then be as they say in their formal statement of disengagement theory: "The evidence offered here has been selected for its accord with the theory" (p. 210).

Cumming and Henry are evidently very much impressed with the work of Cosin with "the very old" and draw parallels to their own interviews (1961, pp. 201-202). But, if the disengagement theorists go out from a small number of chronically confused old people and hypothesize that similar "inevitable ego changes" must occur in all older people, and proceed to build a global theory of aging, then the present writer feels that a very heavy burden rests on a very fragile base.

The teleological explanations and the emphasis on integration of the social system which are prominent features of functionalism are evident in the work of Cumming and Henry (Growing 01d, 1961), but this book is an exception in social gerontology. Most of the research in gerontology has been guided by the principles of interactionist theory or has tended to be descriptive (Rose, 1965, p. 359). As stated above, an interactionist approach has been used in the present study. This writer agrees with Rose (1965) that:

The neat, integrated "systems" of the functionalists may appeal to the esthetic sense of readers, but it seems to us that the facts of social life--in this case the social relations of the aging--are too complicated and varied to be encompassed in any notion of equilibrium. Cultural history and human interactions, organizing concepts which have thus far dominated research in gerontology, are better guideposts (p. 366). 
Such a view is also expressed in Blumer's argument as ably summarized by Buckley, that

it is from the process of ongoing interaction itself that group life gets its main features, which cannot be adequately analyzed in terms of fixed attitudes, "culture," or social structure--nor can it be conceptualized in terms of mechanical structure, the functioning of an organism, or a system seeking equilibrium. 22

Because of its emphasis on process and emergence, the symbolic interactionist perspective shows a potential for growth and development, whereas the functionalist orientation is toward adjustment to the status quo. These two theoretical positions can be compared to the two fundamental normative models of society which John Horton has sharply dichotomized in his article, "Order and Conflict Theories of Social Problems."23 Horton uses Durkheim as a classical example of the order approach and refers to Merton and Parsons as representative of contemporary order model ideas. For conflict models, Horton points to the works of Marx and Mills, respectively, as classical and contemporary examples (p. 37). Order theorists are committed to the maintenance of existing social institutions and stability and equilibrium in the social system. Conflict theory adherents, on the other hand, take a positive attitude toward change. The conflict model is dynamic and emphasizes action and

22

Walter Buckley, "Society as a Complex Adaptive System," in Modern Systems Research for the Behavioral Scientist, ed. Walter Buckley (Chicago: A7dine Publishing Company, 1968), p. 498.

23 John Horton, "Order and Conflict Theories of Social Problems," in Radical Perspectives on Social Problems, ed. Frank Lindenfeld (New York: Macmillan, 1968), pp. 34-5T. 
qualitative growth. These models represent polar ideal types, but they have their utility in that they systematize the implicit values which underlie modern sociological thinking. Horton says: "The conflict theorist invariably questions the legitimacy of existing practices and values; the order theorist accepts them as the standard of health" (p. 39).

of particular importance for the present project is the difference in the image of man and society as expressed by the two perspectives. Characteristic of the order model is the transcendent nature of society, which is viewed as an entity sui generis, greater than and different from the sum of $i$ ts parts. In contrast, the conflict model stands for an "immanent" conception of society as an extension of man: men are society, and the transcendence of society would mean alienation of man from his own social nature. Under the order model, a disruption of social institutions would result in anomy, that is, disequilibrium in the existing society. To recapitulate: the order model implies an anomy theory of societal discontent and an adjustment definition of social deviation, while the conflict model uses an alienation theory of discontent and a growth definition of deviation (Horton, p. 36).

These two models have been used as reference in the present work. We might say that the order model and disengagement theory are related, and that activity theory is compatible with the conflict model.

It has been called in question that disengagement theory as proposed can be considered to be a genuine theory (Streib and Schneider, 1971; Tal1mer, 1967, Veney, 1966). Streib and Schneider suggest that "it might be more accurately labeled a frame of reference or a theoretical 
orientation, for it is not a tightly reasoned, rigorous proposition" (p. 173). Veney feels that an adequate theory of aging from the standpoint of the individual's relationship to his society must specify both the fact of increasing and decreasing engagement, as well as the stages of life during which these occur. He points out that disengagement theory describes only the final stage of the process of involvement with society. He further says that disengagement theory, as it stands, is not a theory in the sense that a theory must introduce a secure ground for prediction. Disengagement from one area is not predictable by disengagement from another.

Atchley (1972) believes that "none of the existing theories can completely explain aging in modern society." He recommends that the investigator "be ready to invent a new explanation if none of the ready-made ones works" (p. 38).

According to what has been customary, in the present research both disengagement theory and activity theory are being referred to as "theories" even though there is some question about their official status. In fact, activity theory has not been formally introduced as a clearcut scientific theory. It has been taken for granted in our middleclass work-oriented culture and shows a relationship to Max Weber's social-action framework and his ideas on the Protestant ethic and the spirit of capitalism.

Contrary to disengagement theory, the position taken in the present dissertation is that aging is not automatic withdrawal from social interaction. As Atchley says, "the external aspects of aging and the socially structured situation can have far greater influence than 
personal desires on the social withdrawal of older people" (1972, p. 224). It is the rest of society that disengages from the older individual by isolating him and no longer seeking his efforts. Atchley further states that disengagement theory is comforting to the rest of society because "it seems to justify the way older people are treated: after all, being cut off from everything is just what they want" ( $p .225)$. In this sense, Cumming and Henry have played right into the hands of those individuals and groups who have decided to exclude older people from the mainstream of society. Atchley also comments that disengagement is not what most older people want; it is what they get (p. 225).

The theory which underlies the present research is inductively conceived; it is based on observations in the empirical world. It is essentially activity theory guided by symbolic interactionism. As Rose (1962) points out, some writers refer to interaction theory as "action theory," thus following the terminology of Max Weber, who independently developed a theory strikingly similar to the American interactionist theory or "symbolic interaction theory" (Preface, p. viii). There seems to be a compatibility between activity theory, symbolic interactionism, and the conflict model of society.

Furthermore, the theory behind the present work is substantive. In sociology, a "substantive" theory is one that "relates directly to the empirical social world--that makes truth claims concerning social 
reality."24 Robert Bierstedt (1959) makes a distinction between substantive theory and metasociological or methodological theory in his article entitled "Nominal and Real Definitions in Sociological Theory. "25 This is the way he explains it:

Just as nominal definitions and real definitions are two different things, and illustrate different vectors of inquiry, so also are methodological theory and substantive theory in sociology. If utility is the test of the first, truth is the test of the second. It is one thing--and an important thing-to develop a language, a. schema, a system of symbols for use in sociology. It is quite another thing to develop a theory. A theory is a point of view and requires an assertion. A conceptual scheme is a language, and requires only a stipulation. A schema is sterile unless it can produce a theory. Substantive theory, in short, is propositional. Its propositions are assertions about society. Its concepts have referents in the empirical world. Its definitions are convertible simpliciter. Its conclusions have truth claims. And it is the ultimate goal of sociological inquiry (pp. 141-142).

A theory, as such, has been defined in many different ways. Denzin (1970) says succinctly: "A theory is a set of propositions that furnish an explanation by means of a deductive system" (The Research Act, Chicago: Aldine Publishing Company, 1970, p. 34). We can add:

Through the process of deduction a theory provides specific hypotheses for research, and through induction research data provide generalizations to be incorporated into and to modify a theory (Modern Dictionary of Sociology, op. cit.), p. 437.

It is hoped that the findings in the present research will be conducive to an improved theory of aging.

${ }^{24}$ Modern Dictionary of Sociology, eds. George A. Theodorson and Achilles G. Theodorson (New York: Thomas Y. Crowell, 1969), p. 438.

25 In Symposium on Sociological Theory, ed. Llewellyn Gross (White Plains, New York: Row, Peterson and Company, 1959), pp. 121-144. 
Contrary to disengagement theory, the view supported by the present research is that older people do not "inevitably disengage" because of some automatic inner force but, rather, that they continue to have the same basic needs that they have formerly had. If these needs are not satisfied, older persons may become alienated and withdraw. This study will illustrate how nonengagement can occur through interaction in the environment. Not all older people withdraw, but those that do are forced to do so by some kind of unfortunate circumstances or the rejection of society.

The thesis of the present writer is that older people have a desire to remain part of society, and that they wish to feel usefur and wanted. W. I. Thomas (1923) has expressed in his "four wishes" an enduring typology of a human being's fundamental needs: the desire for new experience, the desire for security, the desire for response, and the desire for recognition (The Unadjusted Girl, p. 4). Otto Pollak (1948) says: "There are certain organic needs which appear at birth and others which develop through the experience of socialization early in life and all these remain more or less active throughout life" (pp. 45-46). Pollak has slightly modified the "four wishes" of Thomas, and has arrived at five basic human needs: "the desire for (1) physical health and comfort, (2) affection and love, (3) recognition, (4) expression of interests, and (5) emotional security" (p. 46).

This continuity of lifelong needs into old age has been confirmed by the present research, and no support at all for a desire to disengage has been found. Consequent7y, another element will be incorporated into the synthesis which constitutes the theory of the present writer. 
Besides activity theory and disengagement, there is a third major theory emerging in social gerontology, namely, "continuity theory." As described by Atchley (1972),

Continuity theory holds that in the process of becoming an adult, the individual develops habits, commitments, preferences, and a host of other dispositions that become a part of his personality. As the individual grows $01 \mathrm{der}$, he is predisposed toward maintaining continuity in his habits, associations, preferences, and so on...

Continuity theory holds that the individual's reaction to aging can be explained by examining the complex interrelationships among biological and psychological changes; the person's habits, preferences, and associations; situational opportunities for continuity; and actual experience. Te person's 1 ife-long experience thus creates in him certain predispositions that he will maintain if at al1 possible. . .

Continuity theory implies that there are many possible adaptations to aging rather than just a few. This complexity gives continuity theory the advantage of coming perhaps the closest to explaining the full reality of aging ( $p .36)$.

The present research has been very sensitive to changes in the life cycles of respondents, and this writer believes that a tendency toward continuation of accustomed ways of life and personal characteristics is evident from the data obtained. These observations agree with what has been said earlier about persistence of personality and life style among older people. In the opinion of this writer, a person strives for harmony with his way of being rather than for equilibrium with the social system as claimed by disengagement theory (Cumming, 1964). This harmony pertains to a person's beliefs, principles, ideals and sentiments, as well as to the individual's exterior habits and overt behavior. 
It is obvious, then, that the theory in this investigation has several perspectives and several approaches. The prime function of theory is to provide explanations, in this case, an acceptable explanation of engagement and disengagement in old age. According to Denzin, theory must also "generate new images of reality, new hypotheses, and new propositions" (1970a, p. 56).

This dissertation has endeavored to add new information to the knowledge about aging we may already have. It is believed that, by using a new approach, this study can provide fresh vistas. Specifically, features of this work that might be termed contributions toward such a goal are: 1) It is centered on the city; it points out the close relationship between city planning and the needs of a growing urban older population. A better knowledge of the characteristics of the aged would help the planning of housing and services for them; 2) it approaches the study of disengagement from the standpoint of symbolic interactionism and the life history method; 3 ) it gets to the heart of disengagement theory by revealing possible origins and connections of it, that is, that the research of Cumming and Henry (1961, pp. 104-105) admittedly was "adumbrated" by the study of Cosin et al. (1958) which is based on a group of about eighteen chronically confused old patients, a11 women; 4) it takes up the question of intrinsic disengagement and investigates the claim that it is "inevitable"; 5) it stresses continuity of personality and life style and argues that it is not equilibrium that people are striving for, but harmony with their own selves; 6) it, so to speak, lets older people plead their own case by providing verbatim statements of respondents. In this way, it is felt, 
we get a more truthful image of older persons and are able to give them credit for what they still are.

Symbolic interactionism has served here as a perspective to the empirical world and to the social group that we are studying. Looked at in this way, symbolic interactionism is, in. Blumer's words, "an approach designed to yield verifiable knowledge of human group 1 ife and human conduct" (1969, p. 21).

Symbolic interactionism is based primarily on the thought of George Herbert Mead (1863-1931); however, it has a long development and many ancestors. Its conceptual foundations are found mainly in pragmatism, although "strong additional influence comes from neoidealism, both in its older and in its neo-Hegelian version" (Martindale, 1960, p. 374). Manis and Meltzer (1967) state that the roots of symbolic interactionism are to be found in "the rationalism of John Locke, the foreshadowing of the role-taking process by such 'Scottish Moralists' as David Hume and Adam Smith, the idealist epistemology of Kant, and other diverse sources" (Preface, p. v). Mead was also strongly influenced by Darwin, ${ }^{26}$ and, as indicated, symbolic interactionism has been linked to the work of Max Weber. Marvin B. Scott 27 explains this connection:

26

William H. Desmonde, "The Position of George Herbert Mead," in Social Psychology Through Symbolic Interaction, eds. Gregory P. Stone and Harvey A. Farberman (Waltham, Massachusetts: Xerox College Publishing, 1970), p. 55.

27

"Functional Analysis: A Statement of Problems," ibid., p. 25. 
The writings of Max Weber and George $H$. Mead have converged to give us a picture of social action that represents one of the solid foundations of the sociological discipline. According to Weber, "action" involves all behavior to which the actor attaches a subjective meaning; social action involves all action that takes account of the behavior of others by virtue of the meaning the actor attaches to it. Aiong the same lines as Weber, Mead pointed out that man has the capacity for symbolic representations. He remembers the past, anticipates the future, and, on the basis of these memories and aspirations, brings meaning to his actions in the present.

Scott also explains that functionalists too "accept--or at least pay lip service to--one corception of social action. When they turn to undertake empirical studies or construct theoretical systems, however, they adopt another and opposing conception" (ibid.).

In America, symbolic interactionism took shape in the works of John Dewey, W. I. Thomas, Robert E. Park, William James, Charles Horton Cooley, Florian Znaniecki, James Mark Baldwin, and, above a11, in the work of George Herbert Mead. The two foremost recent exponents of the symbolic interactionist approach are Manford H. Kuhn and Herbert G. Blumer, who coined the term "symbolic interactionism" (Blumer, 1969, p. 1). The essence of this view is expressed in the following summary by Blumer:

The term "symbolic interaction" refers, of course, to the peculiar and distinctive character of interaction as it takes place between human beings. The peculiarity consists in the fact that human beings interpret or "define" each otiner's actions. Their "response" is not made directly to the actions of one another but instead is based on the meaning which they attach to such actions. Thus, human interaction is mediated by the use of symbols, by interpretation, or by ascertaining the meaning of one another's actions. This 
mediation is equivalent to inserting a process of interpretation between stimulus and response in the case of human behavior. 28

The concept of symbolic interaction applies to both a theory and a technique, as pointed out by Manis and Meltzer (1967):

Symbolic interactionism constitutes both a theoretical perspective within social psychology and, in the view of many of its interpreters and critics, a methodological orientation as well. Its concern with the "inner," or phenomenological, aspects of human behavior is considered by them to have both substantive and research-technique implications" (p. 1).

In the present research theory and method are interwoven in order to reflect accurately the characteristics and behavior of older people in the real world. This writer agrees with Denzin (1970a, p. 56) that "theory guides research while research guides theory." The next chapter deals with the application of these principles in actual research on aging.

28

Herbert Blumer, "Society as Symbolic Interaction," in Symbolic Interaction, eds. Jerome G. Manis and Bernard N. Meltzer (Boston: ATTyn and Bacon, 1967), p. 139. 


\section{CHAPTER IV}

\section{THE RESEARCH PROCESS: ATTITUDES AND ACTIVITIES}

This chapter gives a detailed account of how the present research was carried out and of what the results were. First, let us recapitulate the objectives we set out to achieve. The goal was to test some hypotheses about disengagement of the aged. We were further concerned with establishing the role of the city in the adjustment of older urban residents. The following hypotheses emerged from empirical observations and through analysis of the literature on aging:

Hypothesis One. Disengagement is not an intrinsic or inevitable phenomenon. If it occurs, it can be traced to various causes other than aging per se. Some older people withdraw because of $i 11$ health, personal misfortunes or social pressures; but the vast majority prefer to remain part of the ongoing life in the community. It is hypothesized here that there is no inherent relationship between disengagement and the process of aging.

Hypothes is Two. Disengagement theory has inaccurately hypothesized that the aged enjoy a disengaged state. This thesis claims, on the contrary, that there is continuity in personality and life style throughout a person's adult life, and that older people are best adjusted if they are able to maintain their accustomed ways of life. If they choose nonengagement, that is an indication of continuation of former habits. 
Hypothesis Three. Life space and all its ramifications are intinately connected with adjustment to aging; therefore a livable urban environment is a determinant in the life satisfaction of the aged. In essence, the present research problem involved the study of the behavior of older people in various situations in an urban environment. The analysis of this behavior has shed some light on the real causes of disengagement, and may serve to make predictions for planning purposes. The preceding chapter covered the theoretical aspects of this study; the present chapter will discuss the research process.

According to the 1970 Census, the urban population in the United States was 73.5 percent of the total population. To the extent that people, as they age, continue to live in the city, engagement or disengagement becomes an urban problem. Planning concerns the whole life cycle. And, with an increasing number of older people in the population, it will not be possible to ignore the elderly for long. As i. Paul Friedberg (1970) has eloquently stated:

The point that may give greatest impetus for reconsidering the plight of the elderly, however, is the sobering thought that it's only a matter of time before we are all "goldenaged" (p. 134).

It is peculiarly fitting to describe our research undertaking in the words of Berger and Luckmann (1966): "Ours is thus an enterprise that, al though theoretical in character, is geared to the understanding of a reality that forms the subject matter of the empirical science of sociology, that is, the world of everyday life" (p. 19).

Mead's "social psychology" has indicated new avenues for empirical research, and $B 1$ umer has provided a methodological orientation in his "symbolic interactionism": 
Symbolic interactionism is a down-to-earth approach to the scientific study of human group life and human conduct. Its empirical world is the natural world of such group life and conduct. It lodges its problems in this natural world, conducts its studies in it, and derives its interpretations from such naturalistic studies (1969, p. 47).

Blumer (1969) says that we need to return to the empirical social world (p. 34), and he tells why:

The answer to it is simply that the empirical social world consists of ongoing group 1 ife and one has to get close to this life to know what is going on in it. If one is going to respect the social world, one's problems, guiding conceptions, data, schemes of relationship, and ideas of interpretation have to be faithful to that empirical world (p. 38).

Blumer states that it is not a simple matter of approaching a given area and just looking at it. He says it is not "soft" study but a "tough job requiring a high order of careful and honest probing, creative yet disciplined imagination, resourcefulness and flexibility in study, pondering over what one is finding, and a constant readiness to test and recast one's views and images of the area. It is exemplified among the grand figures of the natural sciences by Charles Darwin" (p. 40).

In the following passage, Blumer recommends two specific steps in symbolic interactionism research:

That it is demanding in a genuinely rigorous sense can be seen in the analysis of its two fundamental parts. I term these parts respectively as "exploration" and "inspection." These two modes of inquiry clearly distinguish the direct naturalistic examination of the empirical social world from the mode of inquiry espoused by current methodology (p. 40).

Blumer explains in detail what he means by these two terms in

his scheme of research:

Exploration is by definition a flexible procedure in which the scholar shifts from one to another line of inquiry, adopts new points of observation as his study progresses, moves in 
new directions previously unthought of, and changes his recognition of what are relevant data as he acquires more information and better understanding. . . The flexibility of exploratory procedure does not mean that there is no direction to the inquiry; it means that the focus is originally broad but becomes progressively sharpened as the inquiry proceeds (p. 40)...

By. "inspection" I mean an intensive focused examination of the empirical content of whatever analytical el ements are used for purposes of analysis, and this same kind of examination of the empirical nature of the relations between such elements. . . I Inspection is flexible, imaginative, creative, and free to take new directions... Inspection is not tied down to a fixed mode of approach and procedure; it does not start with analytical elements whose nature has been set in advance and never tested or revised in the course of their use; and it develops the nature of the analytical elements through the examination of the empirical world itself (pp. 43-45).

The present research has linked the methods of symbolic interactionism to Weber's "method of Verstehen," which means empathic understanding or sympathetic empathy (Martindale, 1960, p. 385). The concept of "understanding"--the German term Verstehen--may have been used by Weber in a narrower sense than either the German or English word implies, ${ }^{29}$ but, in American sociology, its meaning has been tied to Thomas' "definition of the situation" and Mead's "taking the role of the other," as evidenced by the definition of Verstehen in the Modern Dictionary of Sociology (Theodorson and Theodorson, 1969):

Verstehen, method of. As defined by Max Weber, the use of personal knowledge and insight gained in social interaction and through role taking as a tool in the understanding of the social behavior of others. An observer of social

29

Max Weber, The Theory of Social and Economic Organization, trans. A. M. Henderson and Ta7cott Parsons (GTencoe, I7linois: The Free Press, 1947); p. 87, n. 2. Also see Don Martindale, The Nature and Types of Sociological Theory (Boston: Houghton Mifflin, 1960), pp. 385-388. 
interaction is capable of inferring the participants' definition of the situation (their understanding of and expectations in a situation) through his knowledge of how he would define the situation (p. 460).

The concept of Verstehen has been very helpful in the present undertaking, and it fits in well with the other components of our theoretical approach. It is also mentioned by John Horton (1968) in his paradigm of the conflict model of the normative theories of society. He lists it under the historical model for modes of "scientific" analysis as a "quest" for understanding (Verstehen) through historical analys is of unique and changing events; possible use of ideal type of generalization based on historically specific patterns" (p. 40). Historical elements are very important in the present work because of our assumption of continuity of personality and life style.

In accordance with the practice of symbolic interactionism, our concepts are "sensitizing," that is, they are nonoperationalized until some investigation has been done in the field and we are able to learn the processes representing them and the specific meanings attached to them by the persons observed (Denzin, 1970a, p. 14). B7umer makes a distinction between definitive and sensitizing concepts: "Whereas definitive concepts provide prescriptions of what to see, sensitizing concepts merely suggest directions along which to look." 30

The conceptual framework for the present research was arrived at after careful observation of older people in a variety of situations. Following are some workable definitions of our principal variables.

30

Herbert Blumer, "What is Wrong With Social Theory?" American Sociological Review, 19, Number 1 (February 1954), p. 7. 


\section{DEFINITIONS OF CONCEPTS}

The first group of these terms might be called real definitions of the type which Bierstedt (1959) associates with substantive theory. He distinguishes between nominal and real definitions: "We judge nominal definitions, in short, by their utility; real definitions by their truth" (p. 130). The second group of definitions in this section is operational: it is related to the process by which it will be measured.

\section{Real Definitions of Concepts}

Aging. Aging is regarded as a process and also as a development. Aging refers here to relationships of factors involving chronological age, with the assumption that other variables enter into the explanation of such relationships. In our culture, a person of sixty-five or over is defined as "elderly." But aging is uneven and has to be viewed in the cultural, social and economic setting of the particular individual. We recognize three kinds of aging: biological, psychological, and social. A11 three overlap to a certain extent. In this dissertation, emphasis is placed on social gerontology; but biological and psychological aspects of aging are considered also. We can use the latter as keys to the psycho-logical state and to the behavior of aging persons.

Disengagement. Disengagement means withdrawal from some activity or connection. It essentially implies a change in habits and involvements or associations. It could be release from former occupation or obligation. In some cases, however, nonengagement may simply be a continuation of an individual's former way of life. Disengagement may manifest itself in a multitide of forms--physical, intellectual, social, psychological, and 
spiritual. Any one of these modes, or a combination of them, could contain clues to the relative nonengagement of certain individuals.

The crucial question is, do any of these manifestations indicate the special meaning with which Cumming and Henry have endowed the concept of "disengagement"? The theory of disengagement has been amply analyzed in the foregoing chapters and needs no repetition here. We will only recapitulate that, in the system of Cumming and Henry, mutual withdrawal between the older individual and society represents the state of normal aging, and that, furthermore, there is a suggestion that disengagement is necessary to the maintenance of high morale and "successful" aging.

Cumming and Henry do not really give us a working definition of "disengagement." In describing their sample, they do not say why they consider these people disengaged. As we have seen, the most important criterion for their selection of their panel was age.

It has been the central task of the present research to establish whether there occurred a change in the lives of our respondents, and what the real reasons were for such change if it did take place. Engagement. Engagement usually refers to an individual's activities, occupation, social roles and contacts. But the importance of these involvements may be qualitative rather than quantitative. An activity may deeply absorb an individual, yet there may be no visible motion. An inventor may be "just sitting and thinking" while working out some important problem; a writer may be going for lonely walks while doing some creative work. A definition of engagement, as given by Atchley (1972), encompasses such eventualities: 
Engagement. A commitment on the part of the individual to a particular social role. Commitment can be to one role or to several, it may be deep or superficial, and it may be real or symbolic (p. 339).

Disengagement, then, would be the opposite. The individual would have no commitment to a social role neither real nor symbolic.

Life Space. Life space includes physical, psychological, and social realms. To measure it, we are not restricted to spatial dimensions or actual movement. Life space can be spiritual and mental. For instance, if a person is confined to a small apartment, the knowledge that a bus stops nearby will add to the life space of that person. The mere idea that it is possible to go somewhere if the need arises, adds freedom to a restricted existence.

In this connection, community facilities are of great importance. The use of a recreation room, access to a park or even to a distant view, expand the life space of the elderly. Thus, we see that the concept of life space is intimately tied up with housing, and housing is tied up with the way we design our cities.

\section{Operational Definitions of Concepts}

Characteristics of Engagement.

1. Having a functional role in society or an occupational identity (i.e., performing activities which have an effect upon others in the social system).

2. Being careful of personal appearance.

3. Evidencing ego-involvement (i.e., being personally concerned; experiencing stress).

4. Having an interest in current events.

5. Doing things for others. 
6. Liking to associate with people of all ages.

7. Having the feeling of being useful.

8. Exercising the right to vote.

Characteristics of Disengagement.

1. Lacking purposeful occupations or activities.

2. Being careless of personal appearance.

3. Playing "roleless roles."

4. Showing indifference toward current events.

5. Not being interested in the problems of others.

6. Preferring to associate with older people.

7. Having the feeling of being useless.

8. Having no particular incentive to vote.

Adjustment. Adjustment to aging has already been extensively defined in Chapter II of this work, but it was considered helpful to add here an operational definition of life satisfaction devised by Neugarten, Havighurst and Tobin (1961). In a slightly modified version, the welladjusted person is assumed to have: 1) zest for life as opposed to apathy; 2) resolution and fortitude as opposed to resignation; 3) congruence between desired and achieved goals; 4) high physical, psychological, and social self-concept; and 5) a happy, optimistic mood tone (pp. 137-138).

In order to identify these attributes, it is necessary to study the subjective, as well as the objective, side of human experience. Next is a description of the tools used to accomplish these ends. 
METHODOLOGY

It is important to hold in mind the interrelationship of theory and method. In the present undertaking, we subscribe to Denzin's (1970a) view of the sociological enterprise. He says it rests on the elements of theory, methodology, research activity, and the sociological imagination (p. 5). With reference to the symbolic interactionist perspective, Denzin states that "the very act of engaging in social research must be seen as a process of symbolic interaction, that being a scientist reflects a continual attempt to lift one's own idiosyncratic experiences to the level of the consensual and the shared meaning" (p. 12). He adds that both concepts and methodology act as empirical sensitizers of scientific observation (p. 13).

Denzin holds that methods are of great theoretical relevance, that every method has a different relevance for theory, and that "significant advances in substantive sociological theory will occur only after sociologists adopt a consistent and viable framework for the dual analysis of theory and method" (p. 5). Denzin follows the direction indicated by Mead, Blumer and Kuhn (p. 5). He feels that the sociological imagination demands variability, that processes in sociology should not be too rigorous, but that an open mind is required (p. 6$)$. Therefore, he further recommends, "sociologists must learn to employ multiple methods in the analysis of the same empirical events" (p. 13). This is in effect "triangulation," as Denzin defines it: "Triangulation is the use of multiple methods in the study of the same object" (p. 301). He elaborates upon the logic of triangulation: 
Multiple methods must be used in every investigation, since no method is ever free of rival causal factors, (and thus seldom leads to completely sound causal propositions), can ever completely satisfy the demands of interaction theory, or can ever completely reveal all of the relevant features of empirical reality necessary for a theory's test or development (pp. 26-27).

Since this project is investigating theory, it is especially important to triangulate our methods. We are, in a way, engaged in an exploratory study; therefore we have to take what we can get when we can get it. Webb (1966) states: "Once a proposition has been confirmed by two or more independent measurement processes, the uncertainty of its interpretation is greatly reduced. The most persuasive evidence comes through a triangulation of measurement processes" (p. 3 ).

How does one move from an imaginative theoretical model to the actual operations used in investigations of the empirical world? Blumer (1969) says: "The premises of symbolic interactionism are simple. I think they can be readily tested and validated merely by observing what goes on in social life under one's nose" (p. 50).

In an article on the methodologies of symbolic interactionism $(1970 b)^{31}$ Denzin notes that, in the present period, symbolic interactionists are trying "to bring the ephemeral notions of Mead closer to empirical reality" (p. 448). In this article (1970b), as well as in The Research Act (1970a), Denzin discusses the research methods that are

31

Norman K. Denzin, "The Methodologies of Symbolic Interaction: A Critical Review of Research Techniques," in Social Psychology Through Symbolic Interaction, eds. Gregory P. Stone and Harvey A. Farberman (Wa)tham, Massachusetts: Xerox College Publishing, 1970), pp. 447-465. 
assumed to be available to the symbolic interactionist. They are virtually the same techniques that are currently being used in customary working practices, namely, the experiment, the survey, participant observation, unobtrusive measures, and the sociological interview. Besides, Denzin gives wide room to the life-history method, and he also brings in the "Who am I?" test.

However, as Blumer (1969) states, "reality exists in the empirical world and not in the methods used to study that world" (p. 27). Each one of the methods named above is capable of extracting information from certain aspects of reality; but the secret of success lies not so much in the methods themselves as in the way one employs them. Herein can be found the difference between conventional procedures and the symbolic interactionist approach. Denzin (1970b) writes: "A11 research is a form of symbolic interaction, and, until we recognize this fact and treat our methods in this light, we cannot achieve the necessary empirical links our theory demands" (p. 448). Denzin admits that his discussion has built on Blumer's conviction "that contemporary sociology needs a naturalistic methodology that accurately reflects the empirical nature of human conduct" (p. 465).

The gist of Blumer's message is: "No theorizing, however ingenious, and no observance of scientific protocol, however meticulous, are substitutes for developing a familiarity with what is actually going on in the sphere of life under study" (1969, p. 39). He ends his essay with the terse admonition: "Respect the nature of the empirical world and organize a methodological stance to reflect that respect" (p. 60). 
This advice has been heeded in the present research because it is judged to be sound advice in the opinion of this writer. Consequently, methods have been chosen and instruments have been designed with the premises of symbolic interactionism in mind. After familiarizing ourselves with the area to be studied, it was decided to use the methodologies of the survey, the depth interview, and the life history, which included a number of shorter case histories. Other procedures and techniques have also come into play as, for instance, participant observation and some unobtrusive measures.

It has already been discussed at length how very important the self-concept of the aged is to their adjustment and morale. It is also a central concept in symbolic interactionism. Mead saw the self as a process because it arises in social interaction. It is that aspect of the personality which consists of an individual's developing conception of himself as a result of his experiences with other people (Modern Dictionary of Sociology, op. cit.). Mead (1934) ${ }^{32}$ explains his version of how it develops:

The separation of the "I" and the "me" is not fictitious. They are not identical, for, as I have said, the "I" is something that is never entirely calculable. The "me" does call for a certain sort of an "I" in so far as we meet the obligations that are given in conduct itself, but the "I" is always something different from what the situation itself calls for. So there is always that distinction, if you like, between the "I" and the "me." The "I" both calls out the "me" and responds to it. Taken together they constitute a personality as it appears in social experience.

32 George H. Mead, Mind, Self, and Society, ed. Charles W. Morris (Chicago: The University of Chicago Press, 1962). 
The self is essentially a social process going on with these two distinguishable phases. If it did not have these two phases there could not be conscious responsibility, and there would be nothing novel in experience (p. 178).

We have shown earlier how Ruth Shonle Cavan (1957) has analyzed adjustment to aging with the help of symbolic interactionist ideas and concepts such as self-conception and role-taking found in the work of Mead, Cooley, and others. Nowhere is Cooley's "looking-glass self" more relevant than in the sphere of aging. As Cavan maintains,

The necessary elements for forming, maintaining, or modifying self-conceptions are socialiy approved self-images and social roles for their expression, and a group that supports these self-images and roles. To achieve or modify a self-image, the person must be a member of one of these groups and must value the group's evaluation of himself. He will then incorporate within himself the self-image approved by the group (p. 535).

The self-concept of the aged is fraught with peril at every step as it faces stereotypes and negative attitudes toward aging, and as physical and emotional misfortunes multiply. Some older individuals may accept the stereotypes or succumb to adversities; but others surmount these handicaps. The point that is being made here, is that in either instance, we have a case against the theory of disengagement. Quite simply: If we can trace withdrawal to extrinsic causes, or if nonengagement does not occur, there can obviously be no intrinsic, inevitable disengagement.

A positive self-image will help to overcome obstacles and to continue engagement; and, conversely, being able to prevail over disasters will reinforce the self-image. 
As part of the exploratory phase of our research process, we sought information on the self-images of older people expressed in their own words. This is in conformity with our technique of letting the respondents tell their own story. The instrument used to elicit the self-attitudes of these people was the "Who am I?" test, sometimes called the "Twenty Statements Test," which simply asks the respondent to give twenty different answers to the single question, "Who am I?" A paper with instructions followed by twenty numbered blanks was provided. This unstructured strategy is, in fact, an open-ended question which also leaves a blank space for the answers of the subjects and gives no check points or multiple choices. The objective is to permit the respondent to give spontaneous answers unhampered by prodding or suggestions, and, in this case, to express his conception of himself. Efforts have been made to operationalize the concept of the self and to measure self-attitudes. ${ }^{33}$ In the present instance, the answers to the Who am I? question are brought in mainly as pictures from the real world: to show what older people are truly like in contrast to the puppet-like figures described by Cumming and Henry (1961). The language of these respondents has been given verbatim because it is felt that no paraphrase could do justice to these beautiful minds and souls. Following are three

33

Kuhn and McPartland introduced the Twenty Statements Test for this purpose. See Manford H. Kuhn and Thomas S. McPartland, "An Empirical Investigation of Self-Attitudes," in Symbolic Interaction, eds. Jerome G. Manis and Bernard N. Meltzer (Boston: Allyn and Bacon, 1967) pp. 120-133. 
portraits from everyday life. Let the reader judge if these people are "disengaged." 34

1. Mrs. L. defines "Happiness" by quoting Joseph Addison (1672-1719):

The grand essentials to happiness in

this life are something to do, something to love, and something to hope for.

Mrs. L. is a teacher by profession. These are her responses:

I am a child of God.

Capable, reliable, humble.

Retired but working (tutoring).

Doing Volunteer Work.

Constantly writing letters and cards, and calls to relatives--family affairs.

To friends--thought of old times.

To lonely people, assurance calls.

Find jobs for young and old.

I like to (and I do) travel much.

I've enjoyed international trips.

I've liked and look forward to my annual trip where

I came as a bride.

I like most my (every 4 yrs.) trips to my native state Wyo.

I have exceptionally good health at 84 yrs. come Juty 27 th.

My church and God's goodness are dear and close to me.

34

Names in this dissertation have been disguised. If names of respondents are spelled out, it means that these people have given us permission to use their real name. 
I do not feel lonely. I'm too busy.

I do enjoy my plants \& gardening.

I have hopes we retain the Star-

Spangled Banner as national anthem.

I have hopes we keep our Panama Canal which we built.

I thank God for a good life full of much happiness, liberally sprinkled with sad, difficult and heart breaking interludes, but probably in God's plan.

2. Mrs. V. is working with therapy groups, "giving a boost psychologically, emotionally and physically to Senior Citizens and others." She is eager and self-confident, and mentally alive. She deeply resents being identified with a group that is being dubbed senile just because of age. Here are her answers:

Who Am I

I am "A", a living entity--living in an abode known as a physical body.

I am ageless, timeless, spaceless, having no beginning or end.

I have a physical body that because of core beliefs \& the culture I was born in susceptible to age \& disease.

I have a brain, which is quite agile \& at present is improving because I have more time for study \& thinking.

I have emotions which I have to learn to control $\&$ adjust to live in peace with my fellow occupants of this world.

I have a husband, who is an independent being in his own right.

I have a marriage, which is not without some problems but is working satisfactorily.

I have a son, to whom I presented a priceless gift--the right to live his own life! 
I have a daughter-in-law who is a very good wife \& mother \& with whom I can communicate.

I have 3 grandsons, a priest, a musician \& one in high school.

I am content and/or happy approximately $98 \%$ of the time.

I am very busy. I attend 2 classes. I am doing my genealogy. I help hunting pensions, subsidies, etc. for needy Senior Citizens. I listen but do not become emotionally involved in others' problems.

I write \& receive many letters on subjects

I am interested in.

I do not care to travel for all I need is here \& now. I need only use it.

If I travel, I enjoy it, but it is unimportant.

I am financially "passable" through hard work \& careful planning.

I have a physical body my doctor considers a disaster area. However, once I am in command, I can do anything I decide to do.

I arise at 6 a.m., study, meditate, prepare myself for the day--body, face, hair, nails, etc.--before my husband arises.

I am 5'2", weigh 112 lbs., stand erect, dress carefully, love contact with people, chatter a lot \& laugh a great deal.

I wi 11 be 70 on my next birthday.

Mrs. V. strongly believes in keeping all older people busy. During the interview, she said: "I don't care what they do, but I want them to be doing something!"

3. Mr. Harold C. Mehlig has a background in railroading. He was superintendent of a recreational railroad and has held the position of vice-president of a railroad. At the present time, Mr. Mehlig is self-employed in his own electrical contracting business which he has built up over a period of years. With regard to being active in the later years, he has this to say: "The very many oldsters who really 
want to remain active, take up other work after retirement, which is as it should be. Others, who may have money and don't need to work, soon wither on the vine, so to speak." Mr. Mehilig's replies to "Who am I?" are:

I am 75 yrs. old.

I am working at my trade according to health.

I am exceptionally active for my age.

I love my family. I have my wife, 2 sons, one daughter-in-1aw, \& 1 granddaughter.

We like to travel and enjoy beautiful scenery.

I worked for several railroads for nine yrs.

Started my own Electrical Business 1925 in Lincoln, Nebr., then to Oregon 1941 , and worked for other elect. contractors until 1944 when I went into Elect. contracting for myself. 1962 to 1970 - I was Supt. of a Recreational Railroad which ran between Banks \& Vernonia, Oregon.

I assisted in the building of Portland Zoo Railroad.

I have as my hobby a collection of railroad models.

I enjoy using my cameras to take outdoor scenes when we travel.

I do tire as I age \& try to work.

I make a few trips by Railroad Inspection coach on the Oregon-Pacific \& Eastern Railroad at Cottage Grove, Oregon. I sold this car to them after the Railroad I was in charge of closed operations \& they allow me to use it once in a while \& I, of course, get to be engineer \& as Railroading has been a major interest in my life, I enjoy this experience very much. 
If only all Senior Citizens could have some activity they could enjoy, it would be of great benefit--both mentally \& physically. I consider myself very lucky in this regard.

\section{Harold C. Mehtig}

Mr. Mehlig's philosophy of life is certainly an eloquent plea in favor of activity theory. In fact, all three of the above examples go to the very essence of it. And, since these illustrations are from widely separated walks of life, the scope of their significance is broadened, and we can say that we get an idea of the quality of our older people by viewing these images.

These respondents have also furnished additional information about themselves, which has been incorporated in the rest of this report. Right now, we shall further outline our research design. First, we have an enumeration of the most important variables in this study. Independent Variables (Cause) are:

Age

Sex

State of health

Marital status

Occupation (including retirement)

Life space

Personality

Life style

Dependent Variables (Effect) are:

\section{Engagement \\ Disengagement \\ Adjustment \\ Morale}

It is, of course, understood that many other variables have entered into this research. They have been discussed throughout this 
work. Additional variables also become apparent from the description of our study population.

\section{THE POPULATION STUDIED}

Data were gathered in the Portland-Vancouver area. Portland, Oregon, and Vancouver, Washington, are contiguous cities, connected by the Interstate Bridge over the Columbia River. According to the 1970 census, the population totals for this area are: Vancouver, 42,493; Portland, 382,619 . The percentages of people 65 and over are, for Vancouver, 12 percent; for Portiand, 14.8 percent.

Because of our theoretical orientation, this research has not been restricted to a rigid sampling procedure. Instead, we have engaged in what Blumer has described as "exploration." That is to say, all applicable evidence available has been taken into account. Symbolic interactionists recognize this requirement. Denzin states: "Theoretically directed sampling assumes that wherever possible observations will be made in terms of temporal and situational variations as well as by the relevant natural unit of interaction" (1970a, p. 84). This, of course, implies triangulation of data, which fits the description Glaser and

Strauss (1967) have given for theoretical sampling:

Theoretical sampling is the process of data collection for generating theory whereby the analyst jointly collects, codes, and analyzes his data and decides what data to collect next and where to find them, in order to develop his theory as it emerges. This process of data collection is controlled by the emerging theory, whether substantive or formal (p. 45).

In 1 ine with these precepts, then, careful observation, both participant and unobtrusive, was practiced in the whole area, and life 
and case histories were taken from Portland and Vancouver. The sample for the survey was drawn from Vancouver. The subjects are described as we now enter into the actual operations performed.

\section{THE SURVEY}

Since the proportions of older people in the total populations of Portland and Vancouver are similar, it was decided to take the smaller city as our special or working universe. A study in Vancouver was thought to be more manageable and would therefore more easily lend itself to follow-up strategies and investigation of particular cases. The proportion of older people in Vancouver is also closer than Portland to the national average, which is 9.9 percent of a total population of $203,211,926$, according to the 1970 census figures for the United States.

In 1957, Vancouver, Washington, was chosen as an All-American City. It would, therefore, be reasonable to assume that it has certain characteristics and social patterns that are similar to other communities in the United States and would permit us to generalize our findings. ${ }^{35}$

\section{The Sample}

It was deemed advisable to obtain a sample of retired people in view of the fact that Cumming and Henry have used primarily the "very old" to demonstrate their theory of autonomous inner changes (1961,

\section{5}

For a discussion of special and general universes see Gideon Sjoberg and Roger Nett, A Methodology for Social Research (New York: Harper \& Row, 1968), pp. 129-140. 
p. 104) and their claim of a combination of disengagement and morale (p. 209). It was thought that, if intrinsic disengagement did exist, it would manifest itself during retirement. Furthermore, retired individuals most likely have been subjected to the injuries and indignities that accompany aging. Therefore, there would be a good chance of determining the real causes of any changes in personality or behavior that might have occurred.

The sampling procedure consisted in what is referred to as systematic sampling ${ }^{36}$ with a random start. Every 15 th name was taken from a total of about 5400 retired people listed in the Vancouver City Directory. Approximately 350 names and addresses were thus obtained, and questionnaires were mailed out to these people. If the listing referred to a couple, an extra set of forms was enclosed. Through this process, 176 usable sets of forms were received, and it is on these responses that the analysis of the survey is based. It should be recognized that a sample based on city directory listings is likely to overrepresent the higher sociotconomic levels.

Eight respondents did not give their age, but the age range of those that did is comparable to that of the sample of Cumming and Heriry, namely, from about fifty to ninety. We included one respondent below the age of fifty who had retired for reasons of health and had filled

36

Blalock states that systematic sampling is often used interchangeably with simple random sampling. He says: "In practice since alphabetical ordering is essentially irrelevant to most variables studied, we are usually safe in considering a systematic sample as equivalent to a simple random sample." Hubert M. Blalock, Jr., Social Statistics, 2nd ed. (New York: McGraw-Hi11, 1972), pp. 514-515. 
out our questionnaires and sent them in with good suggestions added. Our oldest respondent is ninety-eight years old. But, regardless of whether these extremes at each end are included or not, the average age of our respondents is about seventy-one years. Table I on the following page shows the age distribution of our survey sample.

We note that a little over sixty percent of these older people are women. Almost half of these women are widowed. Table II gives the marital status of our respondents broken down by sex, and we can see the striking difference in the number of widows and widowers. Oniy 11.43 percent of our male respondents are widowed, while 45.28 percent of our female respondents are widowed. We note that 82.86 percent of the men in our sample are married and living with spouse, and that only 44.34 percent of the women fall into this category. These findings approximate the national statistics on the marital status of our older population at the beginning of 1970 , as reported by Herman B. Brotman of the Administration on Aging. Brotman states that "most older men are married, most older women are widowed." 37 Brotman comments that the preponderance of widows among older women is a result of the difference in life expectancy between men and women and is further intensified by the social custom of women marrying men older than themselves (ibid.).

This disparity between the sexes in marital status is reflected in the living arrangements of older people. Our Table III shows that

\section{7}

The figures in percent distribution on the marital status of all older Americans as of March 1970 are: Male, married, with spouse present, 68.4 percent; widowed, 18.0 percent. Female, married, 33.7 percent, and widowed, 54.6 percent. (Herman B. Brotman, Facts \& Figures on 01der Americans: An Overview LWashington, D.C.: Administration on Aging, 1971. U. S. Department of Health, Education, and Welfare $],$ p. 4). 
TABLE I

AGE OF RESPONDENTS BY SEX

\begin{tabular}{|c|c|c|c|c|c|c|}
\hline Age (in years) & $\begin{array}{c}M_{c} \\
\text { Number }\end{array}$ & $\begin{array}{l}\text { Te } \\
\text { Percent } \\
\text { of Total }\end{array}$ & $\begin{array}{c}\text { Fen } \\
\text { Number }\end{array}$ & $\begin{array}{l}\text { ale } \\
\text { Percent } \\
\text { of Total }\end{array}$ & $\begin{array}{l}\text { Tot } \\
\text { Number }\end{array}$ & $\begin{array}{l}\text { a) } \\
\text { Percent }\end{array}$ \\
\hline 50 and below & & & 1 & .60 & 1 & .60 \\
\hline $51-60$ & 5 & 2.97 & 7 & 4.17 & 12 & 7.14 \\
\hline$(61-65$ & 9 & 5.36 & 18 & 10.71 & 27 & 16.07 \\
\hline$(66-70$ & 19 & 11.31 & 25 & 14.88 & 44 & 26.19 \\
\hline $71-80$ & 24 & 14.28 & 38 & 22.62 & 62 & 36.90 \\
\hline $81-90$ & 8 & 4.76 & 12 & 7.14 & 20 & 11.90 \\
\hline $91+$ & 1 & .60 & 1 & .60 & 2 & 1.20 \\
\hline Totals & 66 & $39.28 * \star$ & 102 & $60.72 * *$ & $168^{*}$ & 100.00 \\
\hline
\end{tabular}

*Eight respondents did not give their age.

**Based on Number of Cases in Male and Female Categories:

\begin{tabular}{lrrrr} 
& \multicolumn{1}{c}{$\%$} & \multicolumn{1}{c}{$\%$} \\
50 and below & & & 1 & .98 \\
$51-60$ & 5 & 7.58 & 7 & 6.86 \\
$61-65$ & 9 & 13.64 & 18 & 17.65 \\
$\vdots 66-70$ & 19 & 28.79 & 25 & 24.51 \\
$71-80$ & 24 & 36.36 & 38 & 37.26 \\
$81-90$ & 8 & 12.12 & 12 & 11.76 \\
$91+$ & 1 & 1.57 & 1 & .98 \\
& - & $-100.00 \%$ & 102 & $100.00 \%$
\end{tabular}


TABLE II

MARITAL STATUS OF RESPONDENTS BY SEX

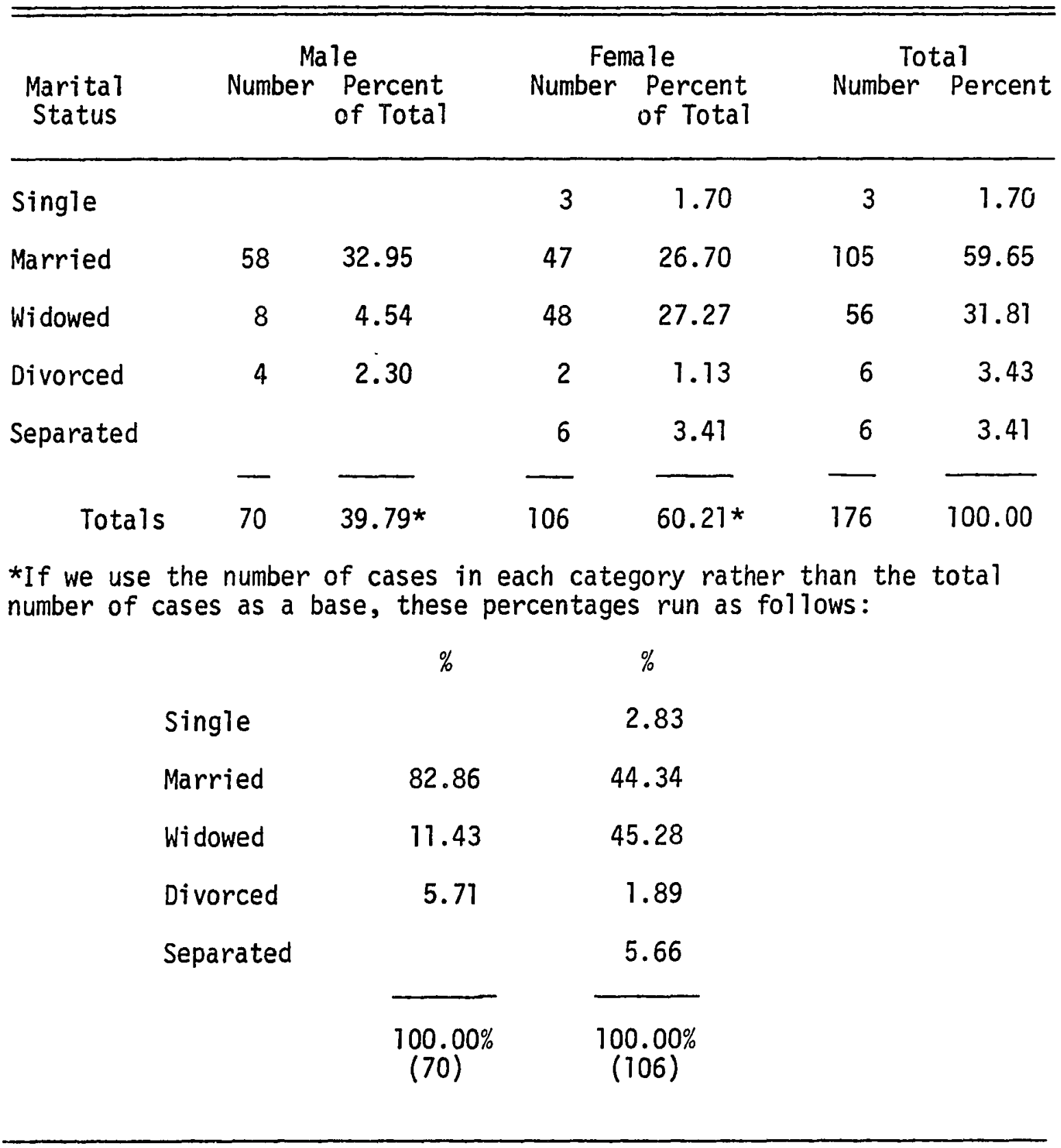


TABLE III

LIVING ARRANGEMENTS BY SEX

\begin{tabular}{|c|c|c|c|c|c|c|}
\hline \multirow[b]{2}{*}{ Living with Whom } & \multirow{2}{*}{ Number } & \multirow{2}{*}{$\begin{array}{l}\text { ale } \\
\text { Percent } \\
\text { of Total }\end{array}$} & \multicolumn{2}{|c|}{ Female } & \multicolumn{2}{|c|}{ Total } \\
\hline & & & & $\begin{array}{l}\text { Percent } \\
\text { of Total }\end{array}$ & Number & Percent \\
\hline Living alone & 10 & 5.68 & 47 & 26.70 & 57 & 32.38 \\
\hline $\begin{array}{l}\text { Married, living } \\
\text { with spouse }\end{array}$ & 57 & 32.39 & 48 & 27.27 & 105 & 59.66 \\
\hline With relatives & 2 & 1.14 & 7 & 3.97 & 9 & 5.11 \\
\hline With housekeeper & & & 2 & 1.14 & 2 & 1.14 \\
\hline In nursing home & & & 1 & .57 & 1 & .57 \\
\hline $\begin{array}{l}\text { In retirement } \\
\text { residence }\end{array}$ & & & 2 & 1.14 & 2 & 1.14 \\
\hline Totals & 69 & 39.21 & 107 & 60.79 & 176 & 100.00 \\
\hline
\end{tabular}

Based on Number of Cases in Male and Female Categories:

$\begin{array}{lcc}\text { Living alone } & 14.5 \% & 43.93 \% \\ \text { With spouse } & 82.6 & 44.86 \\ \text { With relatives } & 2.9 & 6.54 \\ \text { With housekeeper } & & 1.87 \\ \text { Nursing home } & & .93 \\ \text { Retirement residence } & & 1.87 \\ & 100.00 \% & 100.00 \% \\ \text { Number of Cases } & (69) & (107)\end{array}$


82.6 percent of males are living with their spouses, and only 14.5 percent live alone; while only 44.86 percent of females are living with their spouses, but 43.93 percent live alone. The proportions of older people living alone are about the same in our sample and in the national figures given by Brotman:

Of every 100 older persons, more than a quarter (28) live alone or with nonrelatives--7 men but three times as many, 21 , women. This is a reflection of the much larger numbers of widows as compared to widowers- $-55 \%$ of older women are widows while only $18 \%$ of older men are widowers (ibid., p. 6).

There is a great deal of stability in our study sample. Eighty percent of our respondents live in their own homes, and the overwhelming majority of them have lived a long time where they now live. Length of residence by years is shown in Table IV. The average length of residence in Vancouver of these people is twenty-nine years.

This researcher found a great deal of continuity and independence in our sample population. Single as well as married people continue to live in their own homes as long as possible, and go to an institution only as a last resort. The pioneer spirit of self-sufficiency still seems to be alive among these older people as a sort of all-American heritage.

Being able to continue one's accustomed way of life naturally depends upon one's health status. We have already brought out that most researchers have found the health of our older population to be fairly good, and the present findings confirm a statement by Brotman (1970), that "the stereotype of the physically limited older person 
TABLE IV

LENGTH OF RESIDENCE IN VANCOUVER

\begin{tabular}{|c|c|c|}
\hline $\begin{array}{l}\text { Years } \\
\text { Lived }\end{array}$ & & $\begin{array}{l}\text { Number of } \\
\text { People }\end{array}$ \\
\hline Below 2 & & 1 \\
\hline $2-10$ & & 34 \\
\hline $11-20$ & & 19 \\
\hline $21-30$ & & 47 \\
\hline $31-40$ & & 32 \\
\hline $41-50$ & & 17 \\
\hline $51-60$ & & 14 \\
\hline $61-70$ & & 11 \\
\hline \multirow[t]{3}{*}{$71+\quad$ (76 years) } & & 1 \\
\hline & Total & 176 \\
\hline & $\begin{array}{l}\text { Average Number } \\
\text { of Years }\end{array}$ & 29.09 \\
\hline
\end{tabular}


is a gross exaggeration." 38 Table $V$ shows a breakdown of health statistics for men and women, and also gives the figures based on the totals of these two groups. Again, it is notable how closely our findings resemble the national figures for 1970 , as reported by the Administration on Aging. In both cases, the results of surveys show that about 95 percent of 271 older people manage to 7 ive successfully or nearly successfully in the normal community. According to the national figures, only 4.8 percent of al1 older people are homebound, which number agrees with our percentage of those that reported their health as very poor, namely 4.55 percent. The national report furtiner states:

Among the noninstitutionalized elderly, $14.4 \%$ have no chronic conditions at al1 and $85.6 \%$ have one or more chronic conditions ranging from a visual impairment corrected by eyeglasses to a totaliy disabling heart condition (Brotman, ibid.).

Our findings reaffirm what was brought out above in our review of the literature on the health of older people. Health status may have direct effect on disengagement from social contacts, and it does affect greatly disengagement from work (Veney, 1966). But, if people were forced to disengage, there was no evidence of the contentment that Cumming and Henry (1961) associate with disengagement. Rather, people in poor health regretted that they were not able to do the things they would have liked to do. Some of them substituted less arduous activities for those that they could not perform any more, and in some cases there was vicarious participation in spite of failing health. Because this

38

Herman B. Brotman, The 01der Population: Some Facts We Should Know (Washington, D.C.: Administration on Aging, April 1970. U. S. Department of Health, Education, and Welfare), p. 12. 
TABLE $V$

SELF-REPORTED HEALTH OF RESPONDENTS

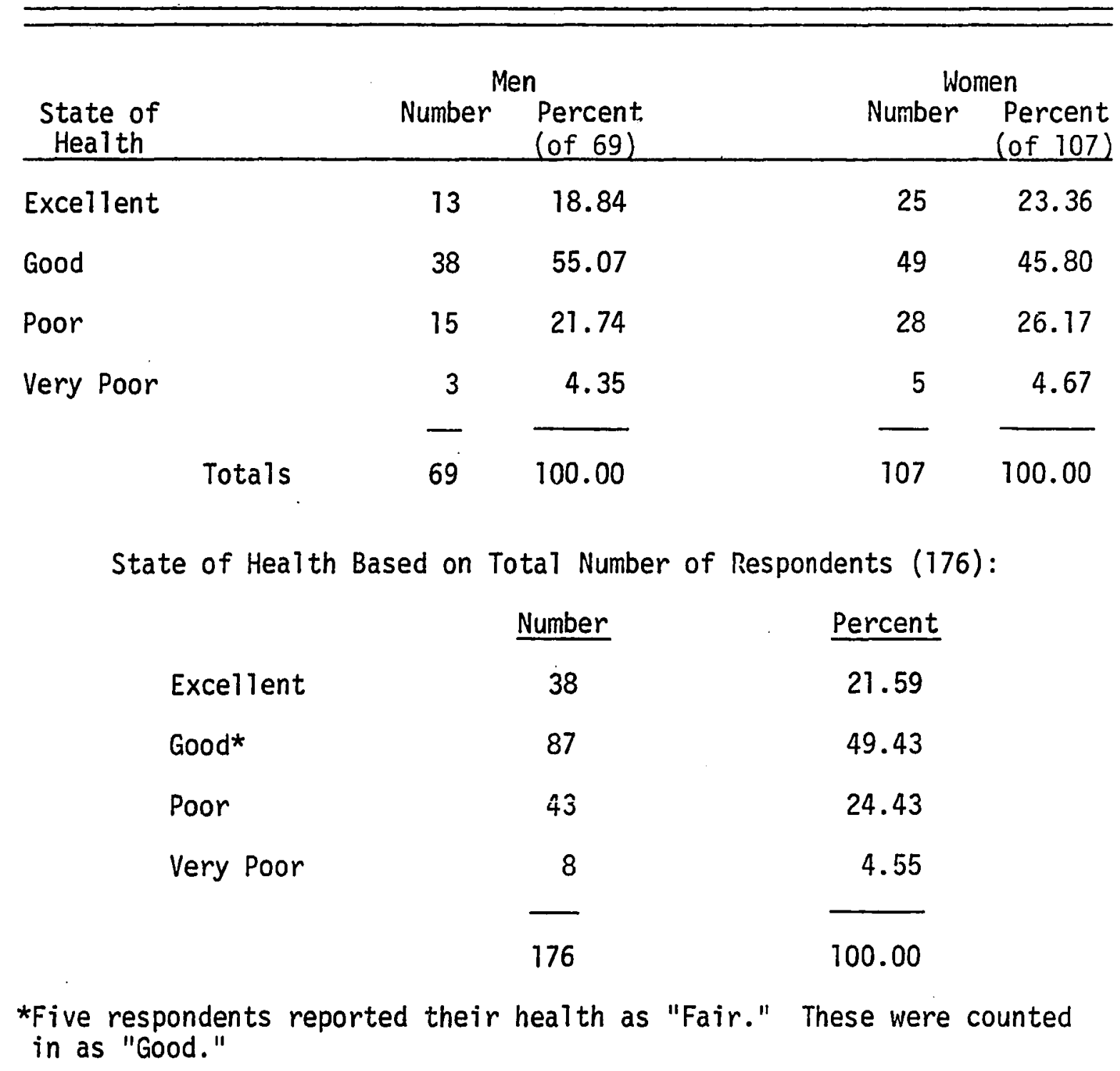


researcher wanted to make a realistic appraisal of disengagement, our respondents were not especially screened for health.

The Instruments

Several questionnaires were designed to elicit the desired information. Forms I and II have been tied in with our operational definitions of engagement and disengagement. They touch upon the factors meant to bring out "engaged" and "disengaged" characteristics in our subjects. (See Appendix for samples of our forms.)

Form $I$ is a subjective measure. It asks about attitudes toward important issues confronting the older person, and has been compiled from material under discussion in this dissertation. Form II is objective. It requests some personal information and inquires about the person's activities which, as a rule, could be observed and verified by someone else. Combined, these two schedules serve to examine the incentives and the behavior encountered among older people. Attitudes may lead to certain activities; conversely, the ability, or inability, to pursue some activities may produce certain attitudes. The answers to Forms I and II are especially important in the testing of Hypothesis One.

Form III deals with urban living qualities which are indispensable to the adjustment of the aged, and it also asks for personal data on living arrangements in the city. All three of these instruments are suitable to self-administration and for mailing, and were so used.

The construction of the instruments was guided by the principle that we should ask simple and straightforward questions about the things we really want to know. This researcher is convinced that, if we ask 
meaningful questions, we will get meaningful answers. The 01 der people themselves know best what their problems are, and what services they need. Their replies were above all used to construe their state of engagement or disengagement.

Forms I, II, and III were pretested in several sessions at a nutrition center for older people, and twenty-two completed sets of these questionnaires were thus obtained. In addition, a small sample (15) was contacted by mail in order to check the adequacy of our instruments. These trial tests proved very useful in that they sensitized our research to the real world which we were exploring and suggested some refinements in our forms. After making some revisions in our instruments, the large-scale administration was undertaken.

Since we requested information on such intangibles as disengagement and adjustment, it was planned to use measures of qualitative data. Where quantification has been used we have employed only simple techniques. Symbolic interactionists feel that some variables affecting human behavior are too elusive to be investigated by the usua? statistical methods. In other words, we cannot rely upon statistical evidence alone. Blumer (1969) is especially outspoken on this point:

The overwhelming bulk of what passes today as methodology is made up of such preoccupations as the following: the devising and use of sophisticated research techniques, usually of an advanced statistical character; the construction of logical and mathematical models, all too frequently guided by a criterion of elegance; the elaboration of formal schemes on how to construct concepts and theories; valiant application of imported schemes, such as input-output analysis, systems analysis, and stochastic analysis; studious conformity to the canons of research design; and the promotion of a particular procedure, such as survey research, as the method of scientific study. I marvel at the supreme confidence with which these preoccupations are advanced as the stuff of 
methodology. Many of these preoccupations, such as those stressing the need for statistical and quantitative techniques, are grossly inadequate on the simple ground that they deal with only a limited aspect of the full act of scientific inquiry, ignoring such matters as premises, problems, concepts, and so on. More serious is their almost universal failure to face the task of out?ining the principles of how schemes, problems, data, connections, concepts, and interpretations are to be constructed in the light of the nature of the empirical world under study. 39

We may infer from the above that $B l$ umer, as a representative symbolic interactionist, liberates the researcher to apply those techniques which are best suited to the peculiarities of a given field, and which will bring out the most important aspects of the problem investigated. Since the present research has yielded both subjective and objective information, it was thought best to use a triangulation of simple methods and thus avoid giving a one-sided picture of the findings.

The Results of the Survey

Earl R. Babbie (1973) writes: "The heart of survey analysis lies in the twin goals of description and explanation. The survey analyst makes measurements of variables and then examines the association between them" (p. 227). This is the procedure in the present report, and we begin with the description of the Attitudes.

Measurement of Attitudes--Form I. On the strength of their opinions and attitudes, subjects could be classified as potentially engaged or disengaged. Our schedule of attitudes is composed of statements which

39

Herbert Blumer, "The Methodological Position of Symbolic Interactionism," in Herbert Blumer, Symbolic Interactionism: Perspective and Method (Englewood Cliffs, New Jersey: Prentice-Ha11, 1969), pp. 26-27. 
are either favorable or unfavorable to engagement, and which could reflect both tendencies, depending upon whether the respondents agree or disagree with them. There is also provision for an answer of "undecided." Obviousiy, this category would have to be left out of the dichotomy. However, it is being given for the record.

Table VI reproduces the attitudinal questions and gives the numbers and percentages of people endorsing each statement. "Agree" or "Disagree" responses have been arranged as reflecting engagement or disengagement in relation to the content of the questions. It must be stressed that these statements embody the pivotal issues in the present dissertation and that they represent the crucial arguments pertaining to aging. The topics include the main components of our operational definitions of engagement and disengagement, such as work versus inactivity, or activity and usefulness versus inactivity; interaction and involvement versus withdrawal; and the playing of meaningful roles.

One look at the results of the Attitude survey wi 11 make it clear that the reaction of our respondents is not in support of disengagement theory. The overwhelming majority favor continued activity and involvement, rather than witndrawal and disengagement, for older people. The consistency of the pattern is impressive since the subjects were chosen by chance and are widely scattered throughout the city, and no doubt far apart in social characteristics. These statements evidently are meaningful to most older people and may have touched upon some felt needs and latent desires. We have to check the replies to the Activity schedule before we come to more definite conclusions, but one thing seems certain to the present writer, and that is that, if all older people had the 
characteristics imputed to them by Cumming and Henry, namely, a builtin mechanism for withdrawal and satisfaction with disengagement, so many of them would not have given replies in favor of continued activity.

Form II, the Activities schedule, also follows the criteria of our operational definitions of engagement and disengagement. It is intended to measure the person's participation and involvement in ongoing life. Numbers and percentages of answers to specific questions are furnished in Table VII and indicate how active the individual still manages to be.

It has been said repeatedly that people do not always do what they say they are going to do. A classical example is the story told by LaPiere 40 in his much quoted article. Words and deeds may not always coincide; but the situation of older people needs special consideration because of the restrictions placed on their activities. By using the principles of symbolic interactionism we become sensitized to the problems of the elderly and keep them in mind when we measure their performance.

If older people cannot do what they would like to do, it does not necessarily mean that they are subject to intrinsic disengagement. In most cases we will find that they have been restrained by other obstacles. Then, if we can demonstrate that extrinsic interference or personal hardship has caused nonengagement, disengagement theory does not hold.

40

Richard T. LaPiere, "Attitudes versus Actions," in Readings in Attitude Theory and Measurement, ed. Martin Fishbe in (New York: John Wiley \& Sons, 1967), pp. 26-37, rpt. from Social Forces, 1934, 13, 230-237. For more analys is of this question see Irwin Deutscher, What We Say/What We Do (Glenview, Illinois: Scott, Foresman, 1973). 
TABLE VI

DISTRIBUTION OF RESPONSES TO ATTITUDE QUESTIONNAIRE

Statement $\quad$ Numbers $\begin{array}{cc}\text { Percent* } & \begin{array}{c}\text { Percent* } \\ \text { Favorable } \\ \text { to Engagement }\end{array} \\ \text { to Enfavorable }\end{array}$

1. Older people in the United

States today are not used

by society as they ought

to be. They are retired

at an arbitrary age regard-

less of their talents.

$\begin{array}{lrr}\text { Agree } & 134 & 76.1 \\ \text { Disagree } & 20 & \\ \text { Undecided } & 22(12.5 \%)^{*} & \end{array}$

2. The physical and mental

fitness of older persons

often extends beyond the

fixed retirement age of

60 or 65 . Consequently compulsory retirement is in many cases a waste of human resources.
Agree
Disagree
Undecided
147
83.5
$6(3.4 \%)$

13.1

3. Compulsory retirement is necessary. All persons should be made to retire at a fixed age regardless of the contributions they are able to make.

Agree
Disagree
Undecided

31

126

$19(10.8 \%)$

71.6

17.6

4. Human life has been prolonged through medical and technological inventions; now society should give meaning to the added years.
Agree
Disagree
Undecided
88.0
11 ( $6.3 \%)$
$* 700 \%=176$

5.7 


Statement $\quad$ Numbers $\begin{array}{cc}\text { Percent* } \\ \text { Favorable } \\ \text { to Engagement }\end{array} \quad \begin{gathered}\text { Percent* } \\ \text { Unfavorable } \\ \text { to Engagement }\end{gathered}$

5. 0lder people should be content to stay at home, live on memories, and accept retirement as a reward for their service to society. Agree Disagree Undecided

89.2

5.7

6. The important thing is a man's ability rather than his age.

$$
\begin{aligned}
& \text { Agree } \\
& \text { Disagree } \\
& \text { Undecided }
\end{aligned}
$$$$
7(4.0 \%)
$$

89.8

7. Age is often a state of mind. Retirement from activity makes people think they are old.

$$
\begin{aligned}
& \text { Agree } \\
& \text { Disagree } \\
& \text { Undecided }
\end{aligned}
$$

$\begin{array}{rl}140 & 79.5 \\ 29 & \end{array}$

8. A new outlook should pervade education and training to reorient our thinking toward learning throughout life.

Agree
Disagree
Undecided

84.1

9. It is natural and desirable for older people to withdraw from an active role in society.

Agree

Disagree

Undecided

$* 100 \%=176$
24

141

$11(6.3 \%)$

13.6

80.1 


\begin{tabular}{|c|c|c|c|}
\hline Statement & Numbers & $\begin{array}{c}\text { Percent* } \\
\text { Favorable } \\
\text { To Engagement }\end{array}$ & $\begin{array}{c}\text { Percent* } \\
\text { Unfavorable } \\
\text { to Engagement }\end{array}$ \\
\hline
\end{tabular}

10. Opportunity for significant social contact and participation in the affairs of the community help maintain the mental health of the aged.

$$
\begin{aligned}
& \text { Agree } \\
& \text { Disagree } \\
& \text { Undecided }
\end{aligned}
$$

11. Gainful employment either ful1- or parttime, is one of the best sources of self-respect and good morale in the aged as in younger persons.

$\begin{array}{lcc}\text { Agree } & 147 & 83.5 \\ \text { Disagree } & 17 & \\ \text { Undecided } & 18(10.2 \%) & \end{array}$

12. 01der people cannot

learn new skills.

Agree
Disagree
Undecided

4
165
7 $(4.0 \%) \quad 93.7$

2.3

13. There should be a redefinition of the role of the elderly. They should not be regarded as simply a group to whom services must be rendered. Instead they should be given the option to retrain for new occupations.
Agree
Disagree
Undecided
81.3
$20(11.3 \%)$

$$
* 100 \%=176
$$




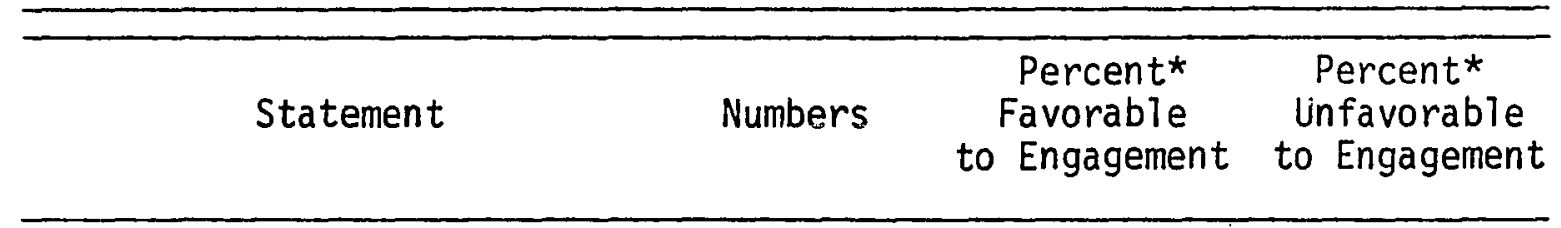

14. 01der people should associate with their own age group rather

than with younger people.

$\begin{array}{lrr}\text { Agree } & 10 & \\ \text { Disagree } & 161 & 91.5 \\ \text { Undecided } & 5(2.8 \%) & \end{array}$

15. Federal, State, and local governments should cooperate in helping the aged help themselves.

$\begin{array}{lrr}\text { Agree } & 155 & 88.1 \\ \text { Disagree } & 6 & \\ \text { Undecided } & 15(8.5 \%) & \end{array}$

3.4

16. 01der persons can absorb new knowledge and make use of it. Agree Disagree Undecided

162

92.1

$5(2.8 \%)$

5.1

17. Mental confusion in the elderly can often be attributed to social isolation as well as to other causes.

Agree

Disagree

Undecided
153

11

$12(6.8 \%)$

86.9

6.3

18. The City should provide counseling services for the psychological and emotional needs of the aged. Agree

Disagree

Undecided

68.2

$$
* 700 \%=176
$$




\begin{tabular}{|c|c|c|c|}
\hline Statement & Numbers & $\begin{array}{c}\text { Percent* } \\
\text { Favorable } \\
\text { to Engagement }\end{array}$ & $\begin{array}{c}\text { Percent* } \\
\text { Unfavorable } \\
\text { to Engagement }\end{array}$ \\
\hline
\end{tabular}

19. Most older people feel happiest in a community where they have contact with people of all ages.

Agree
Disagree
Undecided

161

8

$7(4.0 \%)$
91.5

4.5

20. It is better to help elderly people stay in their own homes than to force them into hospitals or nursing homes.

$$
\begin{aligned}
& \text { Agree } \\
& \text { Disagree }
\end{aligned}
$$$$
\text { Undecided }
$$

1.1

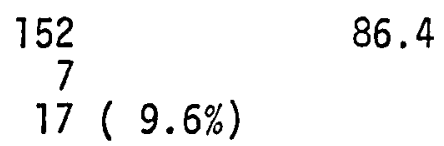

22. 01der people must organize to protect their rights to employment and to more participation in the mainstream of 1 ife.

Agree
Disagree
Undecided
$* 100 \%=176$

69.3

$35(19.9 \%)$

10.8 
Measurement of Activities--Form II. Some of the information in Form II has al ready been reported. The figures on the first four questions regarding sex, age, marital status, and health are given above in Tables I, II, and V, with the description of our study population.

The answers to Question 16, on living arrangements, appear in Table III.

Table VII, which now follows, shows the results of further replies to Form II. The remaining questions in the form had to be dealt with separately. The answers to them have been handled in the following manner:

The replies to Question 8, on reasons for retirement, appear in Table VIII; and a report on Question 10, regarding present activities of respondents, is given in Table IX.

A digest of the comments pertaining to Question 14, regarding personal appearance, follows further down in the text.

Questions 17 and 18, concerning interaction with family and friends, resulted in Tables $X$ and $X I$; and answers to Questions 19 (a) and (b) have been broken down in Tables XII and XIII.

Table VII reveals that 82.9 percent (146) of our respondents marked that they are retired. of the rest, 9.7 percent (17) are not retired, and 7.4 percent (13) gave no answer to the question of whether they are retired. However, 21 percent (37)--16 men, or 9.1 percent, and 21 women, or 11.9 percent--would work if there would be no reduction in their retirement benefits. Thus, altogether over thirty percent of our population is interested in gainful employment. This is a sizable 
TABLE VII

RESPONSES TO QUESTIONS IN FORM II PERSONAL INFORMATION

\begin{tabular}{|c|c|c|c|c|c|c|}
\hline & \multicolumn{2}{|c|}{ Yes } & \multicolumn{2}{|c|}{ No } & \multicolumn{2}{|c|}{ No Answer } \\
\hline & Number & Percent* & Number & Percent* & Number & Percent* \\
\hline 5. Are you gainfully employed at the present time? & 11 & 6.3 & 162 & 92.0 & 3 & 1.7 \\
\hline 6. If "No," would you prefer to be so employed? & 24 & $14.8 * *$ & 129 & $79.6 * \star$ & 9 & 5.6 \\
\hline 7. Are you retired? & 146 & 82.9 & 17 & 9.7 & 13 & 7.4 \\
\hline $\begin{array}{l}\text { 9. Would you work if it would not lead to a } \\
\text { reduction in your retirement benefits? }\end{array}$ & 37 & 21.0 & 119 & 67.6 & 20 & 11.4 \\
\hline 11. Do you feel you are doing something useful? & 140 & 79.5 & 23 & 13.1 & 13 & 7.4 \\
\hline $\begin{array}{l}\text { 12. Do you believe that you could be more useful } \\
\text { if there were no age restrictions on employ- } \\
\text { ment and on other privileges and advantages? }\end{array}$ & 48 & 27.3 & 103 & 58.5 & 25 & 14.2 \\
\hline 13. Do you enjoy doing things for other people? & 166 & 94.3 & 4 & 2.3 & 6 & 3.4 \\
\hline 14. Is your personal appearance important to you? & 174 & 98.9 & 0 & & 2 & 1.1 \\
\hline 15. Do you like to associate with people of all ages? & $? 168$ & 95.4 & & & 1 & .6 \\
\hline Or do you prefer to be mostly with older people? & 7 & 4.0 & & & & \\
\hline $\begin{array}{l}\text { 20. Did you vote in recent elections? } \\
\star 100 \%=176 \quad * * 100 \%=162\end{array}$ & 153 & 86.9 & 23 & 13.1 & 0 & \\
\hline
\end{tabular}


TABLE VIII

REASONS FOR RETIREMENT

\begin{tabular}{|c|c|c|}
\hline $\begin{array}{l}\text { Reason Given } \\
\text { by Respondent }\end{array}$ & Number & Percent* \\
\hline $\begin{array}{l}\text { Compulsory retirement } \\
\text { because of age }\end{array}$ & 39 & 26.7 \\
\hline Voluntary retirement & 56 & 38.4 \\
\hline Poor health & 43 & 29.4 \\
\hline Other reasons & 8 & 5.5 \\
\hline Totals & 146 & 100.0 \\
\hline$* 100 \%=146$ & & \\
\hline
\end{tabular}

proportion considering that we are dealing with people who are classed as retired and whose average age is seventy-one. We also have to bear in mind that health plays an increasingly major role in determining the activities of older people.

Table VIII shows the reasons that respondents gave as motivating their retirement, and we see that poor health is very prominent, being given by 29.4 percent, or 43 of the total of 146 retired nersons. Voluntary retirement has the largest amount of 38.4 percent (56), and compulsory retirement, 26.7 percent (39) is the third largest category.

Among both the retired group and that which is not retired, there are persons who are very much engaged. For instance, the women ask questions like: "How can a housewife retire?" or, they make a 
statement: "I don't think it is possible for women to 'retire.' There are too many demands made on them (me)."

Some of the voluntarily retired had other remunerative projects in mind. Several of them reported that they had rental property and spent their time keeping it up. Some did part-time tutoring, and others found ways to derive a little profit from their hobbies. The feeling of those who said they would work is generally like that of one person who answered "yes," and added, "if I could find a job."

While there are statements like, "I've had enough," "Let the younger people have the jobs," "I wanted to enjoy retirement, travel, do the things I always wanted to do," there is at the same time the need of belonging, as expressed by one man who said that he would withdraw from the "slave market, never from a role in society."

Those who were forced out of their employment are usually very resentful of compulsory retirement. For example:

I am very much opposed to that (compulsory retirement). If I could have my say, I'd say, "no, it depends on the person entirely." ... I think back to my father--how he was. He was so active... and, well, my mother too. People never talked about pushing them into the background. If they were able to do something, they went ahead and did it. Nobody ever said, "Now, you can't do this. You're too old, you're sixty-eight." Nobody ever put that kind of a stamp on anybody.

The same respondent pointed out that some supervisors too are distressed at the practice of compulsory retirement:

I always think of my friend--I guess she was a kind of a manager, at least an assistant manager--at Woolworth, you know, for a number of years. We were talking about retirement, and she said: "It makes me tired. Now I'm gonna have to let this woman go, my very best cashier--because she is sixty-five." And she said: "It makes me sick. She is just as good or better as she ever was." 
This researcher found that, regardless of the employment status of these older people, the meaning of work and participation in which they were nurtured has stayed with them. There may be, as one person said, "plenty to do without working for money," but nevertheless the desire to be considered part of the larger community is very intense. To his affirmative reply to the statement that older people must organize to protect their rights to employment and to participation in the mainstream of 7 ife, one man penned the exhortation: "Right on!"

Most respondents stress that they keep busy, and imply that that is a virtue. Age, sex, marital status, and even health, do not seem to be determining factors. What we are primarily checking on, is whether these peop: : exhibit the symptoms of disengagement as described by Cumming and Henry, but there is no evidence of an inevitable urge to disengage. The replies to the remainder of the questions in Table VII make that clear. Over 79 percent (140) feel they are doing something useful, more than 94 percent enjoy doing tinings for other people, virtually 99 percent feel that their personal appearance is important, over 95 percent 7 ike to associate with people of all ages, and almost 87 percent voted in recent elections.

The most dramatic illustration of a case which refutes intrinsic disengagement is provided by the answers of a lady sixty-one years old to our questions regarding reason for retirement and present activities. Question 8, Form II. What was the reason for your retirement? Answer: "Am amputated. Legs can't be fit with prosthesis. Wheel chair is my 'home." 
Question 10, Form II. What are your principal activities at the present time?

Answer: "Cooking, baking; entertaining, dine out; read books and many antique publications and collect antiques; crochet and do needle point."

This lady lives with a housekeeper, but one must say that she is making a heroic effort to overcome a severe physical handicap and to remain engaged. Her personal appearance is important to her: "Very much so. Dressed well in latest and still do." She sees her relatives almost every day and visits with friends and neighbors "very often." She is also interested in all the current events listed in Question 19: social and economic, political, and cultural; locar, national and international.

The other answers to the questions about present activities include a whole maze of interests and pursuits. Most people reported quite a few activities, thereby indicating that they use their time constructively for themselves and for others. The implication seems to be that there is merit in keeping busy and that being busy is associated with being happy. Following are some examples.

Male respondent: "Voluntary work through RSVP at Ft. Vancouver Historic Site--Large landscaped yard and home garden-Travel--Lapidary--I find no problem keeping busy and happy-even take some classes at Clark College."

Male respondent: "Still work 30 hours a week on volunteer work--Church Treasurer, non-stipendiary; Volunteer, Senior Citizen Advisory Council."

Female respondent: "We have small acreages, make garden, can for us and the children. Raise chickens, rabbits. Do crocheting. Belong to church and work at Mission which is doing services for Missions and local needs of people. I love to cook and bake." 
Female respondent: "Volunteer work in Hospita1, Church, Red $\bar{X}$; bridge playing, being with friends and family--I stay busy."

Some older people are taking care of disabled members of their family and still manage to stay in touch with some organizations and friends in the community and to keep up their interest in a wide range of subjects and events. Following are the replies to the same question by two people in the age bracket which Cumming and Henry term the "very old." However, their statements are a far cry from the disengaged condition described by these theorists.

Male respondent, 83 years 01d: "Church; AARP and get together, Senior Citizens; caring for my wife, and keeping up our home."

Female respondent, 90 years old: "Reading newspapers, doing crossword puzzles, cooking handicapped daughter's main meal, reading magazines, keeping my financial records, some sewing, listening to music on stereo, radio, T.V., watching Perry Mason (TV), "The WaTtons" and nature and Channel (educational) 10 drama, documentary, medical drama and medical science, etc.; taking care of houseplants and cats and kitchen cleanup."

On Question 19, "What kinds of current events interest you?" this lady marked all of them: social and economic, political, and cultural; 1ocal, national, and international. In addition, she named other interests, namely: "Needs of the handicapped and other disadvantaged persons, animal welfare, ecological, and medical advancements." She also votes--by absentee ballot because she does not walk too well. It is hardly necessary to point out that such cases constitute empirical evidence in support of activity theory, and that the data cited show an attachment to life and a desire to keep the ties to society intact as long as possible rather than to sever them. 
There is a great deal more information on the engagement of older people in our findings. The specific activities reported by our respondents have been arranged in broad categories and appear in Table IX.

The first category consists of the remunerative occupations and activities. It includes work for others and self-employment. However, often it is not possible to tell whether an activity is gainful or not. Some hobbies turn out to be very profitable and recreational activities can become productive.

Neither can we be sure if some of the pursuits 7 isted are active or passive, or whether they are solitary or in the company of others. Nevertheless, in the aggregate, the enumeration of activities provides a picture of the engagement of our respondents.

The profusion of activities enumerated in Table IX shows that older people have many resources which help them surmount some of the difficulties they face, and also to lessen the impact of isolation. This thought is expressed in a statement by a lady respondent who is eighty years old and who does volunteer work at the VA Hospital: "I very seldom get lonely--can always sew or call people--loneliness is a state of mind."

Keeping busy, keeping in touch with other people, and keeping up on current events are three important factors for successful aging according to the data which emerge from our study. A closer look at the great variety of things that our respondents engage in convinces us that older people have imagination and creative potential. Our findings point to the fact that the elderly do not succumb to "ego changes 
TABLE IX

PRINCIPAL ACTIVITIES OF RESPONDENTS

Activity or
Type of Employment
(Part- or Full-Time)

1. Gainful Employment

a) Working for others: Tutoring, music teaching, artist, lecturing, nursing, work at cannery, lawn care, other.

b) Self-employment: Rental property, caring for own property, remodeling home, farming, work on acreage, used tool sales, mechanics.

2. Volunteer Work

a) For benevolent institutions: Church, Sunday Schoo7, missionary work, hospital, Red Cross, nursing homes, Homemaker II, State of Washington, R.S.V.P., Senior Citizens, Service Clubs; helping people, visiting the sick, visiting the elderly at homes and other places.

b) For cultural and educational organizations: Work at pubiic school, teaching, at Library, Museum, Vancouver Historic Site; Girl Scouting, general.

3. Homemaking and Family Affairs

Housekeeping, cooking, baking, shopping, canning, business affairs, administrative, keeping financial records, heal th care.

4. Work Connected with the Outside

Yard work, garden, flowers, plants, raising chickens, rabbits; landscaping. 


\section{Activity or \\ Type of Employment \\ (Part- or Ful7-Time) \\ Number Percent*}

5. Hobbies

a) Crafts: Carpentry, cabinet making, wood carving, making small wood articles, model building, repair antique stuff, ceramics, lapidary, petroglyph rubbing, just tinkering, general.

b) Sewing: Mostly by machine.

c) Handwork: Fancywork, crocheting, needlework, needle point, knitting, making rugs.

d) Collecting: Antiques, dolls, stamps, making tape recordings of music and news items.

6. Intellectual Pursuits and the Arts

Reading

Writing, attending school, college, keeping informed (educational, medical, biology), 1 istening to news stories, study mushrooms, photography, TV programs, radio; music (playing piano), painting, drawing.

7. Participation in Group Activities

a) Membership in organizations: Church, U.M.W., Lee Fellowship, John Birch Society, Senior Citizens, Mary-Martha Circle, A.A.U.W., A.A.R.P., Grange, Lodge, Garden Club, Pet Commission, Political Party.

b) Social activities: Social Clubs, Community Club, community affairs, Senior Citizens Center; card playing, playing of games, shows, square dancing, round dancing; "socializing," bridge, entertaining. 


\section{Activity or \\ Type of Employment \\ (Part- or Full-Time) \\ Number Percent*}

\section{Recreational Activities}

a) Travel: long and short trips,

"trailering," travel with Senior Citizens $\quad 25 \quad 14.2$

b) Fishing

Hunting

Golf

$13 \quad 7.4$

$5 \quad 2.8$

$7 \quad 4.0$

c) Other outdoor recreation: camping, hiking, walking, swimming, boating, riding a bicycle, lawn bowling.

9

5.1

d) Various: fun, playing, dancing, bowling, playing pooT, "enjoying life and doing things I couldn't do while working," "anything that comes along."

9. Intimate and Personal Interests

a) Visiting friends and relatives

b) Enjoying people, children, baby sitting, "doing as I want to do," "retired," "serving the Lord," rest.

10. No answer or marked "None."

${ }^{*} 100 \%=176$ (Since most persons engaged in several activities, the totals are more than 100 percent.)

leading to preoccupations with inner states and to the narcissism of the very old" (Cumming and Henry, 1961, p. 215). The information contained in the tables on interaction with relatives and friends and on interest in current events makes clear that the great majority of our respondents 
continue their relationships with others and have a wide range of concerns besides their own "inner states." (See Tables X through XIII.)

More specifically, Table $X$ shows that 7.4 percent see members of their family and other relatives daily, 30.7 percent see them very often, and 27.3 percent often, as compared to 16.5 percent seeing them monthly, 11.9 percent every few months, and 10.2 percent not very often. "Very often" seems to mean "every few days," and "often" apparently stands for "once or twics a week." At any rate, the preponderance of the evidence indicates that older people endeavor to be in frequent touch with those relatives that they have.

The same holds true for contacts with friends and neighbors, as can be seen in Table XI, which itemizes how often our respondents engage in this type of interaction. We note that 20.5 percent visit daily, 12.5 percent very often, and 30.7 percent often. A considerable number, 17.0 percent, said they visit "occasionally," and 11.9 percent do not visit often. Again, the picture is one of social interaction rather than of withidrawal.

This impression of continued activity is reinforced by the answers to Question 19, which consists of two parts. Part a) inquires about interest in current events categorized as social and economic, political, cultural and other. Part b) distinguishes between current events on a local, national, and international basis.

Table XII furnishes the replies to the first part of Question 19, and reveals that the overwinelming majority of respondents had maintained their interest in all of the classes of events mentioned. The figures 
TABLE $X$

"HOW OFTEN DO YOU SEE MEMBERS OF YOUR IMMEDIATE FAMILY OR OTHER RELATIVES NOT LIVING WITH YOU?"

\begin{tabular}{lcc}
\hline At What Intervals Seen & Number* & Percent* \\
\hline Daily & 13 & 7.4 \\
Very often & 54 & 30.7 \\
Often & 48 & 27.3 \\
Monthly & 29 & 16.5 \\
Every few months & 21 & 11.9 \\
Not very often & 18 & 10.2 \\
None*** & 3 & 1.7 \\
& 186 & 105.7 \\
*100\% $=176$ & & \\
**Since some respondents saw their relatives at different intervals, \\
the totals add up to more than 100 percent. \\
***This category includes one "No Answer."
\end{tabular}


TABLE XI

"HOW OFTEN DO YOU VISIT WITH

FRIENDS OR NEIGHBORS?"

\begin{tabular}{|c|c|c|}
\hline At What Intervals Visited With & Number* & Percent* \\
\hline Daily & 36 & 20.5 \\
\hline Very often & 22 & 12.5 \\
\hline Often & 54 & 30.7 \\
\hline Monthly & 7 & 4.0 \\
\hline Occasionally & 30 & 17.0 \\
\hline Not often & 21 & 11.9 \\
\hline None or no answer & 6 & 3.4 \\
\hline Totals & 176 & 100.0 \\
\hline$\star 700 \%=176$ & & \\
\hline
\end{tabular}


TABLE XII

"WHAT KINDS OF CURRENT EVENTS INTEREST YOU?" (a)

Kinds of Events Interested In

Number

Percent*

Four Kinds of Interests:

Social and Economic, Political, Cultural, and "Other"

10

5.7

Three Kinds of Interests:

Social and Economic, Political, and Cultural**

57

32.4

Two Kinds of Interests:

Social and Economic and Political

22

12.5

Social and Economic and Cultural

12

6.8

Various other combinations of two kinds

of interests

13

7.4

One Kind of Interest:

Social and Economic

10.8

Political

8

4.5

Cultural

7

4.0

other

15

8.5

None or No Answer

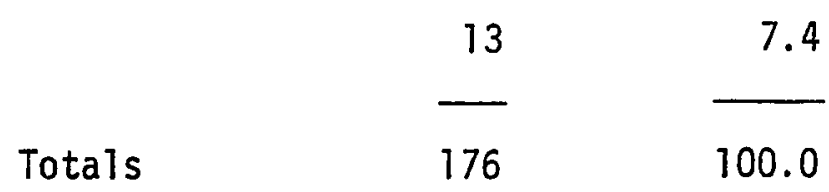

$* 100 \%=176$

**Includes three cases composed of two of these interests and "0ther." 
TABLE XIII

"WHAT KINDS OF CURRENT EVENTS INTEREST YOU?" (b)

\begin{tabular}{|c|c|c|}
\hline Kinds of Events Interested In & Number & Percent* \\
\hline \multicolumn{3}{|l|}{ Three Kinds of Interests: } \\
\hline$\frac{\text { Two Kinds of Interests: }}{\text { Local and National }}$ & 37 & 21.0 \\
\hline National and International & 10 & 5.7 \\
\hline \multicolumn{3}{|l|}{ One Kind of Interest: } \\
\hline National & 6 & 3.4 \\
\hline International & 6 & 3.4 \\
\hline None or No Answer & 19 & 10.8 \\
\hline Totals & 176 & 100.0 \\
\hline$* 700 \%=176$ & & \\
\hline
\end{tabular}

show that 32.4 percent checked that they had the first three types of interests named, and 5.7 percent added a fourth type denoting their special interests in such areas as sports, scientific progress, ecology, history, philosophy, medicine, problems of the handicapped, and various kinds of welfare.

Twenty-six and seven-tenths percent checked two interests, 12.5 percent showing a combination of social and economic and political types 
of events, and 6.8 percent marking a combination of social and economic with cultural things. The social and economic, and the political items are by far the most popular ones, as is also demonstrated in cases where only one category was marked. In these instances, 10.8 percent checked the social and economic and 4.5 percent the political type. Table XIII gives the breakdown of the answers to the second part of Question 19. We see that 44.9 percent stated that they had all three types of interests specified in this part of the question: local, national, and international. Of two interests checked, the leading combination was local and national, amounting to 21.0 percent. Some people marked only one kind of ir.terest, the largest category being local with 10.8 percent.

As a whole, Question 19 has elicited significant information which shows that older people do not automatically lose their interest in what is happening in the outside world. This conclusion is supported by a comment of one man who checked all the places in this question, wrote the word "All" after his marks, and added at the end of this questionnaire:

Have never withdrawn from such interests. Read 2 newspapers and many magazines (slick paper rather than pulp).

I have never missed a presidential election since first voting in 1924. Rareiy miss an "off year" or "speciai" election.

This man was born in 1902, and his remarks go a long way toward confirming our Hypothesis One, that there is no intrinsic or inevitable disengagement because of age. The statement is also typical of the feeling of most older people. They often state that they continue to vote to indicate their interest in the country at large. 
In this connection, the writer would like to refer to a news story in the Vancouver (Washington) Columbian telling about a notable woman who is still voting at the age of 100:

Mrs. Merris, who turned 100 on March 7, has voted in every election since women were given the right to vote in Oregon in 1972. . . . Asked about which years of 1 ife she enjoyed most, Mrs. Merris has a ready answer: "I'm enjoying life most right now." (Bob Beck, "Mattie, age 100, true-blue GOP," The Columbian, March 21, 1977, p. 2.)

The engagement of older people can also be judged by the way they care for their appearance. Good grooming is usualiy indicative of some social participation. In terms of symbolic interactionism, personal neatness is a sign that the individual is still governed by the "generalized other," and is sensitive to the attitudes and expectations of people in the community.

We have seen in Table VII (Question 14), that almost all respondents felt their personal appearance was important. We will now deal with the sequel to this question, "Please explain." This is an open-ended question encouraging the respondents to answer freely in their own words. The replies we received have yielded a great deal of first-hand information which corroborates our hypotheses. Following is a digest of these responses as they apply to our theory. The list includes the most representative statements.

1. Looking neat. These answers link appearance and well-being and consequentiy morale. A desire to be "neat and clean at all times" was the most frequent answer:

"Like to be neat and clean, feel better then."

"Like to look good--feel good."

"Clean mind and body." 
"Clean clothing, hair, nails, complexion, showers."

"Appearance in health and home."

"Well gromed, pleasant, vita1."

"Isn't it normal?"

"To be neat in appearance and have happy frame of mind."

"I take pride in looking well groomed, helps my morale."

2. Personal Pride. "Individual pride," and "personal pride," are often mentioned. This fact has a special importance for the present research because it shows that older people are still egoinvolved, and that the "inevitable ego changes" predicted by Cumming and Henry (1961, p. 213) have not occurred. For instance:

"My personal appearance has always been important to me."

"It's a matter of self-respect."

"We11 I don't think there are any women that don't like to look their best."

"I have pride in my personal appearance."

"I like to look presentable wherever I go."

"Clean pretty clothes and modern hairdo."

"Vanity."

"I do /Consider my personal appearance important/ and enjoy having my hair done. I love clothes."

"One's mental health is improved if one feels one is attractive looking."

3. Looking younger. If people are interested in conveying a more youthful impression of themselves, they are not ready for disengagement. It is rather to be assumed tinat, contrary to disengagement theory, they wish to maintain their social integration. They realize that their 
appearance affects their transactions and the responses they elicit. If they appear elderiy, they may be met with reactions to an aged person, but if they employ the symbolism of a younger personality, they might evoke responses to such an image. Some comments in this group are:

"Try to stay as young looking as possible."

"Don't like to look too 'Grampy.'"

"I wear a wig and special shoes."

"I like to feel neat and up to date."

"You are as old as you feel and appear."

4. Obligation to look good. 01der people who express a consideration for others imply that they still see themselves as interacting members of society. They like to look pleasing and expect others to be the same. Appearance comprises both grooming and demeanor. We quote:

"Attire and the way I conduct myself."

"I think everybody should look neat."

"For those around me."

"I try to be clean, neat and courteous at all times."

"I like to look clean, neat and proper."

"I always like clean neat people."

"Everyone should present an attractive appearance."

"Need to be clean and acceptably dressed."

"For social acceptance."

"I feel you owe the world a good appearance, and as you get older you have to work at it harder, because of physical decline." 
5. Appearance and activity. In this group, the statements deal explicitly with continued activity. The purpose of caring for one's appearance is to keep up public contact, that is, engagement:

"Good posture--body strength for activities."

"Through my art I have public contact."

"I associate with large groups of people."

"I have always had to dress, shave, etc., to meet public."

6. Absence of change. This final category contains evidence regarding the continuity of personality and life style in contrast to disengagement theory. 01 der people have retained their former attitude toward appearance in spite of very advanced age:*

"Good grooming is very important in elderly or any age" (female, age 63).

"It has always been important and always will" (female, age 64).

"Training" (male, age 66).

"Makeup, hair-do's, smart clothes and shoes" (female, age 70).

"The older one gets, the more important personal appearance" (female, age 67).

"Very little changed from years when employed" (male, age 73).

"A habit in early years is not easily cast off" (female, age 73).

"I was taught to always look my best" (female, age 75).

"Because I was always neat because I was teaching" (female, age 79).

"I keep myself clean and presentable" (female, age 89).

"Have always had pride in appearance" (female, age 92).

*In these instances age has been added in order to show continuity. The sex of the person has also been added. 
Using interest in appearance as a criterion, we have demonstrated that older people do not inevitably show the symptoms of disengagement. The crowning statement is by a lady, aged 90 , who has said it all:

"Grooming counts more than 'looks,' features, wrinkles. Being 'interested' and trying to be empathic lights up your expression and despite age you are attractive."

\section{Scoring of Questionnaires}

Our instruments were devised for the express purpose of measuring the engagement of our respondents. If engagement is very low, we are alerted to a special situation which calls for further investigation.

Forms I and II have given us an account of the attitudes and activities of our respondents. However, their engagement or nonengagement can best be evaluated by assigning a total summary score to each questionnaire that was filled out. 41

The essence of our scoring technique is that a plus is given for each answer favoring engagement and a minus for each reply not favoring engagement. One point is given for each answer checked.

On the Attitude schedule (Form I), the total score is the sum of the "agree" and "disagree" answers favorable to engagement less the sum of those unfavorable to engagement. The places marked "undecided" or left blank were disregarded. It is a simple method of measuring the amount of activity and involvement the respondent endorses for older people. The maximum possible score is 22 .

41

In working out the method of scoring, this researcher has drawn on the activity and attitude measures of Ruth Shonle Cavan et al., Personal Adjustment in 01d Age (Chicago: Science Research Associates, 1949) and on the life satisfaction ratings of Bernice L. Neugarten, Robert J. Havighurst, and Sheldon S. Tobin, "The Measurement of Life Satisfaction," Journal of Gerontology, 16, No. 2 (Apri1 1961), 134-143. 
This way of scoring was also adapted to the Activities scheaiule (Form II), and the same maximum score is possible. The items in this form are roughly matched to our criteria of engagement and disengagement, and the total score is the sum of the answers indicating engagement less those showing nonengagement.

In scoring the Activities, the peculiar circumstances of older people were taken into account. As we know, there are often severe restrictions on the opportunities open to the elderly, and they are often prevented from engaging in the activities they would like to pursue. Therefore, the subjects have been rated on how they overcome these obstacles, and on the way they compensate for things they are not able to do any more.

Thus, the manner of arriving at the Activities scores was not purely mechanical, but all the information available was considered, and a great deal depended on the judgment of the investigator. Neugarten et al. used such a procedure in measuring the life satisfaction of their respondents. We are quoting some excerpts from their rating scales in order to illustrate the process that was followed in the present instance:

A. Zest vs. apathy. To be rated here are enthusiasm of response and degree of ego-involvement--in any of various activities, persons, or ideas, whether or not these are activities which involve $R$ with other people, are "good" or "socially approved" or "status-giving." Thus $R$ who "just loves to sit home and knit" rates as high as $R$ who "loves to get out and meet people." Although a low rating is given for listlessness and apathy, physical energy per se is not to be involved in this rating. Low ratings are given for being "bored with most things"; for "I have to force myself to do things"; and also for meaningless (and unenjoyed) hyperactivity. ...

B. Resolution and fortitude. The extent to which $R$ accepts personal responsibility for his life; the opposite of feeling resigned, or of merely condoning or passively accepting that which life has brought him. The extent to which $R$ accepts 
his life as meaningful and inevitable, and is relatively unafraid of death. Erikson's "integrity." Not to be confused with "autonomy" or the extent to which R's life has been self-propelled or characterized by initiative. $R$ may not have been a person of high initiative, but yet he may accept resolutely and relatively positively that which life has been for him. $R$ may feel life was a series of hard knocks, but that he has stood up under them (this would be a high rating). (Neugarten et al., 1961, p. 137.)

Our own data have been enhanced by notes, letters, and telephone cal1s, which shed extra light on some cases, and permit us to appraise engagement more equitably. As an especially worthy example, we quote the following letter from a respondent:

"Dear Friend:

Will try and answer those questions the best I can. I am living alone here with my wife which has been a stroke patient since 1962, and naturally getting worse. She is 79 years old. We have a lady come in 5 days a week to help out. She is completely helpless, not able to talk any more.

I am not complaining, but you can see I am not able to get away from the place much. Only to do the shopping once a week. We have $\frac{1}{2}$ acre of ground and raise a large garden and can and freeze lots of fruit and vegetables. That helps out a lot.

Yours truly,"

This man is 80 years old. By looking at the forms he sent in, one would judge him rather disengaged. He has reported no interaction, al though he does state that he would prefer to be gainfully employed. However, taking care of a paralysis patient is a full-time job, and this man has no time to participate in any kind of activities. But his score reflects that he got credit for the things that he does: taking care of his wife and the house; raising a garden, canning, and doing the shopping. Also considered was the fact that he wrote the 
researcher a note, which shows that he is concerned about keeping good relations with others in society and being courteous and considerate. We have thus applied the idea of Verstehen to our method of scoring. Nevertheless, there are substantially more high scores among the Attitudes than there are among the Activities. Tables XIV and XV show, respectively, the distribution of the scores on the Attitudes and the Activities of our respondents.

TABLE XIV

FREQUENCY DISTRIBUTION OF ATTITUDE SCORES

\begin{tabular}{|c|c|c|}
\hline & Score & Frequency \\
\hline & $\begin{array}{r}0 \\
1 \\
2 \\
3 \\
4 \\
5 \\
6 \\
7 \\
8 \\
9 \\
10 \\
11 \\
12 \\
13 \\
14 \\
15 \\
16 \\
17 \\
18 \\
19 \\
20 \\
21 \\
22\end{array}$ & $\begin{array}{r}1 \\
0 \\
5 \\
1 \\
2 \\
0 \\
6 \\
1 \\
1 \\
5 \\
2 \\
8 \\
3 \\
4 \\
4 \\
3 \\
12 \\
5 \\
21 \\
13 \\
17 \\
16 \\
46\end{array}$ \\
\hline & - & - \\
\hline Totals & & $N=176$ \\
\hline
\end{tabular}


TABLE XV

FREQUENCY DISTRIBUTION OF ACTIVITY SCORES

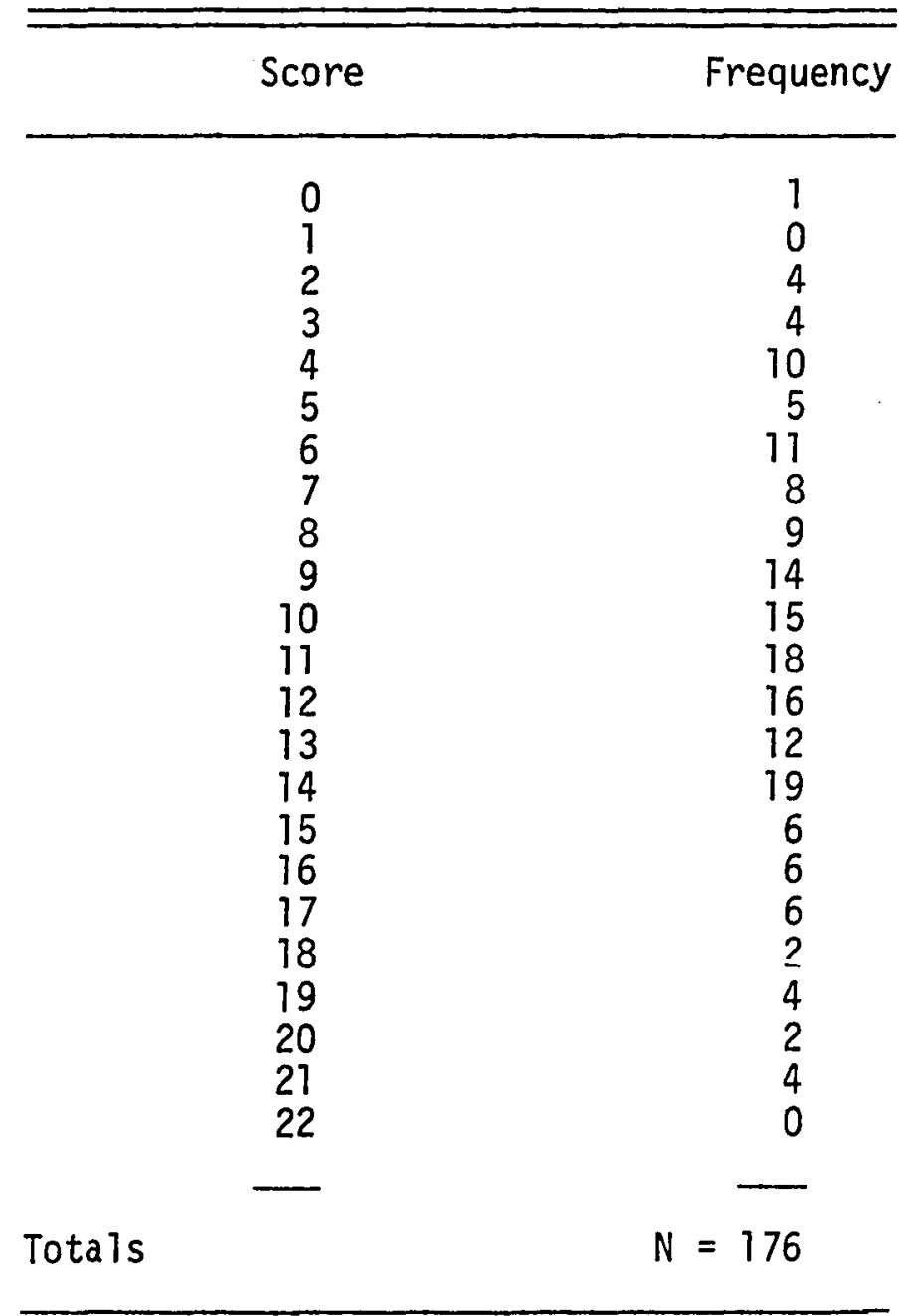

The data contained in the two Frequency Distributions (Täbles $X I V$ and XV) may also be represented graphically. It is interesting to compare the distribution of the Attitude scores and the Activity scores as their patterns are plotted in the line graphs designated as Figures 1 and 2 respectively.

If we smooth the lines between the points to simulate curves, the shape of Figure 1 (attitude scores) is sharply directed upward, 


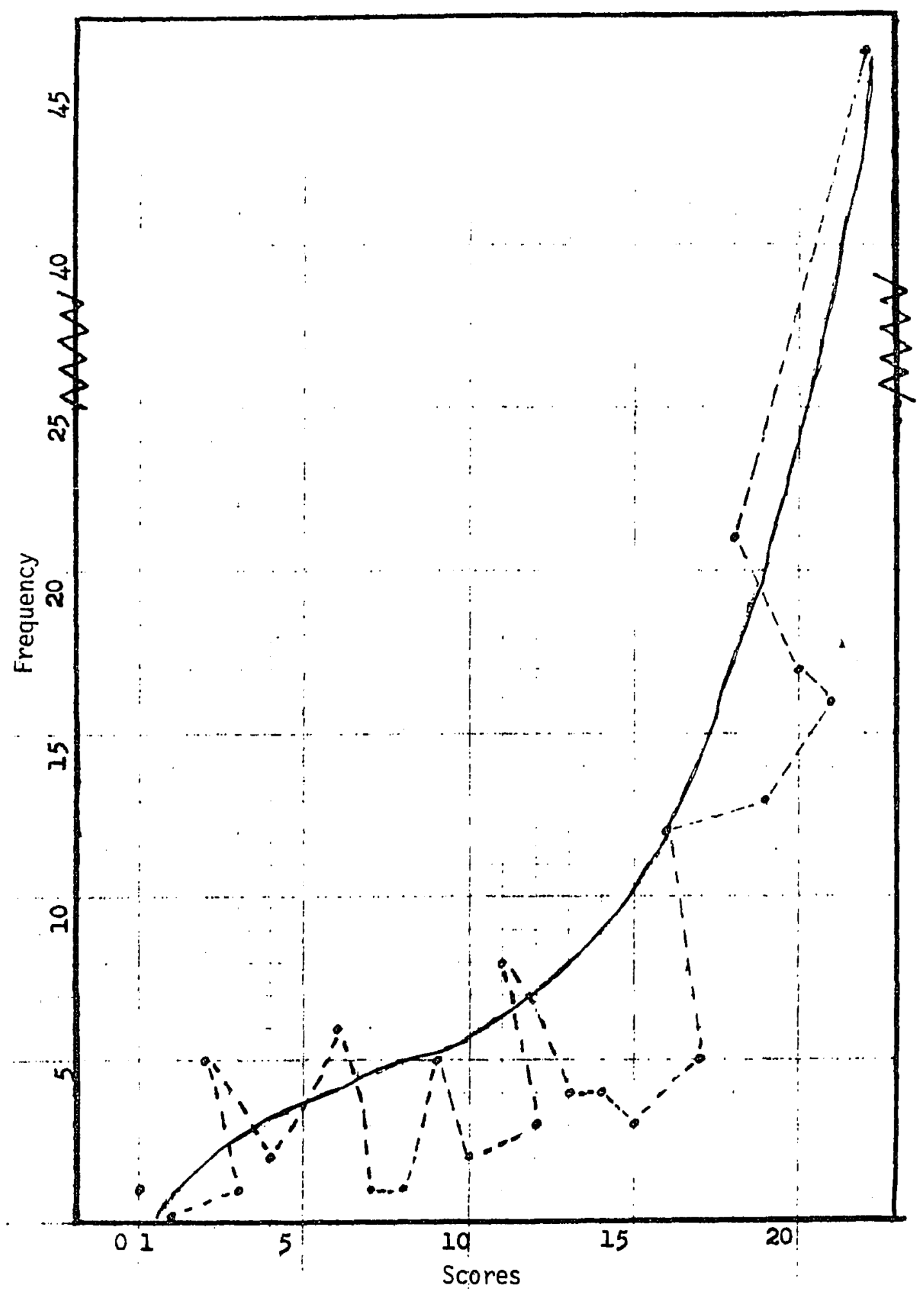

Figure 1. Frequency distribution of attitude scores 


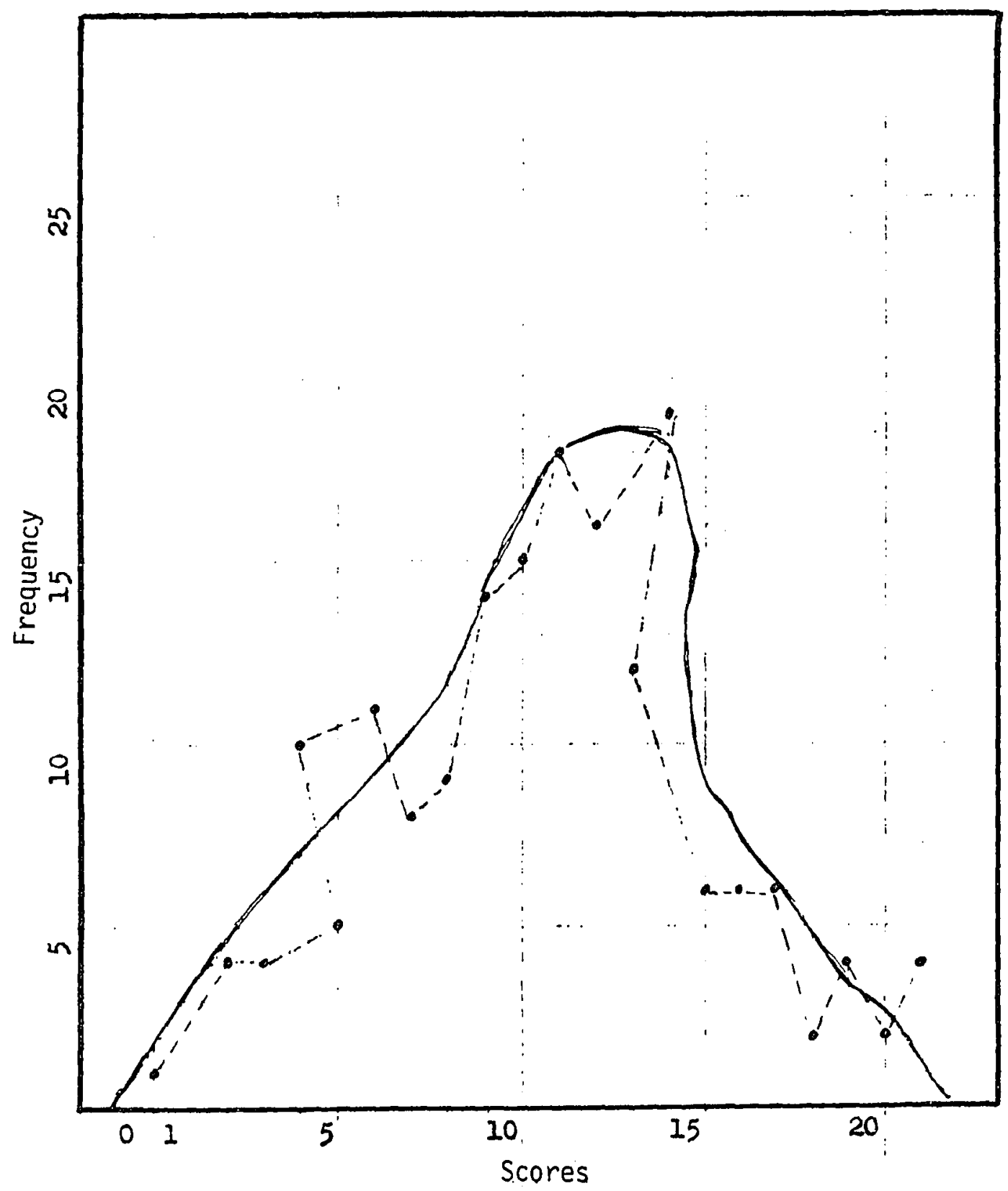

Figure 2. Frequency distribution of activity scores 
portraying the fact that the greatest number of cases is in the higher values, with the mode at the peak. Specifically, this means that, among our respondents, 46 our of 176 received the maximum score of 22 . To the writer this symbolizes the aspiration of older people--a reaching out after what might be.

The graph in Figure 2 (activity scores) indicates what actually is. The distribution of the scores resulted in a frequency polygon which, when smoothed, approximates a normal curve--a realistic reflection of the facts of life.

Pursuing our analogy a step further, we have investigated the association between these two variables, that is, between attitude scores, standing for what participation our respondents endorsed for older people, and activity scores measuring what these respondents themselves do.

Figure 3 is a scatter diagram which shows how the attitude scores and the activity scores vary together. The correlations between these two variables are of particular importance for the present project because they can be used to detect extreme cases which, in turn, may disclose some reasons for different levels of engagement.

The product-moment correlation coefficient for these two sets of scores is .27 , a weak positive relationship which reflects some imperfect associations between individual scores. The means are 17 for the Attitudes, and 11 for the Activities, with standard deviations of 5.5 and 4.5 respectively.

As the graph reveals, there are pairs of measurements which are both high or both low, and there are combinations of one score high and 


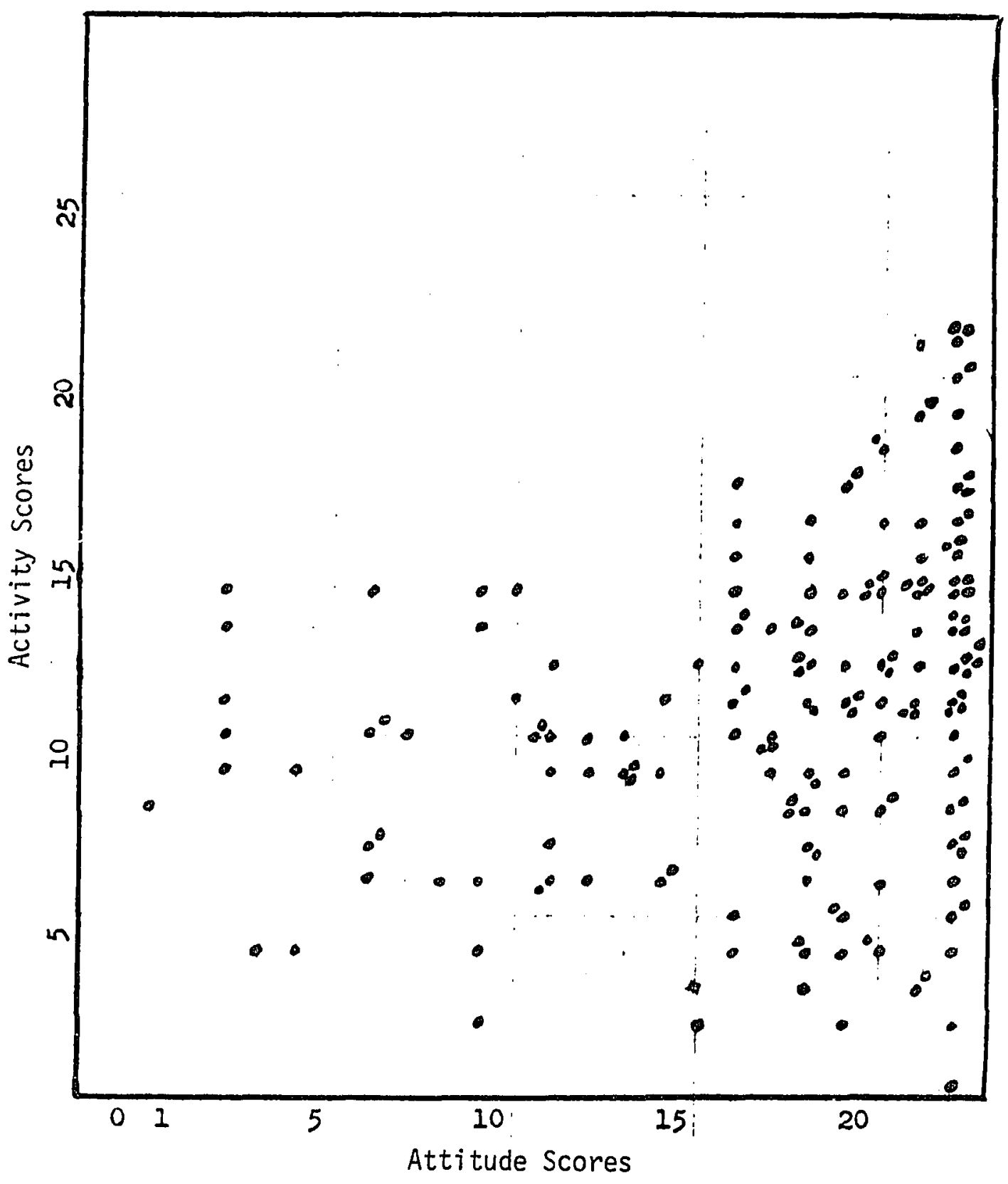

Figure 3. Scatter diagram of relation between attitude scores and activity scores 
the other low. By selecting the extreme cases from the scattergram, the following fourfold scheme of association was obtained:

I. High Attitudes - High Activities

II. High Attitudes - Low Activities

III. Low Attitudes - High Activities

IV. Low Attitudes - Low Activities

These four combinations have become the vehicles for more intense studies of patterns of change and cause and effect relationships. 42

In this connection, it is pointed out that several other researchers on disengagement theory have described four analogous types of relationships among their measures. Maddox and Eisdorfer (1962) have dichotomized activity and morale of their elderly subjects and have arrived at a typology of "high activity" and "high morale"; "high activity" but "low morale"; "low activity" but "high morale"; and "low activity" and "low morale" (p. 256-257). Their data suggest that

. . attention should be shifted from chronological age as an independent variable to the constellation of variables of which age is an index and to variations in the activityrelated characteristics among persons in the same age range (p. 258).

Havighurst, Neugarten, and Tobin, in both their articles of 1963 and 1968, found four combinations of activity and life satisfaction: "All four combinations of activity and satisfaction exist--that is, high-high and low-low are the most frequent; but there are also highlow and low-high patterns. Neither the 'activity' theory nor the

42

This approach was suggested by Dr. Charles D. Bolton. 
disengagement theory accounts satisfactorily for this diversity" (1968, p. 171). These researchers conclude that the personality of the individual determines the type and extent of engagement in the later years $(1968, \mathrm{p} .172)$.

In the present work, the four types of combinations of Attitudes and Activities have been explored for antecedent and intervening variables which might influence some older persons. This investigation is reported in the next chapter. 


\section{C.IAPTER V}

THE RESEARCH PROCESS: THE OLDER PERSON IN THE CITY

The first part of our research process has already yielded a great deal of information which contradicts the theory of Cumming and Henry. As demonstrated by our survey sample, not all older people "disengage." Most of them endorse continued activity for the older age categories and exhibit attributes which fit into our operational definition of engagement. Nobody has reported an overpowering desire to be severed from the rest of society or to seek a "new equilibrium." On the contrary, the majority of our respondents wish to continue their former way of life and they want to remain part of the community.

However, there are some extreme combinations among our measures of attitudes and activities, and some of these disparities have been further investigated. The present chapter reports on this individual variability and on how it was followed up. It also discusses the outcome of the rest of our research by means of life histories and various. kinds of observation.

First, we want to devote our attention to the four cells of special cases which were selected from the correlacion of scores. Table XVI contains the specific scores for each category. Their meaning with relevance to engagement or disengagement was examined in personal interviews as described in the following section. 
TABLE XVI

INTERRELATIONSHIPS OF ATTITUDE AND ACTIVITY SCORES

FOR SIXTEEN RESPONDENTS TO

SURVEY QUESTIONNAIRE

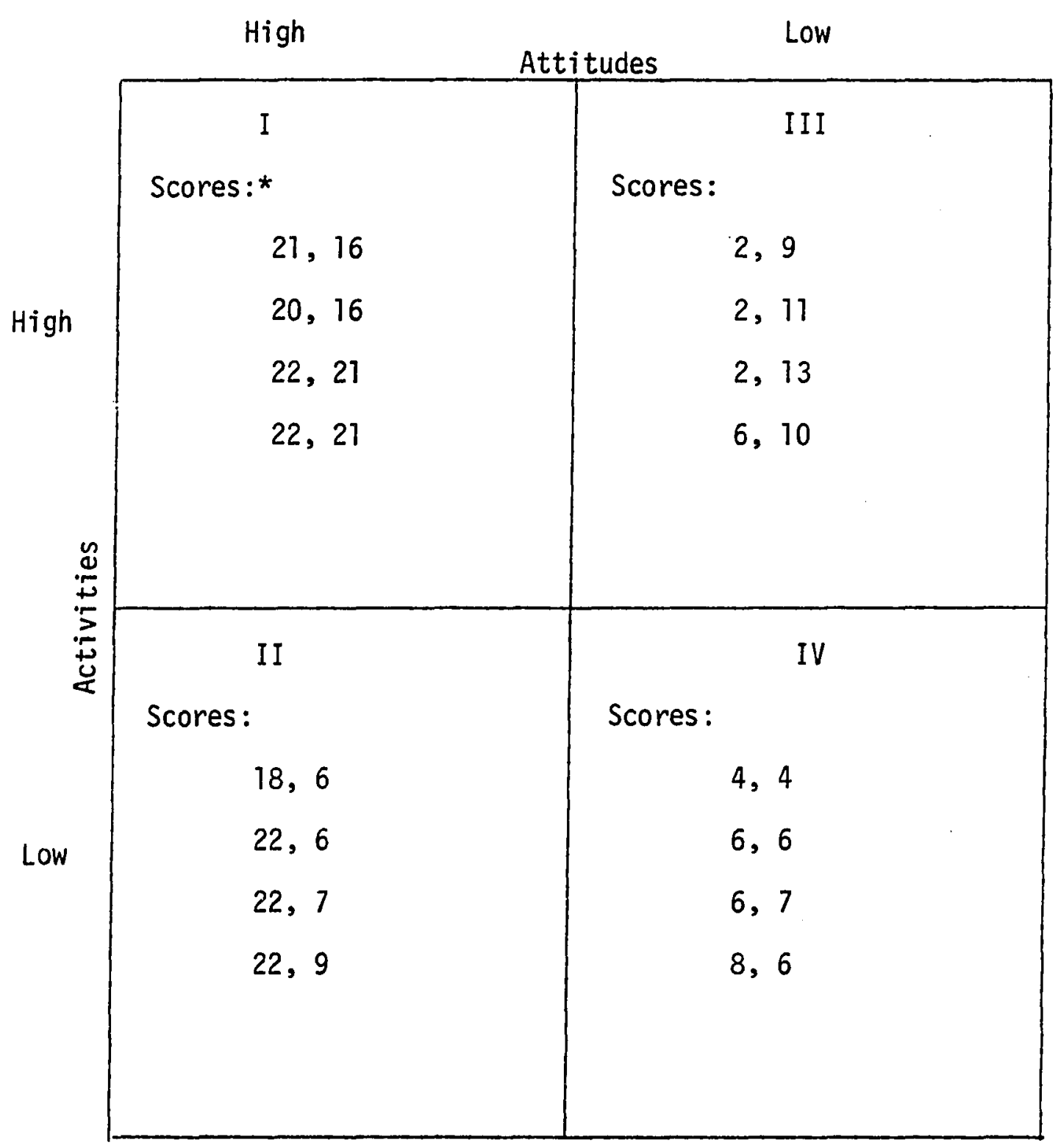

*The Attitude score is the first figure; the Activity score is the second figure. 


\section{THE PERSONAL INTERVIEWS}

Twenty-six personal interviews were obtained in all. Sixteen of them were fitted into our typology of scores, three were detailed enough to constitute life histories, and seven were used as case histories. All of these interviews proved to be a valuable supplement to the survey questionnaire responses. The interviews were conducted in the homes of the respondents and lasted from one to three hours. Most of the conversation was recorded and has been transcribed verbatim.

The two main objectives in these face-to-face encounters were to look for indications of change or continuity over time in engagement or disengagement, and to see if there was any connection between these variables and city services. By studying the situation of the respondents, the researcher endeavored to explain some of the discrepancies in their scores. However, we are just as much interested in discovering what causes high engagement and satisfaction as we are in finding the reasons for low involvement.

Since the crux of disengagement theory is a process of mutual dissociation of older people and society, the sights of the investigation were directed toward such a phenomenon. If a change seemed to have occurred, its reasons and consequences were carefulty analyzed.

A new instrument, form IV, was designed as an interview guide in order to probe into those areas of life which are most likely to manifest change. These are: the work life, the family situation, social and organizational participation, health status, and economic conditions. There are also a number of open-ended questions where the respondent is encouraged to comment freely on various matters of interest (see 
Appendix for a sample of Form IV). One of the main purposes in the use of this form was to provide incentives for the respondent to talk.

It was found that most of the people interviewed were quite eager to talk, and to discuss present and past events in their lives. They were asked to recall what they did before retirement and to describe their activities subsequent to retirement. In this way a great deal of background information was collected which, in conjunction with current facts, provided some longitudinal data that help reconstruct the process of aging for the individuals concerned, are useful in detecting change, and contribute to the testing of our hypotheses. We proceed to give the characteristics of the four types. The individual cases have been designated by the small letters of the alphabet but do not appear in sequence because of the difference in scores. In some cases husband and wife scored quite differently.

\section{Type 1. High Attitudes - High Activities}

Case $u$. Female, age 73. Married, living with husband in own (mobile) home. By profession grade school teacher, and still tutors. Likes physical exercise: rides bicycle, gardens, and travels. Her husband (Case $t$ ) is in poor health and she takes care of him and the home. They are financially comfortable: not poor, but not rich either. They are "in the middle," which has its drawbacks because together they have too much income for the husband to receive his veteran's pension. 
Mrs. $u^{43}$ maintains her former way of $7 \mathrm{ife}$. She keeps busy, but she never was much of a "joiner." However, she does belong to the retired persons' organization AARP, and to the educational associations NRTA, NEA, WEA, and WRT. She goes to some meetings and participates "a little." It appears that she continues to act the same way as she did before. She goes to church and participates in a missionary group, but she does not care too much about community activities in the way of playing cards and the like:

You know, people have such a strange idea about retirement. We1l, just to be entertained all the time, some people think that should be good. If we didn't live that way before, why would we be that way after we retire? It's just silly. And then, well, some older people haven't prepared for retirement and they're bored to tears. But I've never been bored because I find enough things to entertain myself. I like the Library. I love that. We have a wonderful library here in Vancouver, you know--a marvelous library. They will get all kinds of books for you.

Mrs. $u$ has always been a very dedicated teacher, and she likes to accomplish things. She makes beautiful ornamental rugs and she takes delight in raising vegetables in her garden. She likes the focus on learning for older people which is now available at Clark College in Vancouver. She gives the impression of being energetic and capable. She drives her own car and she likes people, but she also likes time to herself. She repeatedly stressed how important independence is to her. However, she would not want to be isolated and would not care for a retirement home. She is very pleased with conditions in the mobile court where she and her husband live. Her one concern is having better bus service. There are no buses on Sundays.

43

Married women are referred to by their own case letter in this typology rather than by their husband's designation. 
There have been some changes in the life of Mrs. $u$. She and her husband never had any children, but she had five brothers and a sister. There is only one brother left now; the rest have passed away. She does have some nephews and nieces living close by. Her husband has two sisters. Mrs. $u$ and her husband do not have very much contact with their relatives, but there is a good family spirit.

Mrs. u can be said to be well adjusted, and she has some interesting ideas about what she would do if she were left alone. She would like to be on a campus site.

I wouldn't like to live in an apartment. No, not till I have to. It has some advantages, I'm willing to admit. My husband says, if he was left alone, he'd get an apartment. But that would be a little different.

Do you know anything about this King's Garden School, up there in Seattle? It's been sponsored by some church. I always thought, if my husband would pass away, that I'd kind of like to be there. Then I'd be right on the campus, and I'd be close to the activities, and I've always liked the schools. I don't know too much about it, but I'd be interested.

This is supporting evidence for activity theory and for continuity of personality and life style in contrast to disengagement. It also illustrates the idea that older people like to remain in harmony with what they have cherished earlier in their lives. ${ }^{44}$

Case e. Female, age 66. Married, Tiving with husband (Case d), age 84 , and her daughter-in-1aw and granddaughter. Her husband is ailing, but Mrs. e is feeling fairly well, although she is still

44

A plan similar to the one mentioned by Mrs. $u$ was explored in a survey of 130 retired faculty members at the University of I17inois. These people wanted to retire where they had spent their active years; therefore a campus site was preferred. See Wilma Donahue, "Where and How 01der People Wish to Live," in Housing the Aging, ed. Wilma Donahue (Ann Arbor: University of Michigan Press, 1954), p. 27. 
recovering from gall bladder surgery and from an accident about a year ago when she fell out of a cherry tree and hurt her back. She is getting better, and she is trying to keep up her work. Mrs. e worked for the Troy Laundry in Portland for thirteen years, and then for Memorial Hospital in Vancouver for seven and a half years. She retired at age 65 because of compulsory retirement, but she is just as busy as ever. She is raising a garden, taking care of her husband and of her granddaughter, and helping her daughter who lives next door and other members of the family.

I hardly ever sit down during the day. I keep going over to her house or the others, all around the yard, and am looking forward to getting my garden in. Last year I had a beautiful garden going, and I fell out of that cherry tree, broke some ribs, and hurt my back. I went to the hospital. Then, when I come home, I still was hurting. I talked to the doctor, he said he thought it was my gall bladder, and put me back in the hospital. I had to have gall bladder surgery.

I hurt my vertebra in the back /by falling out of the tree/. That's the only thing that's bothering me now. It's so much better than it was, and I'm just hoping it will be just like it was.

Mrs. e says she has no hobbies.

No. Just work, work. I've never been able to get to the place of having hobbies. It always seemed to me like a waste of time. I like to get out and work around the garden. I was raised on a farm, and I like to take care of chickens and stock.

Mrs. e has no time for social activities or organizations. She is practical and she is a sympathetic person. Her main interest seems to be helping people. First her family, and then also others.

I have two daughters and two sons. One son lives in Fruit Valley. The other one lives in Santa Monica, California. And that / the little girl staying with her/ is my youngest son's daughter. He and his wife are separated. She is here with me--his wife and his child-- 
but he's in California. She went to Argentina to be with her parents when the little girl was two years old. He could not live in Argentina. He never did figure for her to come back, and she is not a citizen of the United States. After she had been there one year, she couldn't come back unless he sent for her. He didn't want to send for her either. He was "living it up" and having a good time, I guess. He didn't send for her, so I told her she could come and stay here. . .

I guess, I do so much for my children, that I don't have time to do anything else. But I would. If I thought of something somebody really needed, I would go over and do it. I don't need to join a club.

Mrs. e has a deep concern for older people and can see their larger problems, even though happily involved in her own family iife. This interview turned out to be very informative. When she worked at Memorial Hospital, she had a great deal of contact with older people:

I worked in Memorial Hospital. I worked there seven and a half years, and I was the housekeeper. I wasn't a nurse. But they talked to me probably about a lot that they didn't talk to the nurse about.

The writer was fortunate in meeting Mrs. e. She talks readily and extremely we11. The conversation resulted in a great deal of evidence which goes directly to the core of our research. For instance, she insisted that older people do not change merely because of age.

No, no. That's not so. You don't change when you get to be sixty-five. If you felt in good health, you feel you are just the same. You just get to the age where you know that people are not going to hire you like they used to. They won't give you a fuTl-time job--most places won't. - . I think it should be so that they could /work fulltimel if they wanted to. Most people would not want to. I don't think I would ever want a full-time job any more. But you never know.

Mrs. e had looked forward to her own retirement, even though it was compulsory. Her husband needed her. He had a heart attack, but he 
is feeling much better since she has been there to take care of him.

She also wanted to work in her garden. Her life turns around her

children:

I love my children. When they were little I enjoyed the children. I've heard some people say, "My children are driving me crazy." They love to get out, you know. My kids never did drive me crazy. I never thought they were driving me crazy, I never thought I wanted to get away from them. Oh, I guess, there is a difference in people.

However, there is another idea that is close to the heart of

Mrs. e, and that is to help other people stay in their own homes rather than being forced into nursing or "rest" homes. She kept coming back to this topic, which shows that it had been on her mind for some time.

What the old people really need, is somebody to help them live in their own home--anyway, not having to go to a rest home. They really need it. Some organization-there is a van that goes up here and picks up the elderly people and takes them, I suppose, down to the Marshall Center, maybe to some activities for the elderly people there. . . But there are so many people that are not getting the help they need--to stay in their own home. And they would live much longer, and be happier, in their own home than they will if you shut them up in some rest home for the rest of their life. That's what happens to so many people--having to go to a rest home. It is terrible in my estimation: to be forced out of their own home. It's really tragic. They have worked all their lives to pay for their homes and, when they get old, they get shut off somewhere.

They should be made happy in their old age. I'm willing to do my part to help out. I feel like I'm wasting my time if I go down to where they got these programs for the elderly. I feel I should be helping the people that really need the help, instead of going down there and enrolling in some craft shop. . .

When I worked in Memorial Hospital, I had a lot of them in there that were elderly people. People who were still able to take care of themselves in a way, if they just had a little help from the outside. Some of these people over at the hospital--they could go home if they had someone who would come in, maybe once or twice a week, and maybe make the beds, and kind of see that they get something to eat. . . . 
And those people can't go home because they are not able to take care of themselves if there is no one to help them. . . One lady there told me, "Money, with me, is no object. I have plenty of money, but I can't get anyone to stay with me. When they come in, they stay a few days, and they leave. They jusi won't stay and take care of an elderly person day after day. She was going to have to go to a rest home because she didn't have anyone to take care of her. That is the worst thing.

Mrs, e tells us what she learned about rest homes while she worked with elderly patients:

If they have property, they have to sign that over to the rest home, and the rest home will tell them: after that is gone, then we'11 take care of you the rest of your 1 ife--if you don't live too long after you get into the rest home. The older people grieve themselves to death in the rest homes. . .

Another man told me that he went into a rest home, and he signed over six properties to them. He said, he had a forty thousand dollar home. He had other land. They sold the $\$ 40,000$ home, and he'd been in there eight months and they said that the money was gone, and that they would have to sell some more of his property. Well, you know, they couldn't have spent forty thousand dollars on him in eight months.

And that's the kind of a deal a lot of them get in the rest homes. They give them their powers of attorney and first thing, you know, all their property is gone. How some of them live after that, I don't know.

These are the sad things that I have heard. I have seen patients come into the hospital with bed sores. They say they got them at rest homes and that they didn't have them when they went in. They had bed sores clear to the bone.

Mrs. e has touched upon a very serious problem, one that needs constant vigilance. From time to time we hear or read reports in the news media about abuses and neglect of older people in some nursing homes which are run for profit and are understaffed and unsanitary. 45

450 n the evils of nursing homes see Ralph Nader's Study Group Report on Nursing Homes, with Claire Townsend, Project Director and Introduction by Ralph Nader, 01d Age: The Last Segregation (New York: Grossman Publishers, 1971); Richard M. Garvin and Robert E. Burger, Where They Go to Die: The Tragedy of America's Aged (New York: Delacorte Press, 1968). 
Mrs. e continues to describe the problem and outlines a plan

for alleviating it.

There are a lot of elderly people that can't stay in their own home because they couldn't even keep it up. That is what's wrong. If they have children, they might be able to take care of them. But today, most of the cnildren are working. They're not willing to go and look after their parents. It is hard to find someone who can go into the person's home and not pick up the valuables and things. Some of the people "steal the old people blind."

I was feeling so sorry when they were telling me that they were going to have to go to a rest home. And I thought, at that time, it would be nice if a fellow could form a nonprofit organization of volunteer people who would go in-maybe I could go one day, and maybe another lady could go another day. If it were a big enough organization, maybe you wouldn't have to go more than once a month.

If we had some organization that they could call and say, "I'm in the hospital now, and I'm going home tomorrow, Could you send someone to help me--today, and tomorrow, and how long I needed help." If we had a list of all these people who would volunteer their turn, we could call them, and ask them if they could go to this place today, and maybe somebody else tomorrow. But the elderly people would have to know whom they could get in contact with if they needed help: maybe their lawns mowed, maybe their roof leaks. The men could sign up, and young people too. You know, there are a lot of girls and boys and men and women who could volunteer some of their time--maybe only two or three hours.

Mrs. e tells how she and her husband received help when their roof started to leak.

My husband could not get up there, and I couldn't get up there to fix a leak in the chimney. Well, I belong to the Latter-day Saints Church. They sent a man. The man came over with his daughter. She went up the ladder and gave him the shingles, and he fixed the roof. And he wouldn't charge us anything. Now, we appreciated that, and that helped. They fixed the leak around the chimney. It was coming down in the house when it was raining. But, if we hadn't had anyone to talk to, suppose we had had to hire someone to come and fix that, it would have cost a lot of money. 
Mrs. e suggests a program of people helping people and maintains it isn't welfare.

The welfare people have people who go out and help them for a little bit of pay, you know. But they don't have enough people. You have to be on welfare to get any help. You have to be down and out before you can get any money from welfare to help you. But there are an awful lot of people who have money, but they can't get help. They are willing to pay for it, but no one is going to stay and help them. . . But if we could set up a program, they wouldn't have to stay all the time. They could change off--not have the same people all the time on the same case.

The writer is reporting at length on this case, because it so admirably substantiates our theory that the causes of disengagement are in the social system and not in the old people themselves. To Mrs. e, the answer to good adjustment lies in the independence of your own home. She virtually describes the difference between engagement and disengagement.

You know that, in your home, you have your own furniture, things that make you feel like you have something to live for. If you have your property, you can get out and go and come as you please, you can have somebody out, and you have something that makes you feel like you are doing some good. Because, if the freedom isn't there /in the rest homes $\overline{\bar{T}}$, even if you feed them good--I don't know how they treat them there-but I do know that they grieve, and that they don't live too long. If you don't have the wish to survive, you just don't live too long.

Mrs. e herself is a living example of a highly engaged person whose interests extend beyond her own immediate sphere. The plan she has visualized deserves at least careful consideration. There is room for a system whereby older people could help themselves and one another. One specific need that Mrs. e mentions is better transportation. They do not have bus service on Sunday to go to church. We find that the lack of adequate transportation is being mentioned frequentiy in this research. It poses a serious haridicap for those older people who do not 
drive any more, and conceivably the city could render some assistance in this area. And, as Mrs. e pointed out, it would also help to have some kind of central information and referral office that older people could call in case of need.

Case s. Female, age 73. Married, living with husband in own home. Former high school and elementary teacher. Her husband (Case $r$ ) worked for the Internal Revenue Service. Both are retired at the present time, but they are busily engaged in a multitude of things:

Oh yes. We go at it before seven in the morning, and after eleven at night. We're just that busy. If we get to bed earlier, then we always awaken early.

This passage speaks of a great amount of energy and it set the tone for the interview. Both husband and wife are in excellent health and full of enthusiasm for all the good things they can do. They say they participate more in organizational and community functions than they did before their retirement because they have more time now. They are a very religious couple and devote a great deal of time to their church. At the same time they are filled with the joy of life. "The world is beautiful." They enjoy everything: people, children, animals. Their main occupation is remodeling their home. This is an understatement because they have turned it into a work of art. Mrs. s is very artistic, and the house is very ornate. It displays a great many religious murals and pictures.

Mrs. $s$ is a very charming and animated person and talks freely. She tells about her family:

We have been married for forty-four years. We have two lovely children, and they are married to fine Christian people, and my son has three lovely children, and the daughter has 
two. They are all normal and bright children, so we give God the glory for that.

Faith permeates the life of this couple, but it is not a means of escape or withdrawal from the world. These people believe in prayer, but they pray that the Lord may give them health and wisdom to lead a good life and to enjoy the wonderful things on this earth. They would be interested in a suitable type of gainful employment, such as working with children. Mrs. S does not believe that people change with age:

I certainly don't. I feel just as young as when we first got married. And, we're just so busy, and we visit with the children, and we play games. ...

I don't even give my age when I go to the eye specialist because I go in there to have my glasses fitted, and I don't want them to fit them according to age. If I can see better with a certain glass, then I want that glass regardless. I just don't tell people my age. I say I'm a Senior Citizen, that's all. And I don't feel that I am in a separate class. I can just go right down to the store and buy what I want. If I like a dress, I buy that dress, you know.

Mrs. $s$ believes that people should live in their own homes as long as possible--as long as they are not a burden to their relatives or to the neighborhood. She is thankful that she is not a handicapped person.

It's wonderful not to be a handicapped person. But, if I were a handicapped person, I still think that God would show me a way to be happy. I don't believe in giving up. Why should we? God never made the decision that we should give up at a certain age, you know.

Some of the high engagement of this couple is obviousiy connected with their religious fervor. They distribute religious literature, entertain church groups, and have speakers come in to pray for the sick. However, they are not fanatic or unrealistic. They believe in miraculous healing, but they also believe in doctors and medicine. 
Mrs. s says, they "go to the Lord first, and he has answered many, many times with miracles."

Religion evidently sustains these people with spiritual comfort and helps them adjust to the process of aging. But it also makes them more sensitive to the needs and problems of others and thus increases their engagement in material things:

We'll be working on the Cancer Drive in a couple of weeks now--going from house to house. We're just enthusiastic about all the problems of society, and all the joys of society, and the things that are for us to enjoy. Like I say, the world is beautiful....

And I enjoy inviting children in and playing some songs for them, and maybe a game, and give them a treat, and so on. . . And, when I find a mother who has a problem with a child, why, I have different books that I share. A mother said to me the other day, "Oh, I just can't thank you enough for sharing that book on child training. It's helped me so much in solving my problem." That might be my greatest hobby right now--aside from just bringing people back to the Lord.

It is quite obvious that disengagement does not exist for Mrs. s. She and her husband are very much alive to everything that is happening around them. Besides belonging to church organizations, they also belong to a dramatic club and take part in a number of "educational things." They are also interested in politics, and Mrs. $s$ is on a committee for good legislation. She also loves to sew. After remodeling their home, they put in quite a number of trees and redesigned their yard. They planted some bicentennial tulips in red, white and blue rows. They both want to take some courses at Clark College. And they have other plans, as Mrs. s tells us:

We're planning to go to our high school reunion, which will be the fifty-fifth since I was graduated from high school. We're trying to go to that Eastern Washington 
high school reunion of fifty-five years ago. "And you should see the letters. Of the thirty-four that were in the high school, perhaps twenty-eight are still living.

These details help project the image of Mrs. s, and give a more

vivid description of this very unusual personality. Here are some other things she and her husband are engaged in:

We always liked people, we always had people in, we like to entertain. . . We drive to Portland all the time, and we go to different entertainments at the Coliselum; at the Civis Auditorium in Portland, and we went to the Ice Arena . . . and we like to go to the home show, to show the latest in achievement, whether it's mechanical or interior decorating. We had a great time visiting that, and we enjoy historical things. We had some guests from out of town and we took them down to the early Vancouver settlement site, and they enjoyed it. We saw that some buildings, like Dr. McLoughlin's house, had al ready been rebuilt. . . . And we take our guests to the OMSI, and spend hours there. ... Then we go to the Art Museum and see the latest collections down there: . . . And we like to go out to the Zoo, and take the children to the Zoo. It's wonderful to enjoy the things that are available, you know. . . Our Senior program portrayed in the newspaper and special brochure activities for Senior Citizens. Oniy, we have been so busy with our own interests, that we haven't had a chance to take them on. But we do want to take the trips with the Senior Citizens Outreach Program, and we kind of want to get busy with the program too. We haven't found time for that yet.

Mrs. s says we should look to the Scriptures for guidance to a better way of life.

Just use the guidelines the Lord gives us on how to relate to your neighborhood. Then you are going to be kind to the young, the middle-aged, and the old. Be gentle, kind, helpful, trustworthy. And you are going to be loyal to your government. I'm so grateful that we have an embiem "In God We Trust."

No one would question the beauty of such principles. For Mrs. s they certainly have worked. She radiates cordiality and good will. It is uplifting to visit with her. Mrs. s does not believe that life is 
over at sixty-five. She and her husband lived in Pendleton before coming to Vancouver, and they made a great number of friends there.

One of our friends asked us to come back and celebrate her ninetieth birthday. She still lives in her big house with five bedrooms, and everything is just immaculate. Her house looks like she is expecting company every day. ...

We went to the entertainment, and when we got to the club, they greated us at the door, and they had a big cake for her, and she gave a beautiful speech and read some poems for inspiration. . . So I don't think that you need to lay everything aside just because you get to be sixty-five. . . . I think we have much to offer because our life has been enriched by experience, and books we have read, and friends we have made. And friendship is more important now than ever before.

We're having such a wonderfur time--just being busy. So we really haven' $t$ any leisure to sit and watch television. So, that's the way it is.

And we feel that Mrs. $s$ has confirmed our hypothesis for us--that there is no inevitable intrinsic disengagement.

Such people are an untapped resource. They are in good health and willing to work. One might be able to recruit them, at least on a part-time basis, for a program to help other older people.

Case a. Female, age 73. Widowed, living alone. Health excellent. By profession musician: pianist and organist. Still "goes out and plays for somebody once in a while." Would prefer to be gainfully employed, and would work if there would be no reduction in retirement pay. "I would sure like to have a professional job." She lives in her own home in a suburban district and must drive a car because bus service and other conveniences are lacking. "The car seems to be your freedom."

Mrs. a has raised a family, but the children have "grown up and left." She says she sees members of her family weekly, and she visits 
with friends and neighbors two or three times a week. Her community and social activities are "about what I've ever done." She belongs to a church and goes there once a week.

There have been no major changes in the life of Mrs. a recently, but what has changed is her economic situation. She is on fixed retirement pay and feels the inflation. She has been keeping track of her food bill lately, and says that the rise in prices is shocking. Her hobbies are reading, sewing and gardening, but keeping up her home takes a great deal of time and she says she needs a housekeeper. But what she really needs is more money.

Mrs. a has a sharp intellect and is critical and outspoken. She goes to the City Council and "stands up and speaks her piece." She resents that Senior Citizens are put to a disadvantage, but she is just as critical of them as she is of the rest of society: "We have been dumb to the extent that we have let this happen to us." Mrs. a believes that older people should let their views be heard and that they should stand up for their rights. However, she realizes that there is a difference in the ability of people and says, "some people were never worth a hoot anyhow." Thus she has expressed what this researcher believes is true of disengagement, namely, that it is a function of a personality. She continues:

About twice a year I go to the Marshall Center to play bridge. And, as I look at those people, I think some of them look like they were never very--never had much initiative. And, then, some of them would be afraid to put their name on a petition. If you handed them a petition, they would be afraid to sign it. And yet they grumble to each other. 
To remedy their situation, Mrs. a thinks older people should participate more in politics although some of them consider it a "bad word." She feels that the salaries of our representatives are too high and that they get too many benefits. 01der people should watch what laws are being passed and how the Social Security fund is being handled. They should remove their representatives when they don't do what they should do. "If we hadn't let go of the reins, if we hadn't been acquiescent, they would not have been able to pass some of these laws." Mrs. a believes that some of the money which is being paid out in enormous pensions or is just being wasted by our legislators could have been better spent in helping the blind and the needy.

Mrs. a says retirement is a shock, and in order to improve their conditions, older people will have to work together.

To summarize the characteristics of the high-high category, we observe that all four respondents are in good health; they live in their own home; and they have had a career or an occupation. They have an active mind and lead a very busy life. All of them are interested in at least part-time work if it would not reduce retirement benefits. Three of them are married and living with spouse, and they are the most satisfied. The fourth (Mrs. a) is widowed and finds life a great deal harder, but she has remained highly engaged because of her strong mind and very definite ideas. Transportation is a vital factor in the engagement of all these people, and they have pointed out how it could be improved upon. 
Type II. High Attitudes - Low Activities

In this analysis we hope to discover why older people who have endorsed attitudes in favor of engagement have not made high scores on activities .

Case 1. Female, age 75. Widowed and living with her sister in an apartment of public housing. She says her health is good but she was getting over the "flu" at the time of the interview. She "worked out" when she was single; was a housewife after getting married. Is now keeping house and doing sewing for her daughter and grandchildren. Her hobby is fancywork. Economicaliy, she "has no money to throw away; gets along pretty-we1l, though." She divides expenses with her sister.

Mrs. 1 used to go to Eastern Star meetings, but she has no way to go now because she does not have a car. So, again, we have the problem of transportation. As a result, Mrs. 7 has concentrated her attention on her family. Her daughter lives close and she has quite a few relatives living near her apartment. She has five grandchildren and two great-grandchildren. Mrs. 1 and her sister also visit friends in the vicinity to the extent that they can without a car. They also have friends to come and visit them.

Mrs. 1 evidently feels that older people could do a great deal more than she is able to participate in. She rated housing for retired people in her neighborhood as "poor" and she is not very satisfied with the medical facilities available to her. These deficiencies, in addition to lack of transportation, would certainly reduce her amount of engagement. But she also was depressed because of the general economic situation. She is worried primarily about her family. 
What I'm concerned about more than myself are a lot of other things. You know, like these kids that are growing up now with things the way they are. They will have no chance to buy a home from what I can see. You know, as

far as that is concerned, it's doing the harm that I can see.

Case t. Male, age 75. Married and living with wife (Case u). Mr. $t$ is a former auto mechanic, but now he is "not very well." His wife (Case u described under high-high type) is obviously his inspiration, and hence the high score of Mr. $t$ on attitudes. He sees his wife being busily engaged; but he himself is resigned to passive participation because he has had a heart attack and surgery. However, he seems to share his wife's tastes and to enjoy accompanying her when he can. It definitely seems that he would do more if he-could. He al so mentioned the lack of bus service on Sunday.

Case d. Male, age 84, living with wife (Case e, described under high-high type) in own home. Health "poor," had a heart attack. But has given up smoking and is feeling better. His wife is taking care of him. Mr. d retired at age 65 , and is now working in their yard when he is able. He is reading and watching television.

This may again be a case of vicarious involvement. Mr. $d$ watches his wife (Case e) being highly engaged and therefore endorses high participation for older people. The conveniences that he names as lacking are better health care and transportation. His concern, like his wife's, is to be able to stay in their own home.

Case v. Female, age 83. Single, living alone in an apartment. Health "could be better." She has a little heart condition which she has to watch. She says it has been coming on gradually. However, she 
takes some medicine to help her and seems to be "getting along all right." Miss $v$ is a retired milliner who has a number of other talents and interests.

Miss $v$ used to design hats and she is really an artist. This is what her card on her door shows. She has a special talent for painting landscapes and colorful flower arrangements, and her apartment is decorated with her own work.

When Miss $v$ filled out her survey form, she was too modest in listing her activities. She belongs to an art group and is active in it. She also belongs to the Altar Society of St. James Catholic Church and to the Catholic Daughters of America, a national organization. Furthermore she belongs to the St. Joseph Community Hospital Auxiliary, where she does volunteer sewing. She also tries to visit the sick. In spite of her health problems, Miss $v$ says she spends more time now with organizations and friends than she was able to do while she was working. But she cannot push herself too hard. She says she could participate in more things, but her heal th would not permit it.

It was a pleasure to visit with Miss $v$. She is a pretty, wellgroomed woman with gray hair and a young-looking face. She lives on fixed income and has to watch her expenses. Social Security is the only thing she gets from the Government. But she says she could not live on it because she did not get a very high salary when she was working, and she does not get a pension. But she has some "other interests coming in, and some savings, which helps." She does not complain as she has always been a very frugal person. 
Miss $v$ said several things which directly concern aging and the problem of disengagement. She does not think that older people should be separated from the rest of society and kept by themselves in homes or communities: "I think it's better if you associate with different ages." She herself feels that she is still part of the larger community like everybody else.

I still feel that I need it and want it. And I know that I am, because I have lots of friends. 0lder people are part of society. We older people have worked for all that--for all the freedom that they have. And we were young at one time too. I think we have lived through many of those phases that they have to live through nowadays, and we know very likely what they are going through.

Miss $v$ does not get lonesome because she keeps busy all the time, and sine has some comments which fit right into activity theory:

If you have good health, why, I think then you should stay active. Then the age is all right. I don't think that age makes much difference.

Miss $v$ also has a suggestion for housing for older people:

Permitting Senior Citizens to live in low-cost housing, even if their income is above the stated limit. I would be glad to pay higher rent, according to our income.

This section has brought out some significant facts with regard to the causes of disengagement. Even though the older person may endorse high activity and feel that older people are capable of doing these things, there are often unfortunate circumstances which interfere. In these cases high activity has probably been discouraged by widowhood, $i 11$ health, not having a special interest or a profession, not being satisfied with housing, and a lack of transportation. 


\section{Type III. Low Attitudes - High Activities}

The activity scores in this typology are not among the highest in this survey, but the fact that they exceed their respective attitude scores calls for attention. According to Blumer (1969, pp. 40-45), this is exploration followed by inspection.

The interesting part is that all these people were formerly self-employed. It is possible that they did not feel the strain and pressure of employment as much as did the others who were interviewed. For this reason their response to the attitude statements may have been different.

Case k. Female, age 76. Widowed, living alone in an apartment. She says with regard to her health: "It's excellent. All but my arms [she probably has arthritis]. It is pretty good, though. I make it work. I don't want to baby myself. The only thing I'm careful about is when I walk, and step over to walk, and things like that, because I don't want to be an invalid, you know." This answer gives us a clue to the independent nature of this lady. She is a beauty operator, a "cosmetologist" who ran her own shop until she retired at the age of sixty-nine. She grew up in Washougal, where her father bought a store in 1905. She studied voice and sang in the choir in Washougal. The church there will always be something special to her, al though now she belongs to the First Presbyterian Church in Portland. She goes when she wants to go, but she does not want to be forced into doing anything. This is typical of Mrs. k's personality. She was born under the sign of Leo, and she feels she is different. Her hobbies are astrology and music. 
Mrs. $k$ is not an active church or community worker. She belongs to the Rebeccas, but she feels there is too much discord in their groups. She does not want to be tied down, but likes to do things impromptu. At the same time she is very busy. She has not had time to go to the social activities of Senior Citizens. She never did care for lodges, never was a joiner, but now there is the added problem of transportation. Her husband and her son always did the driving. Besides, she does not want to go out alone. She goes to church in Washougal with her sister, or to Portland with her family, but she has no escort to go to parties. Therefore she now gives less time to organizations than she formerly did.

The same applies to friendship. Mrs. $k$ sees her friends less often. It is not because she doesn't want to. She cannot get to them. She still has many friends in Washougal, and she sees them whenever she goes up there. Some of her friends are in rest homes. She goes to see her few special friends there and calls them often. She values her time and spends it on the things she realiy wants to do.

We1l, I don't seem to have enough days for some of the things. Whenever I get a chance, I go up home. I take the bus. It doesn't take long to go up there and come back when I want to come back. And my younger sister, she likes to have me back there. Then I do the cooking, you see. We have time to play cards, and stuff like that.

Mrs. $k$ has two sons, one is a stepson. They come and take her shopping. Mrs. $k$ has always had a very close family relationship, and that may be one reason why she was not more sensitive to the attitude statements:

We were a family of six living close enough to visit once a week. So am not qualified to say. Happy family-expecting my first great-grandchild. Keeps me happy. 
Mrs. $k$ evidently does not realize the plight of some older people who are being pushed aside. She, in fact, has grown up in an extended family.

Well, I wouldn't know because we had Grandma living with us for many many years. They had three daughters who didn't want to be bothered. And here Dad was the only boy, and they /the girls/ never had more than two children neither one of them. And they could have very well kept them, but they felt they couldn't afford it or something. I don't know why. And Mother, who had five girls and a boy of her own. . . Well, I think Grandpa just wanted to be where we girls were because we were always at the piano-singing and playing. And Dad would sit right there, and Grandma would sit right there. Why, Grandpa wouldn ${ }^{i} t$ miss that for anything in the world. We were a close family.

Mrs. $k$ has more freedom since she retired. She enjoys wearing her nice clothes which she could not wear while she was a beauty operator because she had to wear a uniform.

In another way things are worse, since Mrs. $k$ feels the inflation. She has some investments in stocks, but she did not receive the extra dividend she was expecting. She had hoped to take a trip, but now she could not do it. So here is another type of disengagement which has not been considered in disengagement theory.

Nevertheless Mrs. $k$ wants to stay involved. She does not want to "get stale." She reads Newsweek in order to know "what is going on." One problem that Mrs. $k$ found very severe was noise. In her case it was "cruising." She says some "kids" were racing up and down on her street, day and night. "It wouldn't be so bad if they did it tiil eleven o'ciock, or something like that." But, in fact, the noise got worse because the boys knew that Mrs. $k$ was reporting them to the police. older people are sensitive to all kinds of noise, and several people in this survey reported that they were bothered by it. 
Case y. Male, age 80. Married and living with wife (Case $z$ ) in own home. Health excellent until about a year ago. He may have a little heart trouble at this time, and has to be careful. He and his wife lived in Alaska for forty-five years and they were self-employed. They originated and published the Alaska Magazine, and Mr. $y$ is still contributing to this magazine. He retired from his regular work because there was "no need to work gainfully any longer." He and his wife moved to Vancouver, Washington, from Ketchikan, Alaska, but they have been going back for visits to Alaska.

Mr. $y$ describes himself as a very busy person, deeply involved in many activities and hobbies: writing, photography, travel, lecturing, stamp collecting, and so on. He likes to give talks about Alaska, and gets many calls to lecture about "the last frontier." He is a fiftyyear Rotarian from the Ketchikan club. He has gone on many trips to lecture, but lately he has confined his talks to various organizations around Vancouver. He does not drive any more, and his activities are restricted to that extent. He has had to slow down Lecause of the change in his health and needs someone to take over the yard work, but he enjoys doing as much as he can to keep up the home.

The home is located in a new residential district, next to the central city, and it is noteworthy how pleased this couple is with their home. Mr. $y$ rates the housing for retired persons excellent in their community, and says that no conveniences are lacking. He and his wife are both very satisfied with the medical facilities available to them, and they both state that their neighborhood is "ideal." 
Their home is beautiful and shows many art treasures from Alaska. There are paintings and figurines which are steadily rising in value because the artists have died and their unique work has become rare. To Mr. $y$ and his wife, these things represent a good investment, but they also evoke fond memories of the past and thereby help adjustment to the present.

This is a case where an ideal location and availability of services help an older couple be happy and contented. If they could drive a car, they might participate more socially, but they have stayed busy "in a different way." What Mr. $y$ advocates for other older people is: "They should be urged to get out and volunteer their services to the best of their abilities."

Case z. Female, age 76. Married and living with husband (Case y). Health excellent and appearance youthful and animated. This case is really a continuation and a supplement of Case $u$, and Mrs. $z$ is very good at filling in some gaps and completing the story. It is fascinating to 7 isten to her:

"Although I'm seventy-six, and my husband is eighty, we don't feel old. And we don't feel neglected because we worked all of our lives-both of us--and we made and saved a little money, and we're not in need of anything." She and her husband wanted to do something else after retiring. She tells us about their present activities, but we also hear about their background.

We haven't stopped doing anytihing excepting our regular work. We were a long time in Alaska. We lived there for forty-five years, and we were self-employed. We published The Alaska Magazine--The Magazine of Life on the Last Frontier. That was quite a challenge, starting from scratch, you know. And, of course, we found that it involved much more money than we had, but we never gave up and kept right on 
going. We started this in 1935. It was during the height of the Depression. We used our enthusiasm. We stuck right to it, and made it work. We sold it in 1958.

Mrs. z likes to garden and is busy keeping up her place. But she and her husband are also busy writing.

My husband writes. He writes for the magazine. He had a story in the issue before this one. And I'm writing the history of Willard, Washington. I was born and raised there, so I'm the natural one to write it. We still have a little cabin up there.

Mrs. $z$ is a former school teacher:

I taught first at Willard, and then I taught in Seattle. Then I got a position at Seldovia, Alaska, and that's where I met my husband up there. I was a teacher when I got married, and I taught a year or two after that. But we soon became so busy in our own business, that I gave it up, and devoted all my time to the business.

Mrs. $z$ says that they see their friends less often now since they do not drive a car and have moved down here. Up in Alaska, they saw their friends more often. Friends used to drop into their place of business. She also feels it takes a little longer to make friends when you are older.

Their only daughter was born in Alaska, met her husband there, and they were married in 1951. Until recently they lived in Minnesota, but now they and their youngest child have gone back to Alaska. Their two older children are married and are still living in Minnesota. This shows that the family is rather scattered. But Mrs. $z$ says that they see one another about once a year anyway. They come to Vancouver, or Mrs. $z$ and her husband go up to see them.

Mrs. $z$ and her husband are members of the Christian Science Mother Church, but they have not joined the local church. Mrs. $z$ has been a 
member of the Mazamas for about sixty years. She was only sixteen when she joined. She has always enjoyed hiking and climbing, but she does not do any climbing anymore. However, she does take part in the activities of the Soroptomist Club. She joined in Ketchikan, and is a life member now. She goes to the local chapter which is quite a busy club. Mrs. $z$ and her husband also belong to several historical societies in Vancouver, in Oregon, and in Ketchikan.

Perhaps Mrs. $z$ and her husband participate a little less in various activities than they formerly did, but they are still intensely busy. From time to time they go up to their cabin in Willard by a rushing stream. Mrs. $z$ says they enjoy the freedom to come and go as they like. They have more time to get into life and to become involved, and they meet many interesting people at the organizations to which they go.

Mrs. $z$ feels that life is good at this stage--as long as they are together. They enjoy things together and "it means everything." She feels very sorry for people in nursing homes, and she thinks that segregated communities are "such a mistake." She says they should live like people and not like "old people."

Mrs. $z$ is interested in all the current events, and she believes other older people "should find appropriate interests and keep busy at something." Thus there is no indication of disengagement even at an advanced age. It has been brought out that these people have retained their individuality and have not undergone the ego change that would make them withdraw from "others in the social system" (Cumming, 1964). In fact, Mrs. $z$ makes this point quite clear. She believes that older 
people need to feel wanted, and that "you can't go by the years. Some people are reaching the best part of their lives when they are sixtyfive--a time when they are most productive."

Case i. Male, age 72. Married, living with wife in own home. Had a grocery store in McMinnville for ten years, then drove a cleaning and pressing truck in Vancouver. His wife (Mrs. j) was a professional piano player. She played for the church, directed choirs, and taught piano at home. They are both now retired; he wanted "to get off the truck," and she wanted to retire when he did. They are both very busy at the present time "in a different way." They engage in a number of hobbies, and they do many productive things. Mrs. $j$ said, "Whatever you enjoy doing, that's what you want to do." This is, of course, paraphrasing the American formula for happiness, but it works for these two people. They are devoted to each other, and they have mutual interests. That is why it was decided to discuss them as a unit. They were supplementing each other's accounts during the interview, and helped the researcher clear up some of the discrepancies on the original survey form.

Mr. $i$ and his wife are by no means "disengaged." They feel they have more and better friends now than they formerly did. Mr. i had many acquaintances on his route, but now they have more time to see their friends. $\mathrm{Mr}$. $i$ belongs to the Masonic Lodge and attends meetings; Mrs. $i$ belongs to the Eastern Star and to the Rebeccas. She does not attend meetings any more, but she and her husband play pinochle with friends at the Rebeccas. 
Mr. $i$ and his wife are both in excellent health and raise a big vegetable garden. They also cultivate roses, and they both belong to the Rose Club. They are both 72 years $01 d$, but Mrs. j says, she feels more like being 30 . They keep we17. They have good doctors and they get a check-up every six months. They feel "they have been blessed."

Mr. $i$ and his wife have one adopted daughter who lives in Seattle. They have two grandchildren who live in Portland, and whom they go to see every Sunday for a little while. Mrs. $j$ says, "That gives us a boost when we can't see her."

Mr. $i$ and his wife are a friendly, religious, Bible-reading couple. They are not at all withdrawn. The secret is that they have so much to enjoy at home, that they do not devote much time to outside activities. Mrs. $\mathrm{j}$ does needle-point and embroidery; Mr. i collects walking sticks. Mrs. $j$ plays the piano, and Mr. $i$ sings as she accompanies him. The baby grand piano in the living room as well as their record player call attention to their love of music. They told the writer they had just bought some new records--all classical music. What added to the homelike atmosphere, was a huge cat stretched out in front of the fireplace.

But what really strikes one when one enters this home, is the stupendous view. It is indeed overwhelming: every room has a view, and the windows take in a whole wall. The interviewer can well understand that people would enjoy staying home and looking at such a breathtaking sight and never tiring of $i t$. These people believe that the Lord heiped them find this place. In the words of Mrs. $j$ : 
We're grateful for it. That's what we always say, we're so grateful to the Good Lord for all we have, and our view, and everything. And we love to share it. We love to have people come and see it.

There are many other beautiful things to admire in this lovely home. It contains a wonderful collection of antiques which include lamps and dishes.

We have all antique furniture and we have collected antique dishes. We have done that for about fifty years--ever since we've been married. We've been married almost fifty years, and we've collected antiques that long. We went and got them at second-hand stores, and we have refinished all of our antiques.

All of the wood in the furniture is walnut, and some of the pieces are over one hundred years old. Evidently these people are connoisseurs and their collection of antiques has become a very good investment for them. It is something that they can continue to work on and to enjoy after retirement. They had their antiques appraised not very long ago, and Mrs. j said, "you'd be surprised how much we have in antiques."

These two people read a great deal and keep broadening their minds. They say they "keep themselves up." They are concerned with what is going on in the community, in the nation, and in the world. Mr. i feels that older people may vote more regularly than some younger people do.

Mrs. $j$ believes that "life is better after forty."

For this category as a whole we can say that these people are well adjusted. They are intensely involved with home and family, and they identify themselves with society as a whole rather than with the old. 
Type IV. Low Attitudes - Low Activities

This combination of scores obviously suggests that there are problems and these interviews have attempted to look into some of them.

Case 0. Male, age 72. Divorced. Living alone in own home. Health: poor. Right from the start we can see several reasons why this aging man might not be too well adjusted or too highly engaged. Mr. o belonged to the Boilermakers union and worked for a number of machine shops. He is an arc weider by trade. Since retiring he is just taking care of his house and place and "works when he feels like it." His hobbies are flowers, roses. He was also putting in some tomato plants. The house was in good order, and the yard was well kept. In the front there was a beautiful big holly tree full of red berries.

In the yard there also was a swing, and this swing is a strategic item in the public relations of Mr. 0 . It invites the children of the neighborhood to come to visit with him. That is his other hobby: he loves to play with the children.

I spend a lot of time with the kids. I got a lot of young ones around here, you know. My niece used to live right down here, and she'd call me "uncle." The rest of the family was uncle Albert, uncle Will, and uncle so and so. But I was uncle. So she'd bring all her little friends up here and introduce me as "uncle." We11, they'd call me "uncle." She's a schoolteacher now, but the kids still call me uncle. So I've been "uncle" for the last twentysix years for all the kids in the neighborhood. And for older people too. One of the ladies going down the street here one day, collecting for some fund, called me "uncle." I looked at her, and she smiled and said: "I'm Sally's mother. If Saliy could come ip here once a day, she'd have her day made." Sometimes they come back after years. And, of course, they all know me, but sometimes it is hard to recognize them. You know, after a few years, they're going to grow. 
On the wall in the living room there were some very nice pictures made by school children. One of them had an inscription: "To Uncle, from Laurie." He said, "Oh, I appreciate them, you know."

Otherwise, Mr. 0 is rather reserved in his manner. When asked about his family, he said his niece comes to visit him, and his brother comes to take him to church. Mr. O belongs to the Peace Church of the Brethren, and he goes once a week. He enjoys going to church and to visit with some people that he knows over there. He says, some others of his relatives also come over to see him.

Mr. o stresses that he is not a "loner." He says, "When I'm out here in the yard, everybody that goes by waves at me. They al1 know me, everybody in the neighborhood." Life in a high rise building would not appeal to him:

Some of them will go into homes, or move into an apartment way up in a building. They have one downtown here, I think it's eight or ten stories high. They move up to the top in it and sit there, day after day. That wouldn't be for me--not as long as I can avoid it. All you can do is sit and look out of the window.

From the conversation it was evident that Mr. o keeps track of what is happening in the community, and that he also follows the national news. He is not disengaged and does not want to feel isolated, al though he emphasized that he is very independent.

What depresses Mr. 0 is his healtin. He remarked that he is very dissatisfied with the medical facilities available to him. He would like to see some new health programs. "Medicare charges us more and gives us less." He has diabetes, and has to watch that. He is on a diet. His outlook on life and his amount of social participation are directly affected by his personal circumstances. 
Case f. Male, age 84. Married and living with wife in own home. Health good, although he has had "little spells" [heart] in the last few years. His wife (Mrs. g) has a "pacemaker." They both have eye trouble and cannot drive any more. However, one of their sons lives across the street from them. He takes them to church and provides some other transportation. Nevertheless, Mr. $f$ and his wife do spend most of their time at home. They raise a large vegetable garden, and Mrs. g raises flowers, "the kind that's lots of work." She keeps house and bakes cookies for the church. Mr. $f$ is interested in interpreting the King James version of the Bible, and he talked about some of his views. They both still belong to a club which was formerly called the "Golden Age Club," but was renamed the "Forty-niner," in order to get younger people into the organization. They see their friends somewhat less since they do not drive.

Mr. $f$ and his wife recently celebrated their 65th wedding anniversary. They are both from Missouri, where they were married in 1911. Mrs. g taught school before she was married; Mr. f grew up on a farm. They have now lived in Vancouver, Washington, for over thirty years. They had five sons and two daughters. Two of their sons have died. They have nine grandchildren and nineteen great-grandchildren. There is a distinct difference in the personalities of Mr. $f$ and his wife, and the interviewer was able to get some explanations which are important for our theory of continuity. We were primarily interested in checking on the low-low score of Mr. f. He has simply maintained the rate of engagement that he had been used to. He said: "You know, I was raised a 'loner.' My mother died when I was going to 
be six. Then I stayed with my grandmother, then my father bought a farm." The boy was always left to his own company while living on this farm. His brother was six years older than he was. He never had any playmates.

His wife has an entirely different background. She comes from a family of twelve children. "With Mother and Dad, it made fourteen." She had always been used to being around many people, and therefore her answers reflect engagement in attitudes and activities, with scores of 19 and 12, respectively, compared to her husband's 4 and 4 . Besides being a housewife and church worker, she goes to see the elderly at homes and other places.

Mr. $f$ left his father's farm and worked for the U.S. Post Office in Missouri; then he worked for several construction projects in Idaho and in Washington. He finally got a job as a Post Office clerk in Vancouver, where he worked until retirement at the age of 68 .

Mr. f says, he can still "make a living" in spite of inflation and rising prices. It helps to raise a garden, and to have their home "free and clear." They did some selling and trading of property, fixed up a place and sold it with a profit, and traded in their present home. $M r . f$ is very pleased with his investments and they both enjoy their home and doing as they please. That is quite enough for Mr. f; however, his wife says, "I always like to be with a bunch of people--a lot of people."

Case p. Male, age 88. Living with wife (Case q) in own home. Heal th good, but cannot do very much work any more. He works a little in the yard when the weather is nice. He still drives his car and does 
the shopping. "Just keeps going." Mr. p worked for the Burlington Northern Railroad, where he started in 1907. In 1914 he was promoted to engineer. He retired in 1959 at the age of 72 . The railroad is part of the life of this family.

The last fourteen years I worked I was on the Streamliner out of Portland, you know, that went out and went up the river. That was my last fourteen years. I put in fifty-two years rail roading. There are only three engineers around my age of that personnel that are still living.

Our oldest son is an engineer on the road too. In fact, all of my three boys are railroad men. One is in 0ttumwa, Iowa, with the Burlington Northern, and our youngest son is roundhouse foreman in Yakima.

Mr. $\mathrm{p}$ and his wife also have a daughter, who teaches retarded children at Fruit Valley. They have thirteen grandchildren and fourteen great-grandchildren. This is another couple who has recently celebrated their 65th wedding anniversary.

Mr. $p$ and his wife cultivate flowers, especially roses. But he has several hobbies of his own. He "putters around" in the basement, fixing furniture, toys, and so on. His most absorbing pastime, however, is working with rocks--making ornaments, such as bracelets and neck1aces. "I'm a rock hound, you see. I've got quite a work shop down in the basement. I've got any kind of a tool you want to work with on rocks: saws, polishers, grinders." His fingers are not quite as dexterous as they used to be, and he cannot do the fine work any more, but he still treasures his collection of rocks. His wife tells the following story:

Oh, when he first started in, you couldn't get him away from it. I went to lodge one day, and he was supposed to come and pick me up at a certain time. And I waited, and I waited, and I waited. Then I thought, "Well, I'm just going up and take the bus and go home." And he came about the same time--decided to come down for me as I was going to get the bus. 
The other major hobby of Mr. $\mathrm{p}^{\prime} \mathrm{s}$ is reading. He has a wonderful collection of books, which is continually being increased by gifts from his grandchildren who know of his enjoyment of reading. He loves history and likes to keep up with what is happening in the world. Thus, Mr. $p$ finds it necessary to slow down, but he is not severing himself from the rest of the world. He and his wife belong to the Catholic church and attend Mass regularly. They both belong to the AARP and go to their meetings in Vancouver. Mr. $\mathrm{p}$ also belongs to the retired railroad people, and his wife belongs to the "Engineer Ladies," which is the Auxiliary to the Engineers. Those meetings are held in Portland, and Mr. $\mathrm{p}$ and his wife attend when somebody from Vancouver goes over there. Mr. $p$ does not like to drive his car over the bridge any more. But he does like to be with his old friends:

You know, once a month they give a dinner--a pot luck-one month here in Vancouver, and the next month it's in Portland. We went down there the other day, and I sure enjoyed that. I don't go a lot; I will miss it at different times. But I run into so many fellows that I used to work with, you know. They are all retired, and scattered around, and, my gosh, I enjoyed that.

Case q. Female, age 84. Married, and living with husband (Case p) in own home. Health good until about a year ago. She had a stroke at that time, and another slight spell about a month before this interview. She got over these spells pretty well, but she thinks they take a certain toll. She is still keeping house, though, because it is hard to find somebody to help with the work.

You can't get anybody that knows anything. Once upon a time you could get a woman in here that didn't have a home, and she'd be just tickled to death to come and help you. But you can't get anybody any more since they've been on Social Security, and Welfare gives them anything they want. 
Mrs. $q$ says that they will simply have to find someone to help them. Their grandchildren used to come down and do some things, but they have grown up and they are gone. Two of their sons have moved away. Mrs. q said: "Now we need those kids, and now they're gone." Their daughter and one son still live relatively close by and see them often. They also have "wonderful neighbors all around them" with whom they visit. Mrs. q says: "I like people."

The people Mrs. q enjoys most are her own family:

We enjoy our family around us. I think that's the best part of your life. You found your family, and the young ones come along, and then they get married, and they have their husbands and their children come along--I think that is the best part. . . They're all so good. We've been fortunate to get good daughters-in-law.

Mrs. $q$ told about their family reunions, and about some trips to their cabins up on the Washougal river. They have a little cabin for themselves up there, to which they go sometimes.

Mrs. $q$ is distressed about rising prices. She does not like to shop any more because everything she buys costs so much more. And taxes have gone up too. She says, economically, they are getting along, but Mr. p's pension is fixed, and they are not able to get anything new.

However, this gentle, charming women is used to managing things. She said, "When you raise four children you don't have much to go on." They built their home in 1914: "We just built three rooms to start with. We didn't have any money then. We haven't got much now. But we didn't have a thing." There is a pioneer spirit about Mrs. q. She says they taught their children to be good citizens, and they taught them the value of money, and they taught them the value of work: 
When we raised our children, why, they had paper routes, and they had magazine routes, and they'd go and put in wood, and they'd put in sawdust. They kept busy, you know. . . And this was all wilderness up here practically when we built. They had all this to play in, you know.

Mr. $\mathrm{p}$ and his wife have lived 62 years in their present location, and they still feel part of their community. Their low scores are no doubt attributable to their failing health, which is of course connected with advancing age. They simply realize that they cannot work very hard any more. But the interview revealed no change in ideology, and there was no indication of a compulsion to disengage from the social system.

As a whole, the interviews proved very rewarding. They have given us first-hand acquaintance with the life of various groups of older people, and we have learned of some of their problems. The personal data we have received have shed light on some differences in engagement. It is amazing how some statements by the respondents confirm our hypotheses. For instance, one lady said: "There are people who will carry into their retirement years the same characteristics of non-involvement that they had in their earlier adult years. To change them would be a real chore in personality development."

There also emerged certain needs which will be discussed more fully in the next section. Some people would be more active if they had additional conveniences. However, the writer whole-heartedly agrees with another statement by Brotman:

The popular picture of the decrepit, doddering oldster is so gross an exaggeration as to be completely misleading. The overwhelming majority of older people can easily manage in the community if society permits. They could manage even better if society would encourage such activity through the provision of essential services (1972, p. 5). What is most needed is a new "definition of the situation." 


\section{THE LIFE HISTORIES}

It has to be kept in mind that, in investigating disengagement, one deals with change over time. A technique that is ideally suited to detect such changes is the life history. It permits us to study the development of the same individual and to judge observed changes against his own baseline. As Maddox (1965) says, "the use of each individual as his own control minimizes the chance of producing artifacts" (p. 327). Another advantage of studying the individual case brought out by Paddox is that it "makes possible the identification of the persistence of life style of the individual" (ibid.).

The life history permits us to penetrate beneath the surface and to view the inner life of a person as that person gives an account of his or her experiences, including feelings and observations. Denzin states that the "central assumptions of the life history are that human conduct is to be studied and understood from the perspective of the persons involved" (The Research Act, 1970, p. 220). He stresses the value of the subject's "own story" (p. 221), and he points out the close relationship between the life history and symbolic interactionism: "A theory that stresses the 'subjective' side of social experience demands a methodology that explicitly focuses on such data" (ibid., p. 258).

Many authors have successfully used the own story and the life history method. ${ }^{46}$ For instance, Clifford R. Shaw, in The Jack-Roller

46

See Denzin, The Research Act, 1970, p. 258 (Notes) for sources of statements on the life history method. 
(1930, rpt. 1951), has illustrated the method in the story of a delinquent. According to Ernest W. Burgess (in his Preface to the book, i 930 , p. $x i)$, "If Mr. Shaw did not invent, he has perfected and rendered usable /this method as an instrument of scientific research." What the "own story" here reveals is: the point of view of the subject, the social and cultural situation to which the subject is responsive, and past experiences and situations in the 1 ife of the subject. These observations can very well apply to the field of aging and to the problem of disengagement.

One of the most significant applications of the life history to sociological research is Thomas' and Znaniecki's Polish Peasant. 47 It is considered the greatest contribution of both these men to the symbolic interactionist point of view, and it contains the most significant theoretical work done by Thomas (Don Martindale, 1960, pp. 349-350).

In this monumental work, Thomas and Znaniecki placed particular emphasis on the definition of the situation and on transitional problems, that is, being forced to move from one setting to another and having to adjust to a new situation. The problems which arose were too complex to be adequately investigated by the usual methods, and a new approach was called for. What measurements does one apply to definitions of the situation or to life organization? Thomas and Znaniecki advocated the

\section{7}

William I. Thomas and Florian Znaniecki, The Polish Peasant in Europe and America, 5 vols. (Boston: Richard G. Badger, The Gorham Press, 1918-1920). 
life history, the detailed personal narrative, and the exhaustive study of the individual case as appropriate methods to their materials (Martindale, 1960, p. 353).

Definitions of the situation, transitional problems, and problems of adjustment are all present in the world of the aged. Therefore, the methods applied by Thomas and Znaniecki, and their "synthesis" of symbolic interactionism (Martindale, 1960, p. 363), seem germane to the study of aging.

What the present writer has endeavored to do is to use the narratives of the subjects to show their attitudes and activities at different points in time, and thus to locate changes. We can also make meaningful comparisons between our objective and subjective measures to strengthen our evidence. When Cavan et al. (1949) devised their Inventories of Activities and Attitudes, they recommended a comparison with other measures of personal adjustment, including the life history:

In a new field, such as the study of the personal and social adjustment of old people, it is important that the results of the different studies be coinfarable with each other. When they are, the findings a.'e not those of single isolated studies; they have the larger significance which comparison with the data of other studies offers ( $p .148)$.

The three case studies which follow supplement the data gathered from the questionnaires and the interviews.

The Life Story of D'Brooks Hogan

Our first life history is constructed from a voluminous autobiography written by Mr. D'Brooks Hogan, who is domiciled at the Victoria Nursing Home in Portland, Oregon. Mr. Hogan is 85 years old. He maintained residence in his own home until he was in his early eighties. His 
writings extend from his childhood to the present time, and can be used to analyze an individual case over a long period of time. This gives us insight into his adjustments to later life.

There are more than 19 Volumes of Hogan (Annye Nonymus)* writings. The earliest are typewritten; later ones are hand-printed on tablets. The entries, as well as the pages, are numbered. The writer has selected those thoughts and parts of the diary which cast a light on Mr. Hogan's attitude toward disengagement, and on the consistency of his world view throughout the years. To set the tone, we begin with the following:

I am a "shut in." I am old and full of pain; But, still I honestly believe that if I had but one wish left it would be that every one could get at least as much out $0^{\prime}$ life as I do (Vol. 2, 531, \#7018A).

D'Brooks Hogan has written his own story. From what he has written we gain a picture of the man and his life, and we can compare his personality in his younger years with his personality as it is now. A great deal of information about the man is contained in a passage of comparatively recent entry:

I constantly strive to keep sufficient mental balance (at 83) take care of my own individual needs, with pride, just so far as the mechanized book-keeping methods of the day will keep those individuals to run my life - in their handicapped younger, greater ability under self imposed confusion are forcing me into inefficiency and destruction of my pride." (Tablet XIX, p. 1370.)

*D'Brooks Hogan has granted permission, for the purpose of this dissertation, to use his real name and also one or more of his pen names: Annye Nonymus, MUDP (Mixed Up Doctor of Personalities), D'Broody Hen, and Hermit o'Tibbetts Street. 
Mr. Hogan's veritings have a literary style, and the content is largely philosophical. However, their exceptional value for the present study is that they are filled with the philosophy of aging. Aging, to Mr. Hogan, is living more intensely--by helping others. On the wall in his room is a sign, which reads: "Others that's what we live for." He calls himself "Professor Improviser," and is attempting to convert Victoria nursing home into a "Victory" home. He keeps "a kind of social life" going there which the residents need. He tries to keep them engaged: "At first they could not even get out of bed, and now they participate in the social life."

Disengagement theory is certainly repudiated in Mr. Hogan's journal. He is still attached to everything that is alive. In a letter to his grandson, he writes: "I don't know why, son, but seems I still have an interest in seeing this old world I've watched so long still go round like my active little squirrel with his wheel." (Tablet VII, p. 498.)

A unifying thread runs through the records of Mr. Hogan, and that is the constant adjustment to adversities. He has suffered some cruel blows of fate, but has steadily resisted the onslaught of despair, and has remained cheerful and engaged. He is a "survivor" in the words of a person who knows him.

There is enough material available in the autobiography to trace Mr. Hogan's development from a robust man at fifty to an invalid at eighty, and to compare his outlook on life at various stages. At no time does he give in to disengagement. We can see how he compensates 
for the losses and injuries he sustains. When he cannot work in the yard any more, he acquires a fabulous collection of orchids as an outlet for his creativity:

The orchids are an inside job. Oh! well - it all with me will soon pass along . . . but in the meantime I have found a great way to LIVE and keep my mind off my aches and that is good for both me and mine - I shall have lived a little. Who wants a complaining, weeping, walking corpse around? (Vol. 8, \#469.)

Several longer excerpts from Mr. Hogan's writings contribute to telling the story of his life. The following copy of a letter of application, dating from the beginning of the Second World War, tells us about Mr. Hogan's training and work experience, his aspirations, and also about his sense of his own worth.

"To Whom it may concern:

I am still employed. . . by the Feed Mills... doing the type of work for which I have training but I am searching about to see if it possible for me to secure position where I can use more fulty my special training during the present emergency and also be home to my blind wife nightly, here in Portland.

Surely the following listed experiences and training fits me for exceptional value somewhere in the victory program.

Raised on Western Oregon General Farms and nine years following college had first hand experience feeding all classes of livestock and poultry, and crop management.

Four years Farm Management and Nutritional Training at Oregon State College.

Have been a persistent student of research relating to my work for 33 years.

My work with farm nutrition has been my business, recreation and $7 \mathrm{ife}$.

Have had access, through process of my service advisory work, to perhaps 20,000 different farm homes from one to many times each in the last 18 years. My dealings have been with 
families of all nationalities, ages and condition of finance. Have taken particular interest in personal farm home problems.

Have belonged to numerous farm organizations.

Have had an accumulative total, on farms and in feed mill, of near 200 men in my personal employ.

Four and one half years in feeds manufacture where I prepared my own feed ration formulas for Poultry, Rabbits and Dairy.

As a hobby have played around with journalism ever since college days.

Have kept alive my interest in crops fertilization and soil study through the years by rather extensive floral, garden and shrub culture - since leaving the farm.

Have rade nutrition of plant, animal and human not only a 1 ifetira vocation but my pleasure as well.

Am 52 years of age, in excellent health, have not missed a day from work due to $i 17$ health for twenty years, in fact measles at 12 years of age and 3 days with the flu in 1919 is al1 the sickness I recall of ever having.

Have tried to be of value to humanity thus far and hope to be allowed to continue to be.

$$
s / D^{\prime B r o o k s ~ H o g a n " ~}
$$

Here we have the self-portrait of a man, 52 years old, who is fully engaged in all phases of life. We also have the mention of a personal tragedy which has overshadowed most of Mr. Hogan's married life. His writing is filled with references to his "little blind wife." Tragedy has pursued Mr. Hogan, and during the years he has had more than his share of suffering, as we learn from the entries in his diary:

It is 1970. I was born in 1890. Have been married to one woman 54 years. 43 years she totally blind, partially paralyzed, most of the last 10 years bedfast with other ailments. We have had two daughters. One still lives. These two daughters have had 6 husbands. All alive. The husbands have had 14 wives wives so far. Something is wrong. I felt it none of my business to try and find out why because I loved 
them very dearly. Magnified greatly because their mother being incapacitated from their ages of 6 and 9 . I tried to lead an exemplary life. I do not smoke, I never drank, gambled, been arrested for other than car traffic speeds, never in jail, in court. I brot my girls up in church and Sunday school as was then the custom. I moved my family but 3 times in 54 years. Only 11 months in a rented house one of those times. 45 years where I am now alone. What did I do wrong? (Volume 2, 730 \#13169.)

Toward the end of $1971, \mathrm{Mr}$. Hogan writes to a "chosen personal friend":

In my 55 years of married 1 ife, --for two daughters to 18 and 20, when they married and "left the nest," and for wife and myself, 40 cents of every dollar I ever made went to doctors, hospitals, nurses, drugs, health insurances, ambulances. 30 practicing physicians and surgeons, including Mayo Clinic where their brain tumor operation for wife left her blind and with partial paralys is for now 44 years, 10 years a broken hip, which after two long operation hospital sessions doctors never made it possible for her to stand. Later a spastic digestive system developed which has never been cured. Doctors let my mother die at 57, our oldest daughter at 40 . The younger daughter today at 50 depends upon weekly visits to doctors to keep alive and support a family. An almost bedfast husband who spent 19 months in hospital. I have lost track of how many major operations daughter has had since 5 years of age. Two two years ago. As for myself, I now carry--not with complaint-some bound to be my fault--but with pride at 81 years I can still stand--ten "doctor named" and treated ailments now in my body--the painful ones have ceased to continually pain but the awkward deformities remain--feet unable to use regular shoes, lower legs showing lack of good circulation, hands and arms at times "going to sleep" and muscular cramps in legs-these due to irregular working heart not pumping sufficient oxygen into the lungs (sleep after midnite, when pollution lowest, in porch chair), shrinking right leg, 6 inch elastic brace around hips plus a 1 inch and 2 inch belts about the hips "to hold them together," three ailments of eyes, two inoperable. Wore hearing aid until improved hearing made it possible to discontinue, two years now creeping but only slowly enlarging cancer back of my head and now neck. Yes, for fear to quit and to keep family and friends off my back ("Ya oughta see a doctor!") I see my doctor for regular "check ups", have for severa? years taken 11 pills daily, 3 prescriptions. I am paying my own keep an' home needs, for my medicine (and Mrs. Hogan's), doctor and part aid for my little wife in the nursing home out of my So. Sec. monthly check. That's all there is left to use. 
Have done it now for near 3 years." . . (Tablet VII, pp. 531-533.)

I am not asking for more aid--could use a 1 ittle--I

bought So. Sec. that which I have to make do--merely understanding dependable from tinose who can help when a sudden need will eventually come. We hope for only a very short period, instead of a 44 year drawn out suffering disappointment as with that like with that little old lady up in the nursing home is bearing with a lesson of fortitude to all of us. We will never see equalled.

I tried. Why shouldn't my long life of expensive living experience, still continuing be of value to someone? That is why I wrote this for you to read--because I am interested in you. I want to cash in on my investment. God bless you. (Volume VII, p. 534.)

In spite of all the hardships that Mr. Hogan has suffered, he shows no "willingness to disengage" (Cumming and Henry, 1961).

Mr. Hogan asks:

What is more beautiful than a white headed, bright eyed grandmother or an old man with a cultivated mind? There is nothing more valuable than a life full of useful experience and the ability to pass it on to the younger, and assist them to extend their horizon. "To live is to function. (Vo1. 8, \#158.)

By studying disabled persons as well as healthy ones the case for activity theory is strengthened. People wish to be involved and try to contribute in spite of $i 17$ health. Even Mr. Hogan's blind wife is fighting disengagement and spends hours on the telephone trying to keep in touch with the world.

It pleases me much to see my aged little wife, Belle, with her complete blindness, paralysis and inability to walk due to her paining broken hip, spending hours daily slowly knitting squares, with arthritic hand pain with each stitch, for the Red Cross. No glory in that. Just service. Not like the show off of weight throwing committee meetings, rummage sales, church bazars and dinners. Not one of her able bodied friends seem to be interested in such as she is attempting. (Vol. 8, \#188.) 
It has been repeatedly brought out in the present study, and it is confirmed by entries in Mr. Hogan's diary, that various activities may have to be curtailed because of ill health, but that the desire "to belong" does not die out. Mr. Hogan feels that mental as well as physical ailments may be attributed to other causes besides old age.

When I mention mental decay and loss of memory, friends in the same fix try to save face--say it is just old age. SUCH ROT! Eisenhower is my age, half of our Senators are my age or older. Churchill and Baruch are almost old enough to be my father. (Vol. 8, \#98.)

Mr. Hogan's sufferings have left him disillusioned with the medical profession, but certainly not disengaged. He provides an example of another case where age and physical handicaps were no barrier to a person's remaining engaged to the very end:

I knew her for over thirty years and yet while I saw very little of her - mostly only on rare visits - she came nearer being a mother to me than anyone else could during most of that time that my own mother has been gone.

She belonged to no club, lodge or church with which to build an artificial popularity. Her husband died about 21 years ago and since has lived with a son and daughter-inlaw who also were neither organization folks.

She spent a few months with us in a strange city and before many weeks had passed she had friends galore in our neighborhood and held places in their hearts, tho' living at a distance, until her dying day.

For the many years I knew her she was aimost deaf, in recent years almost blind, and otherwise not well from young womanhood, practically to the point of having to be waited upon.

In her own town folks came by the score to try and gather from her some of the wonderful sense of tolerance, good humor, and traits of character of her own building that made her a power with natural attractions.

She never meddled with the affairs of her children.

Last week we buried her. 
There were sixty-eight funeral floral pieces about her casket. Many of these from groups of from six to twenty persons for each floral piece.

SHE was My mother-in-law. (Vol. 8.)

In the case of Mr. Hogan, we can triangulate the data. We can compare his writings with interview data and letters, and with the testimony of third parties. There is an interesting article about him, written by Leonard Wiley, in the Northwest Magazine section of the Sunday Portland Oregonian of April 27, 1969. Mr. Wiley relates Mr. Hogan's story and tells about his misfortunes, and then comments:

Under these desperate conditions you might expect Hogan to be a moody and melancholy man. If you think that you don't know Brooks Hogan. I like to vis it with him whenever I can snatch an hour or two from a busy life. There is never any doubt about what we' 11 talk. Orchids and homely philosophy. All of it is good and most is excellent. (He's been in Readers Digest.)

Mr. Wiley calls his article "Aging Can Be But A Myth."

Mr. Hogan has overcome serious problems and is keeping up his courage in spite of advancing age. His case is also an example of how the city can assist older people in making necessary adjustments and in maintaining mental health. The reason Mr. Hogan was able to survive is that he received help from a social worker connected with the Metropolitan Family Service in Portland. This service is supported principaliy by funds from United Good Neighbors, but the City is now also doing some funding. For instance, it is now paying the salary - of the person who helped rehabilitate Mr. Hogan. 
The Story of Fred Breitmeier

This is the account of the life of an 89-year-0ld man, as told in his own words. The narrative is remarkable for its clarity and coherence, and it is quite revealing of an older person's continuing interest in the activities in which he is still able to participate.

The researcher met Fred at a nutrition center, and he offered to have his story recorded because he wanted people to know "what he had been through." It is a story of hardships indeed. He was born in Russia of German parentage, and barely escaped being drafted into the Tsarist army during the Russo-Japanese War. He came to the United States at the age of nineteen in the year 1906.

Fred has been a farmer. He has worked very hard all his life, but he is retired now and lives by himself on 24th Street in Vancouver. He married a German girl here in America, and they raised a family of six children. In Vancouver, he is near two of his children, a bachelor son and a married daughter.

Hard work and much deprivation have not destroyed the cheerful disposition of Fred Breitmeier. He plays checkers at the nutrition center, and he sang a song for the writer. He still teases the ladies and really seems to enjoy sociability.

What the writer particularly noticed about fred was his desire for independence. As the rest of the older people that were interviewed he loves his home. He is very proud of his "three-bedroom home." Everything is clean and neat, and he does all the work himself. He even does yard work and odd jobs for the neighbors. He raises beautiful 
flowers and cultivates a grape arbor. In the house, Fred has many religious and other inspiring inscriptions on the walls. He has pictures of his family on display, and is particularly proud of a photograph and a framed certificate in commemoration of his golden wedding anniversary. His wife has now passed on. She had a stroke and was in a wheelchair for many years. Fred took care of her. Now he enjoys having his children and friends come to visit him, but he wants to live alone in his own home as long as possible. The researcher has found this to be one of the most predominant characteristics of older people, and is convinced that privacy and independence ought to be at the top of the list when planning for older people. And, they should be given freedom of choice to the extent possible on how they want to live and where they want to settle. This, in the opinion of the researcher, is conducive to successful aging. Making older people feel that they are still responsible for their own lives helps avoid deterioration and mental illness, and thereby saves the city many problems and much expense.

The Story of Mrs. S.

This case history has been condensed by the writer, and will be told in the manner of "impressions of the interviewer."

Mrs. S. is by no means an invalid, although she has various ailments--diabetes, arthritis. She answered the door without using her cane, which was suspended in the kitchen. She has a walking impediment, but she is not a cripple. She moved about the house without the help of the cane, and was standing up a good part of the time without leaning on anything. 
Mrs. S. does her own cooking and much of her housework, although she has a woman come in to help her. She hires somebody to do her yard work. She takes care of her two cats, and was just feeding them when we arrived. She was in an animated mood, and said she enjoyed talking to us. She wants us to come back again.

The house is modest, but looks neat and comfortable. There are many keepsakes and various other treasured possessions on display. Among them are photographs of her three daughters, and a gold medal which was awarded to Mrs. S. for her outstanding participation in the North Shore Animal League. Mrs. S. loves animals and makes regular contributions to several organizations which are trying to protect them. Mrs. S. has a friendly and warm personality and she talked very readily.

Mrs. S. had a high score on the Attitude schedule (22), but only a score of 4 on her Activities. During the visit it became quite clear why her Activities score was so low. She likes to be with people, and would enjoy participating in a number of functions if someone would take her. She cannot drive a car because of her arthritic condition. However, she loves music and would love to attend concerts and recitals. She is also interested in plays and enjoys comedies. It became obvious that her biggest problem is lack of transportation. She cannot afford a taxi, and has to depend on her friends who occasionally invite her to go along. It came out in the conversation that her relatives do not bother about taking her anywhere. Mrs. S. is a widow, and there is an estrangement between her and the family of her late (second) husband who passed away three years ago. She feels that her friends are much more sympathetic and helpful than her relatives are. Her three daughters live in California. 
Obviously, Mrs. S. is not disengaged because of some intrinsic tendency; her activities are restricted as a result of some obstacles which could be overcome with the proper arrangements and help from the community. She also needs transportation to the doctor.

All in al1, Mrs. S. is a victim of circumstances, which include a fixed retirement income and rising prices. She loves people and entertainment, and keeps busy in her home. She likes to sew and make her own clothes. In her situation, the interaction has to come to her. But she seemed ready to participate when the opportunity arose. To state it in her own words: "If I had transportation now, I could contribute a lot."

The research reported in this chapter has included materials from case studies and life histories. We have attempted to balance the objectivism of the survey and participant observation with data reflecting more covert, internal elements of social behavior (Denzin, 1970a, p. 258). As already brought out, this researciner believes that we need both objective evidence and the empathy embodied in the operation of Verstehen in order to penetrate into the complexity of our subject matter, that is, the relation between disengagement and aging.

The evidence we have gathered by the methods of personal interviews and the study of case histories reveals the fact that older people want to retain their individuality and independence, but that they also do what they can to remain part of their community. Our respondents are engaged in meaningful activities unless restricted by failing health or personal misfortunes. The following section deals 
with factors related to the environment and to service facilities, which also play an important role in fostering or hindering the engagement of older people.

\section{THE IMPLICATIONS FOR THE CITY}

The data from the personal interviews and the life histories supplement our information from the mail survey. We are now in possession of empirical evidence which contradicts the theory of intrinsic disengagement. We have studied the possibilities leading to low engagement, and found that prominent among them are lack of social support and absence of essential services. Our Form III asks questions about the urban environment and how it could be made better for older people. The answers we received suggest good housing, counseling and placement centers, better medical facilities, reduction of noise and other pollution, etc. This kind of city planning benefits all members of the population.

These are the specific figures on some deficiencies mentioned by respondents in Form III:

1) Housing. Twenty-four (14\% of 176) said the housing for retired persons in their community was poor or very poor. Representative comments are: More housing for the elderly is needed; especially needed is more low-rent housing for retired persons; "More housing for older people who are not considered low income and yet do not have enough income to pay regular rent and find it hard to pay the increasing costs of mairtaining their own home." One person writes that housing in his community is "well located to desired facilities and services, but above the financial reach of many aged persons." Another 
respondent says there is "need for more housing for the lower middle class older people who cannot keep up their own homes any more."

2) One person said good roads were needed; two people said there were no sidewalks; and two others reported a lack of sewers.

3) Transportation. Fifty-seven (32\% of 176) need better transportation in order to take better care of themselves, be more independent, help others, and be generally more engaged. Specific complaints were that buses don't run on Saturdays, and that there are no buses on week ends, Sundays, or holidays. In some cases, the bus stop is too far away. This refers to convenient public transportation; however, in some cases it has to be somewhat specialized transportation to fit the needs of the elderly. One lady writes transportation is needed "for those of us who are crippled with arthritis."

There is a vital need for a personal transportation service for those people who cannot drive but live alone. The main occasions are to nelp them do their shoppirs and to take them to the doctor and back home. The problem is illustrated by one respondent:

They say you can call up that Dial-a-Ride. But they will only go on certain days, and they are not going to wait for you. You have to wait in the lobby of the clinic. And, even though you've got a date for, say, eleven o'clock, you're lucky if you get to see the doctor by $7: 30$. So, they are not going to sit out in that car and wait for you. So, what's the use of calling them? I tell you, when you get old and handicapped, you're sure handicapped.

Here is an opportunity to work out an arrangement that would provide a much needed service for some older people.

One respondent mentioned the need of a sheltered bus stop, which of course would help everybody, but especially the elderly and the ailing. 
4) Medical facilities. Thirty-three (19\% of 175) stated that they needed better heal tin care. Aside from convenience and accessibility, the quality of medical services is'a major concern to older people. Some o $i$ them find Medicare confusing or inadequate and do not avail themselves of it. In some instances there is an expression of desperation: "Don't get sick, even with Medicare. If you do, pray that you die."

Several respondents feel that government could give better health care, and that Hedicare could help more: "Improve Medicare so that people seek help when they need it, and not wait until it is a must." City planning is crucial with regard to the location of services, and decentralized health care could mean an alternative to institutionalized care. The handicapped are particularly dependent upon proximity to health centers.

In this respect, an aging population is more vulnerable, and the city will have to cope with its rising numbers. The writer has observed how eáger most people are to overcome their physical handicaps, and to keep right on going. One remarkable example is Mr. Douglas Russell, whom the writer saw several times at a nutrition center. Mr. Russell is the editor and publisher of the Cheers Magazine, a delightful little monthly publication for Senior Citizens. Mr. Russell is 68, and he uses a wheel chair, but he was in good spirits and very much engaged when the writer talked with him. Mr. Russell has studied journalism and considers himself a professional writer. In addition he has musical talents, and he is a commercial artist who draws pictures for nis magazine. He had polio as a child, but he has never 
given up. He has remained active throughout his $1 \mathrm{ife}$, and has participated in many programs for the elderly and the handicapped. Even ariter suffering a stroke, Mr. Russell is making a heroic effort to resume writing.

Mr. Russell described to this writer a plan that he thought would work to give better medical care to handicapped people and to the elderlj who are not mobile. He suggested that one should build a large central hospital to serve multiple purposes of medical, health, and therapy needs with complete hospital facilities and a staff of doctors representing all specialties. Surrounding the central complex of hospital buildings there could be built public housing and other homes for the handicapped aged. The hospital staff could then help these neople. Some of them live too far away from medical facilities, even if they are eligible for Medicare and Medicaid. Often they are unable to yet help winen they need it most.

Mr. Kussel7's point is this: The Government is now spending billions of dollars for Medicare and Medicaid, housing and other helps to the aged sick and handicapped. In many cases people cannot avail themselves of needed help, and the procedures to obtain care are too complicated and exhausting to sick elderly people. A hospital central to contiguous dwellings for the incapacitated and handicapped older people would produce much better results. In a larger city, two or more such arrangements might be necessary. But it would help keep many people out of nursing homes and help them remain in homes of their own. Another respondent expressed a related idea, namely that there are many duplications of effort in Vancouver, but that "unfortunately a 
large portion of the programs available now are not adequately reaching the least independent (poor, $i 11$, handicapped) aged."

5) Counseling and placement center. One hundred and twentyseven ( $72 \%$ of 176 ) believe it is important to have a counseling and placement center to inform older people of job opportunities and to help them secure employment near their home. Since the percentage recommending this particular item is so much higher than that wanting other conveniences, we shuuld consider it carefully. It speaks for the significance of work in the lives of our respondents.

We already know that about thirty percent of our population showed interest in gainful employment; more than double that number evidently would like to have a counseling and placement center just in case it is needed. President Franklin D. Roosevelt said:

I believe in the inherent right of every citizen to employment at a living wage and I pledge my support to whatever measures I may deem necessary to inaugurating self-liquidating public works . . to provide employment for all surplus labor at all times (The New Dictionary of Thoughts, 1965, p. 741).

To the question, "What could older people do in a city?"

Erdman Palmore has a ready answer:

There are thousands of hospitals, libraries, schools, colleges, highways, and recreation areas that could and should be built and staffed. There is an unlimited amount of counseling, social service, community organization, group therapy, tutoring, and training that could usefulty be done if enough people were willing to organize the resources for these purposes. And one of the greatest resources that could be channeled toward tinese ends is the experience, skill, and devotion of millions of aged persons. The fact that much of this resource is currentiy being wasted is a shame for the present and a hope for the future (1969, p. 64). 
The high percentage favoring an employment office also helps us test our hypothesis on engagement. Having access to such an office would be associated with a functional role in society or an occupational identity. Interest in employment is associated with interest in continued engagement.

The writer was sitting in a restaurant, and became a participant in the following conversation:

Today is my last day at work. I have turned 65 , and I have to retire. I don't know what I am going to do. I think I will go to the unemployment office to see if they have something for me. I can't just sit around doing nothing. I live alone. During vacation I thought I would go crazy. I would like to get some part-time work."

6) Quiet. Ten (6\% of 176) complained of excessive noise from various sources. It would be worth while to investigate such cases on an individual basis. One might find that some of these disturbances are unnecessary.

7) Shopping facilities. Twenty-eight (16\% of 176) 1isted an array of stores and other business establishments that were missing from their neighborhood. These included grocery stores, shopping centers, supermarkets, drugstores, restaurants, 1 unch rooms, clothing stores, and a hardware store. There were also requests for beauty parlors.

8) Recreation. Twenty-five (14\% of 176) expressed a wish for more recreational facilities for Senior Citizens, so that they could have places to meet and to participate in community programs. There were requests for a place for dinner, a recreation room, and whole new Senior Citizen centers for social events. Other things that were 
lacking were a church, a library, parks, and more land for gardens for the elderiy. But there were also suggestions to add swimming pools, tennis courts, and "a lawn bowling green (or better two) in the central park, maintained by park bureau." Two people wanted "good trave1 programs."

It seems to the writer that the possibilities for activity here are unlimited, and the opportunities for the urban community to be of help extraordinary. With all this desire for interaction and participation, these people certainly are not disengaged.

9) Shut-ins. Seventeen (10\% of 176) expressed concern for the elderly who are confined to nursing homes or to their own homes. We need programs in which some of these patients can participate. Delivery of hot meals and home maintenance are important services to help older people remain in their own homes. Somebody suggested: "Have the nurse stop more often, say once a week instead of about three months." Another person wrote: "A systeni needs development which would provide information on temporary or permanent 'shutins,' i.e., interests, physical condition, abilities (mental and/or psychological)." It was stressed that conditions in rest homes and nursing homes must be improved.

10) A number of people who maintain their own homes have stated their need of a housekeeper or some kind of household help. For some of them this poses a very serious probiem, and perhaps some helpful arrangement could be worked out. Here are some notes and suggestions:

I am 89 years of age and am in excellent health, except crippled and partially blind. Anything I can do sitting is easy for me, if it doesn't require good eyesight. I have to have household help. 
Need a more helpful arrangement for hiring help.

We find it difficult to find help to come in when

ill (would pay). A list of competents should be available if we need to call.

The researcher thought that some such requests might be handled in conjunction with a counseling and placement center. It would be best if older people had one central place to call. If necessary, they could then be directed to another agency.

11) Law enforcement. Twelve (7\% of 176) said they needed protection against vandalism, various traffic problems, and excessive speeding. Therefore they suggested more police patrol.

12) Economic needs. Fifteen (9\% of 176) poirited out the tragedy of a sharply reduced, fixed income, with no possibility of supplementing it. It seemed a relief to them to be able to tell someone of their economic plight.

More help for the real low income people. Some don't get enough to live like human beings.

A housewife writes:

I can work but when I do they take my wages out of my husband's S.S.I. checks. He don't have enough left over to pay the household bills, which he likes to pay. It makes him feel that he still is head of his home.

Another response on how to improve the condition of older people was:

Just to see they are taken care of. One thing that is not being done is to take care of the low income people. How would anyone like to live on $\$ 100$ a month? I am not in that category, but I sure feel sorry for them. It is a shame.

01 der people need more money to fight inflation, and a number of them have expressed their hopelessness as prices go higher and higher 
and their pensions stay the same. These are the things that worry them, and these worries cause disengagement--not some mysterious ego change.

01der people get attached to their community, and they seem to feel that their community can find some solutions to their hardships. Several of them suggested that more merchants and restaurants might work out special plans to give discounts to Senior Citizens on food, gasoline, labor on cars and appliances, on ambulance service and taxi fare, and also on recreation.

13) Where in the city should older people live? As quoted by Beckman (1969, p. 282), "the elderly want to be insulated but not isolated." We have found this observation true in our research. Time and again older people have told us that they prefer to live in the community like everybody else. And our Table VII shows that 95.4 percent said they liked to associate with people of all ages.

The writer is aware that there are two schools of thought on the best location of housing for the aged. Many gerontologists take the position that social integration is beneficial to both the aged and the community. However, not all sociologists agree with this view. Irving Rosow (1967, pp. 292-293) writes that social theory would indicate just the opposite: "Informal association develops around similar statuses of which age is one extremely powerful factor. . . Accordingly residential proximity should not integrate the old and the young." 
The answers to our Form III reaffirm that our respondents do not want to be segregated from the rest of society but want to remain part of the normal community. Here are some of the comments:

I think older people should live where they want and do what they want.

I do not think of myself as old. I resent efforts to make a separate class of older people. I think the old expanded family in which 3 and even 4 generations lived as a family was better than the present nuclear family. I believe the older person should be integrated into the community.

Less emphasis on the Senior Citizen label. It Timits us. To shove any segment of people into a class does this. I want a cross section of all ages.

Form III is indispensable to testing our Hypothesis Three that a good urban environment helps adjustment to aging. Besides it supplements our information on activity and engagement. There seems to be an indication that those people who are pleased witil their environment and with various services they receive are better adjusted and tend to be more engaged; those who are left out of participation feel forcibly disengaged. For example, one lady says she was forced to retire at age 65 , and she does not feel that she is being useful enough. Another person would like to have:

People taking more interest in lonely widows and widowers. Life has no incentive when living alone.

Still another one simply suggests: "Keep them active."

Urban planners and social gerontologists can do a great deal together to lessen disengagement. The urban community has a responsibility to those people who have helped build it: It can now help them lead better lives. 
CHAPTER VI

SUMMARY AND CONCLUSIONS

By advancing their theory, Cumming and Henry have introduced a concept of enormous implications. If we accept intrinsic disengagement, it means that between 20 and 25 million people in our society will become increasingly non-productive and will have decreasingly significant roles; if we reject intrinsic disengagement, the society must concern itself with developing meaningful activities for those older citizens who can profit by them.

The foregoing research has shown no evidence of the type of disengagement imputed to a11 older people by Cumming and Henry (1961). Where symptoms of nonengagement have appeared, the circumstances surrounding the particular case have usually provided an explanation. Our strongest evidence was contained in the spontaneous statements of our respondents.

We have tested our hypotheses by the strategy of analytic induction and by the application of multiple methods to the same study, that is, by the use of triangulation. According to the Modern Dictionary of Sociology, "induction" is:

The logical process in which generalizations are inferred from specific facts. Essentially, induction is the process of reasoning from individual instances to general principles (op. cit.). 
Specifically, "analytic induction" is a form of induction distinguished from enumerative induction by Florian Znaniecki, and held to yield universal generalizations. . . In analytic induction, to determine their essential characteristics. These essential
characteristics are abstracted from the specific cases and
generalized on the assumption that if they are essential they
must hold in other cases. . . W. S. Robinson has argued that
the differences between analytic induction and enumerative
induction are differences of degree rather than kind. He
maintains that the sophisticated statistician gradualiy moves
toward analytic induction through the constant modification
and refinement of his hypotheses (ibid.). We note that reference to the work of Znaniecki and Robinson 48 in this Dictionary provides a bridge between analytic and enumerative induction, and both kinds have been used in the present research. Denzin (1970b) has pointed out how the observer in a research project can obtain systematic means of assessing his final conclusions by the use of analytic induction in combination with statistical and theoretical sampling models. He feels that this combination provides a rigorous set of standards for the researcher, and he recommends analytic induction, with its emphasis on discovering negative cases and formulating universal-interactive propositions, as "the main line of action" for the scientific process (p. 460).

Both Denzin (1970b, p. 460) and Robinson (1951, p. 812) cite Lindesmith as having provided a model of analytic induction as a

48

Florian Znaniecki, The Hethod of Sociology (New York: Farrar and Rinehart, 1934); W. S. Robinson, "The Logical Structure of Analytic Induction," American Sociological Review, 16, No. 6 (Dec. 1951), pp. 812-818. 
scientific process in his well-known study of opiate addiction. 49 Robinson (p. 812) further states that Znaniecki "holds that analytic induction is the true method of the physical and biological sciences, and that it ought to be the method of the social sciences too" (Znaniecki, op. cit., pp. 236-237).

In the present study, the use of the inductive method has given consistent results, in that no instances of intrinsic disengagement have been discovered. In the examination of individual cases, we have been able to show that other causal factors were responsible for relative nonengagement if it occurred.

Our main proof of the tendency toward continued engagement has come from the empirical social world. We have looked for substantive rather than for statistical significance. Because of the qualitative nature of our data, it was decided not to use statistical tests of significance in this studys 50 but to verify our hypotheses empirically. Our research problem has been to examine the behavioral phenomena of older people in relation to disengagement, and to determine the variables which influence such behavior. To this end we have employed some operational definitions which are needed to demonstrate the

\section{9}

Alfred R. Lindesmith, Opiate Addiction (Bloomington, Indiana: Principia Press, 1947).

50

Hanan Selvin, among others, has directed some criticisms against the use of statistical tests of significance in survey research. See Hanan C. Selvin, "A Critique of Tests of Significance in Survey Research," American Sociological Review, 22 (October, 1957), pp. 519527. 
existence of these phenomena. A11 our hypotheses have been substantiated by the prevalence and the recurrence of the specified criteria. 51

As Blumer (1969) has stated,

Empirical science pursues its quest by devising images of the empirical world under study and by testing these images through exacting scrutiny of the empirical world (p. 23).

This writer feels that inductive analysis has given us insight into this empirical world, and that the sheer bulk of our evidence speaks for itself. We shall summarize our basic substantive findings, and indicate how they confirm our hypotheses.

Our Hypothesis One is based on the premise that there is no inherent relationship between disengagement and the process of aging, and that there exists no automatic intrinsic withdrawal mechanism caused by age alone. Some of the misfortunes which age brings in its train may lead to nonengagement, but as a rule older people use all the means available to remain active and engaged. I11 heaith, widowhood and forced retirement act as deterrents from action. But people in such a state regret their inability to participate and to become involved; they do not exnibit increased morale because of disengagement, as Cumming and Henry (1961) claim.

Table VI (pp. 122-126) shows that the responses to our Attitude questionnaire overwhelmingly erudurse engagement for older people; and

51

Zena Smith Blau has used a similar method for tests of a hypothesis in "Structural Constraints on Friendships in 01d Age," American Sociological Review, 26, No. 3 (June 1961), pp. 429-439. 
Table VII (p. 128) gives the high percentages of respondents wanting to be with people of all ages, enjoying doing things for other peupie, taking care of their appearance, and voting--which are all characteristics of engagement according to our operational definition. We have given a great number of comments testifying to the fact that "keeping busy" is a virtue to these older people; and Table IX (pp. 135-137) pays tribute to the resolution and fortitude of retired people to engage in almost innumerable worthwhile activities. Tables $X$ (p. 139) and XI (p. 140) indicate that older people like to be with members of their family, and that they visit oftein with their friends and neighbors. Tables XII (p. 141) and XIII (p. 142) show that the majority of older people have a wide range of interests; in other words, that they resist the idea of becoming stale or "disengaged." As Brotman (1972) says, "For all [e]derly/ it is a struggle against being pushed out of the mainstream into a subculture--a subculture of poverty and of social uselessness" (p. 1).

Hypothesis Two claims that older people tend to persist in their personality and life style, and that they are best adjusted when they are able to do so. This hypothesis also states that disengagement theory misrepresents the image of older people.

We have projected portraits of our respondents and believe we have corrected some false images. We have also quoted their statements to depict their characteristics and to bring out the high level of their mental competence. The open-ended questionnaire, supplementing Question 14 in Table VII (p. 128) by asking for reasons why older people felt their appearance was important, was especially useful. The 
reasons they gave helped test Hypothesis Two by disclosing the persistence of personality and life style in the respondents. The case histories also assist in bringing out the persistence of personality in life style.

The researcher was interested in symptoms of change in order to establish whether there was any tendency toward disengagement. With that purpose in mind, a series of personal interviews was completed witich yielded a wealth of information on the characteristics of older people, as well as on their needs and aspirations. The writer wanted to investigate the typology of the four combinations of attitude and activity scores which have been described. The interviews gave the investigator a chance to penetrate below the surface, and to probe somewhat deeper into some subjective areas. It is clear from the transcribed statements that the respondents spoke freely and left the writer much better informed as to why some of them were not more active, and as to what might be done to help these people. The summary which follows each typology indicates what the writer learned with respect to the areas susceptible to change, but in none of the cases were there signs of intrinsic disengagement.

By having triangulated our approaches by means of the survey, the interviews, observation, and case histories, we feel we are in a better position to comment on how the urban community could help older people lead happier lives. Our research has acquired the "larger significance" that Cavan et al. (1949, p. 148) refer to. 
Thus we look at Hypothesis Three with better understanding of how the urban environment affects the lives of older people. We have posited that a livable urban environment is a determinant of good adjustment in the later years. Our Form III and the interviews have disclosed some deficiencies and some possibilities for improvement which are closely connected with the well-being of our older population. Hypothesis Three assumes a special significance in the context of urban studies. This is where sociologisits and urban planners have a challenge to cooperate in improving the lot of the elderly.

The section, Implications for the City, has enumerated the vast possibilities for practical application of knowledge gained from descriptive and theoretical studies including housing, transportation, health care, home maintenance, meals on wheels, shopping facilities, recreation, and, above all, a counseling and placement center. There were requests for more jobs, more employment opportunities. The size and the variety of this list are enough to confirm a hypothesis that a good urban environment, or life space, determines successful aging. We have used the recurrence of this expected relationship as a criterion for accepting Hypothesis Three. In fact, all three of our hypotheses have al ready been confirmed during the process and analysis of this research by the patterns of recurrence in the different groups we have studied in many walks of life. The results are consistent, and the message is clear: According to the results of our research, and based on the data we have obtained, there exists no intrinsic disengagement; therefore, older people do not become automatically disengaged. Consequently, the recommendation of this researcher is 
that the city plan for active older people. Since it is a fact that everybody in turn gets older, everybody would have something to look forward to in a carefully planned community where their former contributions will be remembered, and where the distressing picture painted by Ralph Nader (1971) would not apply:

Twenty million Americans--10 per cent of the population-are over sixty-five years old. Within a hyperbolic youthoriented society and economy, these citizens are being increasingly "structured" out of their just share of material, psychological, and social benefits. "Out of sight, out of mind" is perhaps the most succinct description of the workings of institutional and individual forces on the elderly. More and more they are separated from the rest of society, by a kind of geriatric segregation as consumers, residents, relatives, victims, and other roles which they choose or are compelled to assume ( $p$. ix).

As an antithesis to this, one can accord older people nobility and make them feel that their city accepts them and is willing to extend a meaningful role to them. To make human dignity possible, it is necessary to look at their potential rather than at their age.

The writer has relayed the stories of some of these people and has portrayed them in their real life settings. Most of them say they do not feel old. By their statements and by their actions they have rejected the theory of disengagement. A lady at the age of 90 writes to us that she is:

Willing to still consider new ways of looking at things, listen as well as tell my own opinions. Give as well as take. Forgiveness.

With this eloquent plea for the case of engagement the writer would like to end the present dissertation. It is hoped that our findings will inspire some city planners to develop services and 
to promote programs for the elderly which will add to justice and dignity. Most likely an older population that meets encouragement to be active instead of constant frustration will further disprove the theory of disengagement. 
BIBLIOGRAPHY

ARTICLES AND CHAPTERS

Albrecht, Ruth. "The Social Roles of 01d People." Journal of Gerontology, 6 No. 2 (Apri1 1951), pp. 138-145.

Armstrong, Herbert W. "The Western World's Growing Tragedy--Growing 01d Before Our Time." The Plain Truth, XLI, No. 11 (Dec. 1976), p. 1 .

Beckman, R. 0. "Acceptance of Congregate Life in a Retirement Village." The Gerontologist, 9, No. 4, Part 1 (Winter 1969), pp. 281-285.

Be11, Tony. "The Relationship Between Social Involvement and Feeling old Among Residents in Homes for the Aged." Journal of Gerontology, 22, No. 1 (Jan. 1967), pp. 17-22.

Bierstedt, Robert. "Nominal and Real Definitions in Sociological Theory." In Symposium on Sociological Theory. Ed. Llewellyn Gross. White Plains, New York: Row, Peterson and Company, 1959, pp. 121-144.

Birren, James E. "The Aged in Cities." The Gerontologist, 9, No. 3 (Autumn 1969) Part 1, pp. 163-169.

Blau, Zena Smith. "Structural Constraints on Friendships in 01d Age." American Sociological Review, 26, No. 3 (June 1961), pp. 429-439.

Blumer, Herbert. "Society as Symbolic Interaction." In Symbolic Interaction: A Reader in Social Psychology. Eds. Jerome G. Manis and Bernard N. Meltzer. Boston: A7Tyn and Bacon, 1967, pp. 139-148.

In Herbert Blumer. Symbolic Interactionism: Perspectives and Method. Englewood Cliffs, New Jersey: Prentice-Hal7, 1969, pp. T-60.

"What Is Wrong With Social Theory?" American Sociological Review, 19, No. 1 (February 1954), pp. 3-10. 
Brehm, Henry P. "Sociology and Aging: Orientation and Research." The Gerontologist, 8, No. 2, Part II (Spring 1968), pp. 24-31.

Buckley, Walter. "Society as a Complex Adaptive System." In Modern Systems Research for the Behavioral Scientist. Chicago: Aldine, 1968, pp. 490-513.

Burgess, Ernest W. "Personal and Social Adjustment in 01d Age." The Aged and Society. Ed. Milton Derber. Champaign, I1l.: Industrial Relations Research Association, 1950, pp. 138-156.
Adjustment.i" "Social Relations, Activities, and Personal (Jan. 1954), pp. 352-360.

- "Aging in Western Culture." Aging in Western Societies. Ed. Ernest W. Burgess. Chicago: The University of Chicago Press, 1960, pp. 3-28.

Butler, Robert N. "The Facade of Chronological Age: An Interpretative Summary." American Journal of Psychiatry, 119, No. 8 (Feb. 1963). Abridged in Middle Age and Aging. Ed. Bernice L. Neugarten. Chicago: University of Chicago Press, 1968, pp. 235-242.

Cameron, Paul. "Ego Strength and Happiness of the Aged." Journal of Gerontology, 22, No. 2 (Apri1 1967), pp. 199-202.

Carp, Frances M. "Some Components of Disengagement." Journal of Gerontology, 23, No. 3 (July 1968), pp. 382-386.

Cavan, Ruth Shonle. "Self and Role in Adjustment During 01d Age." Paper read at the Twentieth Groves Conference on Marriage and the Family, May 1, 1957, East Lansing, Michigan. Published in Human Behavior and Social Processes: An Interactionist Approach. Ed. Arnold M. Rose. Boston: Houghton Miff7in, 1962, pp. 526-536.

Cosin, L. Z., Margaret Mort, Felix Post, Celia Westropp, and Moyra Williams. "Experimental Treatment of Persistent Senile Confusion." The International Journal of Social Psychiatry, IV, No. 1 (Summer 1958), pp. 24-42.

Cumming, M. Elaine. "New Thoughts on the Theory of Disengagement." New Thoughts on 01d Age. Ed. Roverit Kastenbaum. New York: Springer, T964, pp. 3-78.

Cumming, Elaine, Lois R. Dean, David S. Newe1l, and Isabel McCaffrey. "Disengagement: A Tentative Theory of Aging." Sociometry, 23, No. I (March 1960), pp. 23-35. 
Denzin, Norman K. 1970b. "The Methodologies of Symbolic Interaction: A Critical Review of Research Techniques." Social Psychology Through Symbolic Interaction. Eds. Gregory P. Stone and Harvey A. Farberman. Waltham, Mass.: Xerox College Publishing, 1970, pp. 447-465.

Desmonde, William H. "The Position of George Herbert Mead." Social Psychology Through Symbolic Interaction. Eds. Gregory P. Stone and Harvey A. Farberman. Waltham, Mass.: Xerox College Publishing, 1970, pp. 55-62.

Desroches, Harry F. and Bernard D. Kaiman. "Stability of Activity Participation in an Aged Population.". Journal of Gerontology, 19, No. 2 (April 1964), pp. 211-214.

Donahue, Wilma. "Where and How 01 der People Wish to Live." In Housing the Aging. Ed. Wi Ima Donahue. Michigan University Conference on Aging, 1952. Ann Arbor: University of Michigan Press, 1954, pp. $21-36$.

Doyle, Earl C. "The Building Industry and Housing the Aging." In Housing the Aging. Ed. Wilma Donahue. Ann Arbor: University of Michigan Press, 1954, pp. 48-54.

Filer, Richard N. and Desmond D. O'Connell. "A Useful Contribution Climate for the Aging." Journal of Gerontology, 17, No. 1 (Jan. 1962), pp. 51-57.

Friedman, Eugene A. "The Impact of Aging on the Social Structure." In Handbook of Social Gerontology: Societal Aspects of Aging. Ed. Clark Tibbitts. Chicago: University of Chicago Press, 1960, pp. 120-144.

Goodstein, Leonard D. "Personal Adjustment Factors and Retirement." Geriatrics, 17, No. 1 (Jan. 1962), pp. 41-45.

Gordon, Margaret S. "Aging and Income Security." In Handbook of Social Gerontology. Ed. Clark Tibbitts. Chicago: University of Chicago Press, 1960, pp. 208-260.

Havighurst, Robert J. "Personality and Patterns of Aging." The Gerontologist, 8, No. 2, Part II (Spring 1968), pp. 20-23.

Havighurst, Robert J., Dernice L. Neugarten, and Shel doñ S. Tobin. "Disengagement, Personality and Life Satisfaction in the Later Years." Age with a Future. Proceedings of the Sixth International Congress of Gerontology, Copenhagen, 1963. Ed. P. From Hansen. Philadelphia: F. A. Davis, 1964, pp. 419-425. 
Havighurst, Robert J., Bernice L. Neugarten, and Sheldon S. Tobin. "Disengagement and Patterns of Aging." In Middle Age and Aging: A Reader in Social Psychology. Ed. Bernice L. Neugarten. Chicago: University of Chicago Press, 1968, pp. 161-172.

Henry, William E. and Elaine Cumming. "Personality Development in Adulthood and 01d Age." Journal of Projective Techniques, 23, No. 4 (Dec. 1959), pp. 383-390.

Henry, William E. "The Theory of Intrinsic Disengagement." Age With A Future. Proceedings of the Sixth International Congress of Gerontology, Copenhagen 1963. Ed. P. From Hansen. Philadelphia: F. A. Davis, 1964, pp. 415-418.

Hoben, Edmond H. "Planning Considerations in Urban Communities." In Housing the Aging. Ed. Wilma Donahue. Ann Arbor: University of Michigan Press, 1954, pp. 39-47.

Hochschild, Arlie Russe11. "Disengagement Theory: A Critique and Proposal." American Sociological Review, 40, No. 5 (Oct. 1975), pp. 553-569.

Horton, John. "Order and Conflict Theories of Social Problems." Radical Perspectives on Social Problems: Readings in Critical Sociology. Ed. Frank Lindenfeld. New York: Macmillan, 1968, pp. 34-5T.

Jacobs, Ruth Harriet. "The Friendship Club: A Case Study of the Segregated Aged." The Gerontologist, 9, No. 4, Part 1 (Winter 1969), pp. 276-280.

Jeffers, Frances C. and Claude R. Nichols. "The Relationship of Activities and Attitudes to Physical Well-Being in 01 der People." Journal of Gerontology, 16, No. 1 (Jan. 1961), pp. $67-70$.

Kapnick, Philip L., Jay S. Goodman, and Elmer E. Cornwe11, Jr. "Political Behavior in the Aged: Some New Data." Journal of Gerontology, 23, No. 3 (JuTy 1968), pp. 305-310.

Kastenbaum, Robert. "Theories of Human Aging: The Search for a Conceptual Framework." Readings in Gerontology. Eds. Ruth $M$. Brewer, Marvin M. Janzen, and Frances G. Scott. Eugene: University of Oregon, Schoo! of Community Service and Public Affairs, Center for Gerontology, 1969. II-A, pp. 1-26.

Kleemeier, Robert $W$. "The Effect of a Work Program on Adjustment Attitudes in an Aged Population." Journal of Gerontology, 6, No. 4 (Oct. 1951), pp. 372-379. 
Kleemeier, Robert W. "Attitudes Toward Special Settings for the Aged." Processes of Aging: Social and Psychological Perspectives. Eds. Richard H. WiTliams, Clark Tibbitts, and Wi Tma Donahue. New York: Atherton Press, 1963, II, pp. 101-121.

Kuhlen, Raymond G. "Aging and Life-Adjustment." Handbook of Aging and the Individual. Ed. James E. Birren. Chicago: University of Chicago Press, 1959, pp. 852-897.

- "Development Changes in Motivation During the Adult Years." In Relations of Development and Aging. A symposium presented before the Gerontological Society at the 15th Annual Meeting, Miami Beach, Florida. Ed. James E. Birren. Springfield, I11.: Charles C. Thomas, 1964, pp. 209-246.

Kuhn, Manford H. and Thomas S. McPartland. "An Empirical Investigation of Self-Attitudes." In Symbolic Interaction. Eds. Jerome G. Manis and Bernard N. Meltzer. Boston: A7Tyn and Bacon, 1967, pp. 120-133.

Landis, Judson T. "Social-Psychological Factors of Aging." Social Forces, 20, No. 4 (May 1942), pp. 468-470.

Landis, Paut H. "Emerging Problems of the Aged." Social Forces, 20, No. 4 (May 1942), pp. 460-467.

LaPiere, Richard T. "Attitudes vs. Actions." In Readings in Attitude Theory and Measurement. Ed. Martin Fishbein. New York: John Wiley \& Sons, 1967, pp. 26-31.

Lebo, De11. "Some Factors Said to Make for Happiness in 01d Age." Journal of Clinical Psychology, IX, No. 4 (Oct. 1953), pp. 385387.

Lehr, Ursula and G. Rudinger. "Consistency and Change of Social Participation in 01d Age." Human Development, 12 (1969), pp. 255-267.

Leveen, Louis and David Priver. "Significance of Role Playing in the Aged Person." Geriatrics, 18 (Jan. 1963), pp. 57-63.

Levin, Sidney. "Depression in the Aged: The Importance of External Factors." New Thoughts on 01d Age. Ed. Robert Kastenbaum. New York: Springer, 1964, pp. 179-185.

Lipman, Aaron and Kenneth J. Smith. "Functionality of Disengagement in 01d Age." Journal of Gerontology, 23, No. 4 (Oct. 1968), pp. 517-521. 
Loewenberg, I. S. "Designing Homes for the Aging." Housing the Aging. Ed. Wilma Donahue. Ann Arbor: University of Michigan Press, 1954, pp. 55-63.

Lowenthal, Marjorie Fiske and Deetje Boler. "Voluntary vs. Involuntary Social Withdrawal." Journal of Gerontology, 20, No. 3 (July 1965), pp. 363-371.

Ludwig, Edward G. and Robert L. Eichhorn. "Age and Disillusionment: A Study of Value Changes Associated with Aging." Journal of Gerontology, 22, №. 1 (Jan. 1967), pp. 59-65.

Maddox, George L. 1962a. "Geronts with High Morale." Elaine Cumming and Wi 17 iam E. Henry. Growing 01d: The Process of Disengagement. New York: Basic Books, 1967. Reviewed by George L. Maddox. Contemporary Psychology: A Journal of Reviews, VII, No. 11 (Nov. 1962), pp. 414-416.

- "Disengagement Theory: A Critical Evaluation." The Gerontologist, 4 (June 1964), pp. 80-82, rpt. in Readings in Gerontology. Eds. Ruth M. Brewer, Marvin M. Janzen, and Frances G. Scott. Eugene: University of Oregon, School of Community Service and Public Affairs, Center for Gerontology, 1969. II-C, pp. 1-5.

"Fact and Artifact: Evidence Bearing on Disengagement Theory." Normal Aging: Reports from the Duke Longitudinal Study, 1955-1969. Ed. Erdman Pa7more. Durham, N.C.: Duke University Press, 1970. I, pp. 318-328, rpt. from Human Development, 8 (1965), pp. $117-130$.

- 1966a. "Persistence of Life Style Among the Elderly." Normal Aging: Reports from the Duke Longitudinal Study, 1955-1969. Ed. Erdman Palmore. Durham, N.C.: Duke University Press, 1970. I, pp. 329-337.

- 1966b. "Retirement as a Social Event in the United States." Aging and Social Policy. Ed. John C. McKinney and Frank T. de Vyver. Nelv York: Appleton-Century-Crofts, 1966, pp. $117-135$.

Maddox, George and Carl Eisdorfer. "Some Correlates of Activity and Morale Among the Elderly." Social Forces, 40 , No. 3 (March 1962), pp. 254-260.

Miller, Stephen J. "The Social Dilemma of the Aging Leisure Participant." Older People and Their Social World. Eds. Arnold M. Rose and Warren A. Peterson. Philadelphia: F. A. Davis, 1965, pp. 77-112.

Neugarten, Bernice L. "Personality and the Aging Process." Processes of Aging: Social and Psychological Perspectives. Ed. Richard $H$. Wi7liams, Clark Tibbitts, Wi Tma Donahue. New York: Atherton, 1963. I, pp. 327-333. 
Neugarten, Bernice L. "A Developmental View of Adult Personality." In Relations of Development and Aging. A symposium presented before the Gerontological Society at the 15th Annual Meeting, Miami Beach, Florida. Ed. James E. Birren. Springfield, I11.: Charles C. Thomas, 1964, pp. 176-207.

- 1968a. "Adu1t Personality: Toward a Psychology of the Life Cycle." Middle Age and Aging. Ed. Bernice L. Neugarten. Chicago: University of Chicago Press, 1968, pp. 137-147.

- 1968b. "Developmental Perspectives." Aging in Modern Society. Ed. Alexander Simon and Leon J. Epstein. Psychiatric Research Report \#23. Washington, D.C.: The American Psychiatric Association, 1968, pp. 42-48.

Neugarten, Bernice L., Robert J. Havighurst, and Sheldon S. Tobin. "The Measurement of Life Satisfaction." Journal of Gerontology, 16, No. 2 (April 1961), pp. 134-143.

"Personality and Patterns of Aging." Middle Age and Aging: A Reader in Social Psychology. Ed. Bernice L. Neugarten. Chicago: University of Chicago Press, 1968, pp. 173-177.

Niebanck, Paul L. "Knowledge Gained in Studies of Relocation: A Challenge to Housing Policy." Patterns of Living and Housing of Middle-Aged and 01der Peopie. U.S. Department of Health, Education, and Welfare, Public Health Service Publication No. 1496. Washington, D.C.: U.S. Government Printing Office, March, 1965, pp. 107-116. Rpt. Readings in Gerontology. Eds. Ruth M. Brewer, Marvin M. Janzen, and Frances G. Scott. Eugene: University of Oregon, School of Community Services and Public Affairs, Center for Gerontology, 1969, IV-B, pp. 1-10.

Palmore, Erdman B. "The Effects of Aging on Activities and Attitudes." The Gerontologist, 8, No. 4 (Winter 1968), pp. 259-263.

"Sociological Aspects of Aging." Behavior and Adaptation in Late Life. Ed. Ewald W. Busse and Eric Pfeiffer. Boston: Litt7e, Brown and Company, 1969, pp. 33-69.

Parsons, Talcott. "Viewpoint: 01d Age as Consummatory Phase." The Gerontologist, 3, No. 2 (June 1963), pp. 53-54.

Pressey, Sidney L. "Viewpoint: Not All Decline!" The Gerontuiogist, 6, No. 2 (June 1966), pp. 66 and 125.

Pressey, S. L. and Elizabeth Simcoe. "Case Study Comparisons of Successful and Problem 01d People." Journal of Gerontology, 5, No. 2 (April 1950), pp. 168-175. 
Riesman, David. "Some Clinical and Cultural Aspects of Aging." The American Journal, LIX, No. 4 (Jan. 1954), pp. 379-383.

Robinson, W. S. "The Logical Structure of Analytic Induction." American Sociological Review, 16, No. 6 (Dec. 1951), pp. 812-818.

Rose, Arnold M. "A Current Theoretical issue in Social Gerontology." The Gerontologist, 4 (1964), pp. 46-50, rpt. in 01der People and Their Social World. Eds. Arnold M. Rose and Warren A. Peterson. Philadelphia: F. A. Davis, 1965, pp. 359-366.

Scott, Marvin B. "Functional Analysis: A Statement of Problems." Social Psychology Through Symbolic Interaction. Eds. Gregory P. Stone and Harvey A. Farberman. Waltham, Mass.: Xerox College Publishing, 1970, pp. 21-28.

Streib, Gordon F. "Disengagement Theory in Socio-Cultural Perspective." International Journal of Psychiatry, 6, No. 1 (JuTy 1968), pp. 69-76.

Streib, Gordon F., Wayne E. Thompson, and Edward A. Suchman. "The Cornell Study of Occupational Retirement." The Journal of Social Issues, XIV, No. 2 (1958), pp. 3-17.

Strunk, Norman. "Financing Homes for Owner Occupancy." Housing the Aging. Ed. Wilma Donahue. Ann Arbor: University of Michigan Press, 1954, pp. 155-168.

Tal1mer, Margot and Kutner, Bernard. "Disengagement and the Stresses of Aging." Journal of Gerontology, 24, No. 1 (Jan. 1969), pp. 70-75.

"Disengagement and Morale." The Gerontologist, 10, No. 4 (Winter 1970), Part 1, pp. 317-320.

Taves, Marvin J. and Gary D. Hansen. "Exploration in Personal Adjustment After Age 65." Geriatrics, 17, No. 5 (May 1962), pp. 309-316.

Tibbitts, Clark. "Middle-Aged and 01der People in American Society." Readings in Gerontology. Eds. Ruth M. Brewer, Marvin M. Janzen, and Frances G. Scott. Eugene: University of Oregon, School of Community Service and Public Affairs, Center for Gerontology, 1969. I-B, pp. 1-14.

Tobin, Sheldon S. and Bernice L. Neugarten. "Life Satisfaction and Social Interaction in the Aging." Journal of Gerontology, 16, No. 4 (1961), pp. 344-346.

Tuckman, Jacob, Irving Lorge, and Frederic D. Zeman. "The Self-Image in Aging." The Journal of Genetic Psychology, 99, Second Half (Dec. 1961), pp. 317-327. 
Videbeck, Richard and ATan B. Knox. "Alternative Participatory Responses to Aging." In 0lder People and Their Social World. Eds. Arnold M. Rose and Warren A. Peterson. Philadelphia: F. A. Davis, 1965, pp. 37-48.

Vivrett, Walter K. "Housing and Community Settings for 01der People." In Handbook of Social Gerontology. Ed. Clark Tibbitts. Chicago: University of Chicago Press, 1960, pp. 549-623. Rpt. in Readings in Gerontology. Eds. Ruth M. Brewer, Marvin M. Janzen, and Frances G. Scott. Eugene: University of Oregon, School of Community Service and Public Affairs, Center for Gerontology, 1969. IV-A, pp. 1-58.

Whitten, Elise. "How 0ld Is Aged?" The Digest: Review of Reviews, August 21, 1937, pp. 20-21.

Williams, Richard H. "Changing Status, Roles, and Relationships." Handbook of Social Gerontology. Ed. Clark Tibbitts. Chicago: University of Chicago Press, 1960, pp. 261-297.

Wilner, Daniel M. and Rosabelle Price Walkley. "Some Special Problems and Alternatives in Housing for 0lder Persons." Aging and Social Policy. Ed. John C. Mckinney and Frank T. de Vyver. New York: Appleton-Century-Crofts, 1966, pp. 221-259.

Youmans, E. Grant. 1967a. "Disengagement Among 01der Rural and Urban Men." In Older Rural Americans: A Sociological Perspective.

Ed. E. Grant Youmans. Lexington: University of Kentucky Press, 1967, pp. 97-116.

- 1967b. "Family Disengagement Among 01der Urban

and Rural Women." Journal of Gerontology, 22, No. 2 (April

1967), pp. 209-211.

Zborowski, Mark. "Aging and Recreation." Journal of Gerontology, 17, No. 3 (July 1962), pp. 302-309.

Zborowski, Mark and Lorraine D. Eyde. "Aging and Social Participation." Journal of Gerontology, 17, No. 4 (Oct. 1962), pp. 424-430.

\section{OTHER DOCUMENTS}

Beck, Bob. "Mattie, Age 100, True-Blue GOP." The Columbian, March 21 , 1977 , p. 2 .

Eolton, Charles D. "Outline of Symbolic Interactionist Frame of Reference." Portland State University: Mimeographed paper, 1970. 
Brotman, Herman B. The Fastest Growing Minority: The Aging. Talk by Herman B. Brotman, Administration on Aging, Department of Health, Education, and Welfare, at the 1972 National Agricultural Outlook Conference. Washington, D.C.: United States Department of Agriculture, Agricultural Research Service, 50th National Agricultural Conference, February 24, 1972.

- The 01der Population: Some Facts We Should Know. Washington, D.C.: Administration on Aging. Apri] 1970. U.S. Department of Health, Education, and Welfare, Social and Rehabilitation Service.

Facts and Figures on 01der Americans: An Overview, Number 5, T971 U.S. Department of Health, Education, and Welfare, Social and Rehabilitation Service, Administration on Aging.

. "The 01der Population: The Paradox--Success as a Problem." Facts and Figures on 0ider Americans: An Overview, Number 5,1977 . U.S. Department of Health, Education, and Welfare, Social and Rehabilitation Service, Administration on Aging, p. 1.

Deane, Early. "Fred Meyer on Portland: If He Didn't Love It He Wouldn't Criticize It." The Sunday Oregonian: Forum, January 18, 1976, page 1, section E.

Hogan, D'Brooks. Diary: The Autobiography of D'Brooks Hogan.

Life Histories: Two taped life histories: Mr. Fred Breitmeier and Mrs. S.

NRTA New Bulletin, Vol. XV, No. 10, November 1974. Washington, D.C.: National Retired Teachers Association.

Retirement: Background and Issues. Prepared by James H. Schulz and the Technical Committee for Employment and Retirement. Washington, D.C.: White House Conference on Aging, February 1971.

The Aged and Society. Ed. Milton Derber. Publication No. 5. Champaign, I17.: Industrial Relations Research Associates, 1950.

Whittemore, L. H. "Two Elder Statesmen With Young Ideas." The Sunday Oregonian: Parade, November 23, 1975, pp. 10-12.

Wiley, Leonard. "Aging Can Be But A Myth." The Sunday Oregonian: Northwest Magazine, April 27, 1969.

Wong, William. "Sailing On." The Wall Street Journal, XCII, No. 113 (June 11, 1975), pp. 1 and 18. 
BOOKS

Abrams, Charles. The City is the Frontier. New York: Harper and Row, 1965.

Arthur, Jul ietta K. How to Help 01der People. New York: J. B. Lippincott, 1954.

- Retire to Action: A Guide to Voluntary Service. New York: Abingdon Press, 1969.

Atchley, Robert C. The Social Forces in Later Life: An Introduction to Social Gerontology. Belmont, Calif.: Wadsworth, 1972.

Babbie, Earl R. Survey Research Methods. Belmont, Calif.: Wadsworth, 1973.

Berger, Peter L. and Thomas Luckmann. The Social Construction of Reality: A Treatise in the Sociology of Knowledge. Garden City, New York: Doubleday, 1966; Anchor Books, 1967.

Birren, James E. The Psychology of Aging. Englewood Cliffs, New Jersey: Prentice-Hai7, 1964.

Blalock, Hubert M., Jr. Social Statistics. 2nd ed. New York: McGrawHill, 1972.

Carp, Frances Merchant. A Future for the Aged: Victoria Plaza and Its Residents. Austin: University of Texas Press, 1966.

Cavan, Ruth Shonle, Ernest W. Burgess, Robert J. Havighurst, and Herbert Goldhamer. Personal Adjustment in 01d Age. Chicago: Science Research Associates, 1949.

Clark, Margaret and Barbara Gallatin Anderson. Culture and Aging: An Anthropological Study of 0lder Americans. Springfield, Illinois: Chartes C. Thomas, 1967.

Cooley, Leland Frederick and Lee Morrison Cooley. The Retirement Trap. Garden City, New York: Doubleday, 1965.

Cumming, Elaine and William E. Henry. Growing 01d: The Process of Disengagement. New York: Basic Books, 1961.

De Grazia, Sebastian. Of Time, Work, and Leisure. Garden City, New York: Doubleday, Anchor, 1964.

Denzin, Norman K. 1970a. The Research Act: A Theoretical Introduction to Sociological Methods. Chicago: Aldine, 1970. 
Deutscher, Irwin. What We Say/What We Do. Glenview, Illinois: Scott, Foresman, 1973.

Field, Minna. The Aged, the Family, and the Community. New York: Columbia University Press, 1972.

Fields, Chris L. Behind the Curtain of Retirement. Philadelphia: Corrance, 1966.

Friedberg, M. Paul, with El len Perry Berkeley. Play and Interplay: A Manifes to for New Design in Urban Recreational Environment. New York: Macmilian, 1970.

Friedmann, Eugene A. and Robert J. Havighurst. The Meaning of Work and Retirement. Chicago: University of Chicago Press, 1954.

Garvin, Richard M. and Robert E. Burger. Where They Go to Die: The Tragedy of America's Aged. New York: Delacorte Press, 1968.

Havighurst, Robert J., and Ruth Albrecht. 01der People. New Vork: Longmans, Green and Co., 1953.

Housing the Aging. Michigan llniversity Conference on Aging, 1952. Ed. Wirma Donahue. Ann Arbor: University of Michigan Press, 1954.

Human Behavior and Social Processes: An Interactionist Approach. Ed. Arnold M. Rose. Boston: Houghton Mifflin, 1962.

Koller, Marvin R. Social Gerontology. New York: Random House, i968.

Kutner, Bernard, David Fanshel, Alice M. Togo, and Thomas S. Langner. Five Hunderd Over Sixty: A Community Survey on Aging. New York: RusselT Sage Foundation, 1956.

Landis, Paul H. Social Policies in the Making. New York: D. C. Heath, 1952.

Martindale, Don. The Nature and Types of Sociological Theory. Boston: Houghton Mifflin, 1960.

Mead, George H. Mind, Self, and Society. Chicago: University of Chicago Press, 1934. Ed. Charles W. Morris, 1962. University of Chicago Press.

Menotti, Angelo Alfonso. Aging, Illness and Disengagement: Are They Similar? Ph.D. Dissertation. Washington University, 1967. 
Modern Dictionary of Sociology. Eds. George A. Theodorson and Achilles G. Theodorson. New York: Crowe11, 1969.

Neugarten, Bernice L. and Associates. Personality in Middle and Late Life. New York: Atherton Press, 1964.

Niebanck, Paul L., with the assistance of John B. Pope. The Elderly in 01der Urban Areas: Problems of Adaptation and the Effects of Relocation. Institute for Environmental Studies. University of Pennsylvania, 1965.

01d Age: The Last Segregation. Ralph Nader's Study Group Report on Nursing Homes. Claire Townsend, Project Director. New York: Grossman, 1971.

Pollak, 0tto. Social Adjustment in 01d Age: A Research Planning Report. New York: Social Science Research Council, Bulletin 59, 7948.

Pressey, Sidney L. and Raymond G. Kuhlen. Psychological Development Through the Life Span. New York: Harper, 1957.

Reichard, Suzanne, Florine Livson, and Paul G. Petersen. Aging and Personality: A Study of Eighty-Seven 01der Men. New York: John Wiley, 1962.

Riesman, Davi. with Nathan Glazer and Reuel Denney. The Lonely Crowd: A Study of the Changing American Character. New Haven: YaTe University Press, 1961.

Rosow, Irving. Social Integration of the Aged. New York: The Free Press, 1967.

Shaw, Clifford R. The Jack-Roller: A Delinquent Boy's Own Story. Chicago: University of Chicago, 1930. Rpt. Philadelphia: Aibert Saifer, 1951.

Sjoberg, Gideon and Roger Nett. A Methodology for Social Research. New York: Harper and Row, 1968.

Snyder, PauT Wayne. The Effect of New Marriages Among the Aged Upon the Disengagement Process. Ph.D. Dissertation. University of Florida, 1971.

Social Psychology Through Symbolic Interaction. Eds. Gregory P. Stone and Harvey A. Farberman. Waltham, Massachusetts: Xerox College Publishing, 1970. 
Streib, Gordon F. and Clement J. Schneider. Retirement in American Society. Ithaca, New York: Cornell University Press, 1971.

Symbolic Interaction: A Reader in Social Psychology. Eds. Jerome G. Manis and Bernard N. MeTtzer. Boston: ATTyn and Bacon, 1967.

Tal1mer, Margot. Social, Economic and Health Factors in Disengagement of the Aging. Ph.D. Dissertation. Yeshiva University, 1967.

The New Dictionary of Thoughts. Ed. Tryon Edwards. Revised by C. N. Catrevas, Jonathan Edwards, and Ralph Emerson Browns. Standard Book Company, 1965.

Thomas, William I. and Flurian Znaniecki. The Polish Peasant in Europe and America: Monograph of an Immigrant Group. 5 vols. Boston: Richard G. Badger. 1918-1920.

Thomas, William I. The Unadjusted Girl. Boston: Little, Brown, and Company, 1923.

Thomas, William I. and Dorothy Swaine Thomas. The Child in America: Behavior Problems and Programs. New York: Alfred A. Knopf, 1928.

Veney, James E. The Theory of Disengagement Reapplied: Aging Among Farmers With Heart Disease. Ph.D. Dissertation. Purdue University, 1966.

Webb, Eugene, J., Donald T. Campbe11, Richard D. Schwartz, and Lee Sechrest. Unobtrusive Measures; Nonreactive Research in the Social Sciences. Chicago: Rand McNaTly, 1966.

Weber, Max. The Theory of Social and Economic Organization, trans. A. M. Henderson and Talcott Parsons. Glencoe, Illino is: The Free Press, 1947.

- The Protestant Ethic and the Spirit of Capitalism, trans.

Talcott Parsons. New York: Charles Scribner's Sons, 1958.

Whitman, Howard. A Brighter Later Life. Englewood Cliffs, New Jersey: Prentice-Hal7, 1967 .

Williams, Richard $H$. and Clacidine G. Wirths. Lives Through the Years: Styles of Life and Successful Aging. New York: Atherton Press, 1965.

Wilson, Robert L. Urban Living Qualities from the Vantage Point of the E]derly. Chape] Hill: University of North Carolina, 1960. Institute for Research in Social Science. 
APPENDIX 
FOPM I

Page 1

WHAT THE POILOWING QUESTIONNAIRE, IS ABOUT:

This is a survey of the problems and interests of older people in American soclety. Wo would approciate getting your opinion on some of the questions that arise in the later years, particularly for those people who dwoll in the city.

please read the statements which express varlous attitudes toward aging. Then mark the proper place as to whether you agree or disagree. If you cannot possibly wake a decision, mark mindecided."

ALC RPPLTES WILL BE KEPT ENTIRETI CONTIDWTIAL.

1. Older people in the United States today aro not used by soclety as they ought to be. They are rotired at an arbitrary age rogardless of thoir talents.

2. The physical and mental f1t:dess of older persons of ten extends beyond the fixed retirenont age of 60 or 65. Consequently corpuloory retirenent is in wany cases a waste or human resources.

3. Corpulsory ret1rement is nocessary. All persons should be nade to retire at a flxed age regardioss of the contributions they are able te make.

4. Human 11fe has been prolonged through medical and technological inventlons; now sceloty should give meaning to the added yoars.

5. older people should be content to stay at hore, live on revorles, and accept ret1roment as a reward for their service to soclety.

6. The 1roportant thing is a man's ab111ty rather than his age.

7. Age is often atate of mind. Rotirement from actioitg makes people think they are old.

H. A new outlook should pervade educatlon and tralning to reorient our thinking toward learning throughout ilro.

9. It is natural and desirable for older poople to withiraw frow an active role in soeloty.

10. Opportunity for signiricant sorilal cisntact and participation in the arfairg of the corerunity help maintain the sental health of the ared.

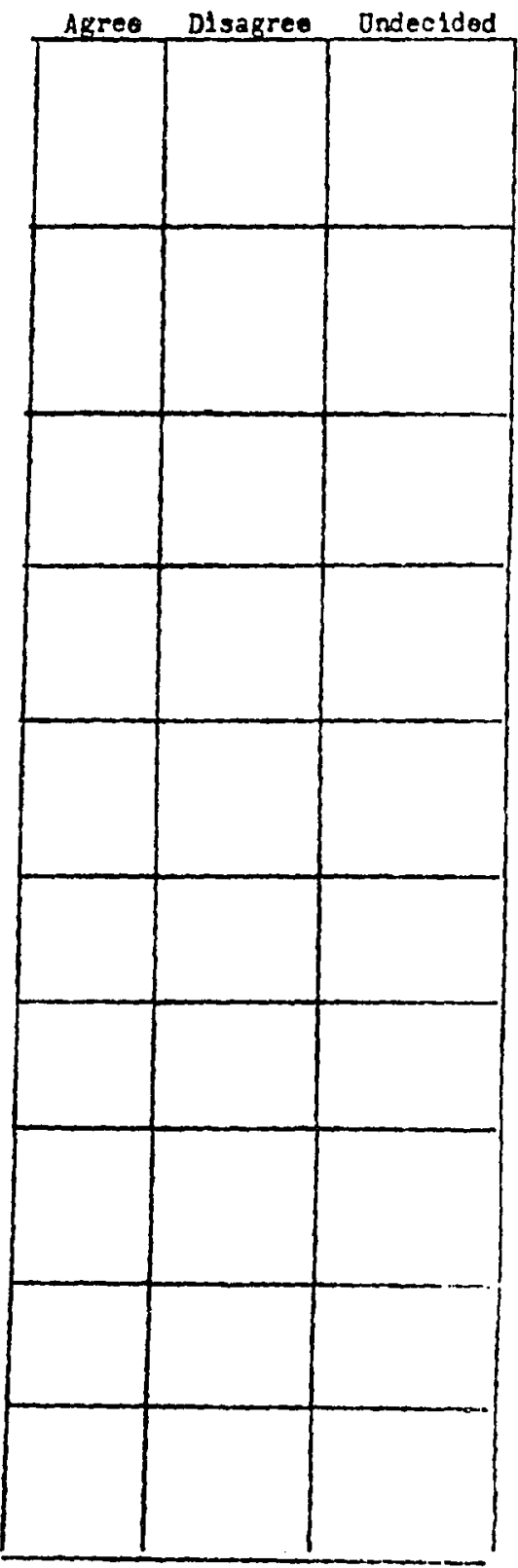


11. Gainful erploywent, elther full- or partt1ae, is one of the best sources of seif-respect and good morale in the aged as in younger porsons.

12. Older people cannot learn new skills.

13. There should be a redefinition of the role of the elderly. Thoy should not be regarded as simply a group to whom services must bo rendered. Instead they should be given the option to retrain for new occupations.

14. Older poople should associate with tholr ow age group rather thin with younger poople.

15. Fodoral, State, and local govermments should cooperate in helping the aged help thewselves.

16. Older persons can absorb neu knouledge and make use of $1 \mathrm{t}$.

17. Mental confusion in the olderly can often be attributed to soctal isolation as well as to other causes.

18. The City should provide counsoling services for the psychological and erotionel needs of the aged.

19. Most older people foel happlest in a community where they have contact with pooplo of all agos.

20. It is better to holp oldoriy pooplo otay in their own hores than to force them into hospitals or nursing homes.

21. Apathy in the old 1s orten due to a feeling of Insecurlty and enforced idleness.

22. Older people wust organ120 to protect tholr rights to oxployment and to moro partieipation in the arinstroan of 1190.

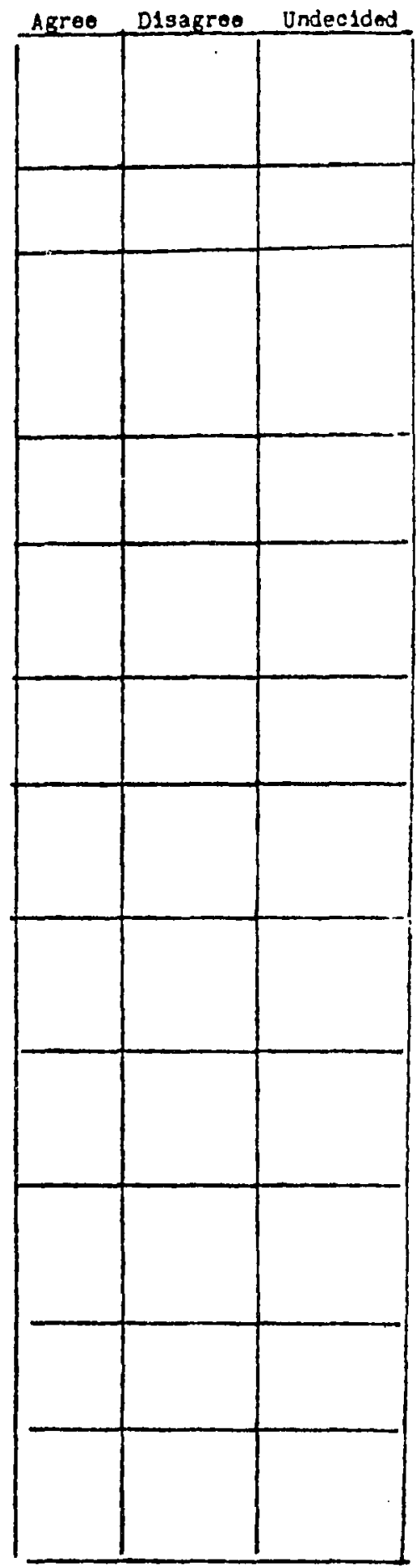


TO PERSONS OF RETIREARNT AGE:

Please Plil out this questionnatre. Your answers will be treated confidentially. The information you give may help better the ilfo of older people generally. You noed not give your name unless you wish to do so. Ploase check the appropriate spaces and try to answer all questions. THANK YOU.

1. Sex:_Malo; Pemalo. 2. Dato of birth:

3. Mar1tal status:___ Married;____Single;____ Divorcedi___Widowed;___Soparated.

4. Health: ___ Excellent; __ Cood; ___ Poor; ___ Vory poor.

5. Are you gainfully orployod at the present time? ___ Yes; ___ No.

6. If "No," would you prefer to be so employed? ___ Yes; ___ No.

7. Are you retired?___Yes; ___no. B. If mYes," what was the reason for your retirement?

9. Would you work if it would not lead to a reduction in your retirement benefits? Yos: No. No.

10. What are your principal activities at the present time?

11. Do you feel you are doing something usefuls Yes: N_ No.

12. Do you belleve that you could be more useful if there woro no ago restrictions on erployment and on other priviloges and advantages? Yos ; No.

13. Do you enfoy doing things for other people? Yos; No.

14. Is your personal appearance important to you? Yes; No. Please explain:

15. Do you like to assoctate with people of all ages? mostly with older people? ; or do you prefer to be

26. Do you live alone? Yos; No. If not, with whon?

17. How orten do you seo mombers of your lmodiato familg or other relatives not 21 ing with yoa?

18. How often do you visit with frlende or naighbors?

19. What kinds of current events Interest you? Please chect one or more:

a) Soc192 and Beonomic; Pol1t1c.18 Cultural; othier.

b) Local: Nat1onsl; Internat1onal: Nono.

20. DId you vote in recent elections? Yes; No. 
URBAN LINIMG QUALITIES DAPORTANT TO OLDER PERSONS. - Pleaso try to answer all questlons.

1. How long have you lived in (or near) the elty whero you now Ilve? years.

2. In which part of the city do 5001180 ? Central city. ; Next to central city. ; Older residential district ; Now rosidential district ; Suburben district ; Other

3. What nre your present 11ving arrangenents? Living in own hore: Rent1ng: Rouse: Apartment; Public housting: Rot1rement residence: Living in the howe of your chlidren; Other.

4. How would you rato your commenty on providing adequate housing for retired persons? Excellent: Good; Fa1r; Poor; Very poor.

5. Row satigfled aro you with arallablo madical facllities in your comsunity Very sat1sfied; Sarmmas satisfledi Hot very satisfled Very

6. What advantages does your nelghborhood havo? ___ Not too much no1se; Cood shoppling fac1l1ties; Convenient transportation; Restaurants: Churches; Parks; Recroational rac1l1t1es: Older dwellings; Other older swople; Other.

7. What conveniences are lacking in jour part of tom?

8. Would having additional conventences and/or serifices help you load a roro sat1sfactory life from the standpoint of the following categories? please check as wany as you wish:

Boing mepe Independent:_____etting botter heal th Malntalning your ow housohold; __ Taking care of your personal needs; Participating in cormunity programs: ___ Belping othor older poople; Other.

9. Do you belleve $1 t$ important to have a counseling and placement center to inform older people of job opportunitios and to help them secure exployment noar thelr howe? Yos: Ho.

10. Please state ang other suggestions that you any have to iroprove conditions ror older pooplo in your elty: 
please respond to the folloulng questlons. Your answers wlll bo kept strictly confidontial. Feol ireo to make edditiunal comments. THAKK YOU VBRY MUCH!

I. Please try to think back to the time when you were rras 40 to 50 years old. Is there a grest differanos between your aclivities then and now? speoliscaliy,

1) Hod has your work ohanged?

A. Provious l1no of york:

B. Prosent occupationt

Aro you as busy as over? Yos: $\mathrm{Ho.}$

c. Do jou have any hobbles? Ios; Ho. If "Yes," what are thirgi?

2) Do you particlpate in conmunity and/or churcin work? Yos; No.

a) Do you devote asre time to it than formarly? Yes; No.

U) Do you devote lass time to it then formorly? Yos ; _. No.

c) About the sam amount of tive? Ho.

3) Do you belong to sore organieationa? Yos ; Ho. If "Yos," which ones?

Do you glve wore or less tive now to organisations than when you were younger?

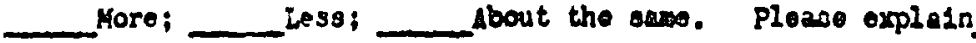

4) Do you soe your frlends more or loss often nou then formecly? More ofton now; Lass often now; About tho oamo.

If you soe your frlends less often now, is it boonses They moved;

You noved; You have lost intorost in thos; Iou cannot arford 1l: Fou are physically not able to get about; tou have fovor friands kecause some of then passed aray: other?

II. Has there been a aterlal change in your fanlly ajtuation in recent years? Yos: No. No. If so, in what ways?

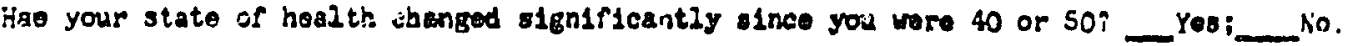
If so, ploase cownent:

Has thore been a substantizi ohange in your oconomic situation becmes of conditions affocting particularly the inccoo of oldor persone-for example, flxed reilmement pay, inflation, riging prices? Yosi Ho, Coments 
III. 1) What are tho best things about the ago you aro now?

3) 18 you grou older, do things seem to be better or worse than you thought they would be?

$$
\text { Botter? Worso. In what ways? }
$$

3) Does intoraction with other poople contributo to your ilfo satisfiction?

Yos Ho.

4) Do you enjoy having tiso to yourself? Yos? No.

5) Row high a value do you place on your independence? Vary high; Fairly high; Dot vory high.

Or, would you sey-- compared to your gounger gress,

6) Iow are nore Hilling to let your family run your lifo? Yes; No.

7) You arn nore gulded in your way of life by the opinion of other poople! Yos: No.

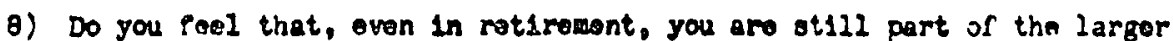
communt ty'i

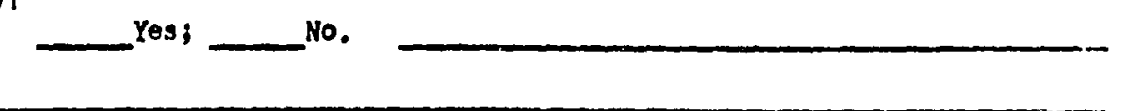

